\title{
Seismic While Drilling (SWD) Techniques with Downhole Measurements, Introduced by IFP and its Partners in 1990-2000
}

\author{
Ch. Naville', S. Serbutoviez' ${ }^{1}$ A. Throo' ${ }^{1}$ O. Vinckél and F. Cecconi ${ }^{2}$ \\ 1 Institut français du pétrole, 1 et 4, avenue de Bois-Préau, 92852 Rueil-Malmaison Cedex - France \\ 2 Geoservices, BP 20, 93151 Le Blanc-Mesnil Cedex - France \\ e-mail: charles.navill@iff.fr - sylvain.serbutoviez@iff.fr - alexandre.throo@ifp.fr - olivier.vincke@ifp.fr - cecconi@geosrv.com
}

Résumé - Techniques de sismique pendant forage avec mesures de fond, inaugurées par l'IFP et ses partenaires en 1990-2000 - La sismique pendant forage ( $S W D)$, comprend toute technique opérée pendant que le train de tige est dans le puits, pendant le forage effectif ou pendant les manœuvres d'ajout de tige ou de nettoyage. Deux techniques utilisées par l'industrie sont développées ici :

- l'écoute sismique du trépan pendant forage (drillbit-SWD), usitée depuis 1986, qui consiste à enregistrer le signal avec un nombre indéfini de capteurs de surface, ainsi qu'un signal de référence représentatif des vibrations du trépan ;

- le profil sismique vertical pendant forage $(V S P-W D)$, qui consiste à enregistrer le signal émis par une source de surface avec un capteur sismique et un enregistreur intégrés à la garniture de forage (BHA). Cette technique émergente est opérée depuis l'année 2000 principalement par la société Schlumberger.

Les deux techniques efficaces suivantes, assimilables à la sismique pendant le forage, ne seront pas discutées ici :

- la technique de VSP dans le tubage (TLC), en particulier le VSP au câble avec outil descendu au câble dans un tubing de production ou un train de tiges de forage ;

- le «VSP intermédiaire», qui consiste à acquérir un VSP conventionnel au câble avant la pose et la cimentation d'un cuvelage (casing), afin d'affiner le calage du puits à la sismique de surface et de prédire les zones en surpression au-dessous du trépan.

Les développements récents effectués par l'IFP et ses partenaires en sismique pendant forage ont bénéficié de la technologie de transmission temps réel à haut débit par fils et tiges câblés du système TRAFOR, qui a permis d'exécuter rapidement des tests terrains cruciaux.

Pendant la période 1986-2003, la pratique d'écoute sismique du trépan visait une utilisation continue sur la profondeur totale du forage, avec peu de capteurs de surface, et sans adjonction d'enregistreur de puits pendant le forage : cette technique a donné des résultats mitigés, quasi nuls avec les trépans de type PDC (Polycrystalline Diamond Cutter). Les meilleurs résultats ont été obtenus avec l'usage de trépan de type tricône, lors du forage de formations plutôt dures, en évitant des valeurs faibles pour les paramètres de poids sur outil (WOB) et vitesse de rotation (RPM).

L'IFP a introduit dans la technique d'écoute sismique du trépan les innovations suivantes :

- les mesures de fond pendant forage, afin de mieux comprendre le processus d'émission sismique du trépan ;

- l'amélioration de l'architecture mécanique de la garniture (BHA) en intégrant un élément amortisseur permettant d'optimiser la qualité du signal source émis et de diminuer les émissions secondaires indésirables ; 
- conception et fabrication d'une technologie sismique d'écoute du trépan avec mesure de fond pendant forage, validée par une succession de tests terrain sévères : cette phase de développement a été effectuée en partenariat avec l'industrie et avec le soutien de la Commission européenne et du ministère français de l'Industrie ;

- restriction de la technique sismique d'écoute du trépan à la configuration du walkaway inverse, assurant les meilleures chances d'application industrielle ;

- intégration des connaissances et du savoir-faire de disciplines multiples : forage, mesures de fond $M W D$ et sismique, acquisition et traitement des données.

De façon similaire, la technique de PSV pendant forage (VSP-while drilling) a fait l'objet d'une investigation, donnant les résultats suivants :

- définition et validation de capteurs sismiques résistant aux conditions sévères de vibration de fond pendant le forage ;

- test terrain de la méthode de VSP-WD, afin d'évaluer la qualité du signal obtenu par VSP-WD relativement au signal obtenu par VSP conventionnel au câble. Les résultats obtenus permettent de définir les applications industrielles de la méthode ;

- amélioration de la précision d'horloge embarquée dans l'enregistreur sismique de fond pendant forage pour les systèmes sans fil.

Enfin, le présent article relate la chronologie de l'émergence des techniques de sismique pendant forage, et esquisse quelques perspectives prévisibles compte tenu des développements parallèles accomplis par les principales sociétés industrielles de diagraphie pendant forage.

Abstract - Seismic While Drilling (SWD) Techniques with Downhole Measurements, Introduced by IFP and its Partners in 1990-2000 - Seismic While Drilling (SWD), specifically encompasses the seismic techniques operated while the drillstring is lowered in the borehole, during effective drilling, during manœuvres or while connecting drill pipes. Two SWD techniques have been used by the industry:

- drillbit-SWD, which consists in recording the seismic noise generated by a rock bit under effective drilling on any number of surface seismic sensors. This technique have been used steadily since 1986;

- Vertical Seismic Profile While Drilling (VSP-WD), which consists in recording the seismic signal generated by a surface seismic source on seismic sensors integrated inside the downhole Borehole Assembly (BHA). This emerging technique have been operated since year 2000 about, mainly by Schlumberger.

Two efficient wireline VSP techniques aimed at gathering geological information potentially useful to the drilling decision making process, and which could rightfully be assimilated to SWD techniques, will not be considered here:

- the technique of Tube Logging Conveying (TLC), in particular the TLC-VSP, where a wireline VSP tool is lowered inside the drillstring through a side entry sub at the top of the drillstring;

- the standard wireline logging technique of "intermediate VSP", which consists in recording a VSP with a set of wireline logs right before setting an intermediate casing, is used to predict geological features and possible overpressures in depth intervals located hundreds of meters below the intermediate drilled depth, with good success in some geographical regions.

The recent developments achieved by IFP and its partners in SWD greatly benefited from the availability of a high rate and real time wireline transmission system while drilling called TRAFOR, allowing for fast field testing of the SWD methods.

In the past 18 years (1986-2003), the drillbit-SWD technique practiced by the industry, aimed at a continuous application over the whole drilling depth span, with only a few surface sensors, and without any downhole measurement technology (MWD), reached a very mitigated success rate: although the geophysicists have been intrigued by the large amount of seismic energy imparted to the ground by some types of drillbits, the drillbit-SWD technique fails to yield any substantial results in many circumstances: in the early 1990's, the industry had already gathered an extensive enough experience so as to define the necessary conditions for obtaining any useful drillbit signal: drilling formations sufficiently hard, with a 
roller cone bit type equipped with milled teeth or inserts, and avoiding the lower range values for the Weight On Bit (WOB) and Round Per Minute (RPM) drilling parameters. The innovative drillbit-SWD technique input from IFP in the past decade is described in the present paper and consists in:

- introducing downhole measurements while drilling, in order to understand the downhole process of seismic emission by roller cone rock bits mostly;

- improving the mechanical design of the BHA, by integrating a shock absorber element in order to optimize the quality of the seismic signals imparted into the ground and to reduce the amplitudes of undesirable secondary seismic emissions, which considerably complicate the subsequent seismic processing and blur the final seismic image;

- designing, manufacturing and validating an operational MWD assisted drillbit-SWD technique through a set of successive, complete and severe field tests achieved through several $R \& D$ projects in partnership with the industry;

- restricting the application of drillbit-SWD technique to the reverse seismic walkaway configuration to be applied in geological-geographic areas ensuring the best chances of operational and economic success;

- integrating the knowledge and know-how of multiple categories of specialists in the various domains of drilling, MWD and seismic, involved in the multidisciplinary applied SWD field operations.

In a similar approach successfully applied to the drillbit SWD developments, the technique of VSP-while drilling has been investigated, resulting in several advanced achievements, namely:

- definition of downhole seismic sensors able to withstand severe drilling conditions;

- field testing the feasibility of the VSP-WD method as a whole, in order to evaluate the quality of the recorded seismic signal in comparison with the equivalent signals from the conventional wireline technique. Depending on the level of seismic signal quality obtained, the domain of application of the $V S P-W D$ technique and the priorities in the successive technological developments to be implemented have been defined;

- improving the precision of downhole clock to be embarked in an industrial wireless downhole recorder able to sustain the rough downhole drilling conditions of shock and temperature variations.

Last, the present paper overviews the emergence of SWD technique in a brief preliminary history, and is ended with the expression of a few prospective views taking in account the developments achieved by other prominent industrial organizations active in the difficult and promising domains of seismic while drilling technique and field practice.

\section{NOMENCLATURE}

\begin{tabular}{ll} 
SWD & \multicolumn{1}{l}{ Seismic While Drilling } \\
Drillbit-SWD & Method of recording the Drillbit Seismic noise \\
& While Drilling \\
MWD & Measurement While Drilling \\
TRAFOR & $\begin{array}{l}\text { high rate/real time TRAnsmission system du } \\
\text { ing FORation }\end{array}$ \\
SACZ & Surface Accelerometer in Z-vertical axis \\
DACZ & Downhole Accelerometer in Z-vertical axis \\
EMWD & Electro-Magnetic While Drilling \\
EM-SWD & Electro-Magnetic Seismic While Drilling \\
POOH & Pull Out Of Hole \\
BHA & BoreHole Assembly \\
DP & Drill Pipe \\
DRU & Downhole Recorder Unit \\
SCU & Surface Command Unit \\
TB & Time Break \\
WSP & Well Seismic Profile \\
VSP-WD & Vertical Seismic Profile While Drilling
\end{tabular}

$\begin{array}{ll}\text { WA } & \text { WAlkaway (seismic survey) } \\ \text { S/N } & \text { Signal-to-Noise ratio } \\ \text { NMO } & \text { Normal Move Out } \\ \text { twt } & \text { two way time } \\ \text { ENEL } & \text { Italian National Electricity company } \\ \text { GDF } & \text { Gaz de France } \\ \text { EC } & \text { European Community. }\end{array}$

\section{INTRODUCTION}

We present here a history of the SWD techniques. The first known attempt to exploit the vibration signal emitted by the drillbit was made around 1968 by an IFP geologist, M. Chapuis (from personal communication of L. Chaize, geophysicist now retired from IFP). M. Chapuis having observed that in vicinity of the drilling apparatus, "the harder the formation under drilling, the stronger the noise", he then decided to record the noise level from drilling with a geophone planted into the ground in the vicinity of the rig, in order to obtain a formation "stiffness" indicator versus 
depth. Later, Elf-Aquitaine geoscientists and drillers improved the technique by fixing an accelerometer at the top of the drillstring, attached to the nonrotating part of the injection head: monitoring of the vibratory energy level versus depth was displayed continuously and in real time while drilling, constituting the Snaplog [1]. In 1983, Elf was eager to develop the horizontal drilling technique, and invited $C G G$ to record some seismic noise while drilling a horizontal drain, using vertical geophones on surface and an accelerometer on top of the drillstring, which from now on we will refer to as SACZ (Surface Accelerometer along Z-axis). Correlating the geophone signals by the SACZ pilot random signal came naturally to the mind of the geophysicists well versed in the art of vibroseis. Interesting and positive results came with a second drillbit SWD test at shallow vertical well, using air drilling. The first SWD attempt in the horizontal drain did not yield any encouraging results as the drill bit in a horizontal well generates S-wave propagating vertically and very little P-waves, which could not be recorded properly with vertical geophones, but this detail had been overlooked at the time and understood later. A few years passed until Elf filed for a patent in 1985, [2], then Western-Atlas published interesting results obtained onshore in North America in wells drilled by Amoco, in 1986 (Tomex ${ }^{\mathrm{TM}}$-type SWD survey, [3]). Unfortunately, the geophysical experience accumulated by numerous seismic contractors with various operating companies soon showed that the Tomex ${ }^{\mathrm{TM}}$ technique would not yield systematic good results: the results are quite insufficient when a PDC bit (Polycrystalline Diamond Cutter) is used, and good results were not regularly obtained even with roller cone bits in favorable conditions: i.e. while drilling hard/medium hard formations, with roller cone teeth long enough, with appropriate drilling parameters and with simple geometry of the well trajectory. Before 1990, very limited technical exchanges occurred between geophysicists and drillers, and seismic measurements were not authorized to interfere in any way with the drilling process, thus the quality of drillbit reflection results could not be guaranteed.

\section{DRILLBIT SWD AND VSP-WD}

This section describes the feasibility of drillbit SWD and VSP-WD experiments with downhole measurements of the reference signal and emergence of a new drillbit technique using a shock absorber, 1991-1998, by IFP and Gaz de France (GDF).

In the early 1990's, IFP developed a prototype of a high rate transmission system in real time instrumented with a 16 channel downhole digitizer called TRAFOR (système de TRAnsmission de données pendant FORage, [4]), using a wire link to the surface through wired drill pipes: this system was designed by the mechanical and electronic engineers of IFP Drilling Department with the aim of analyzing the

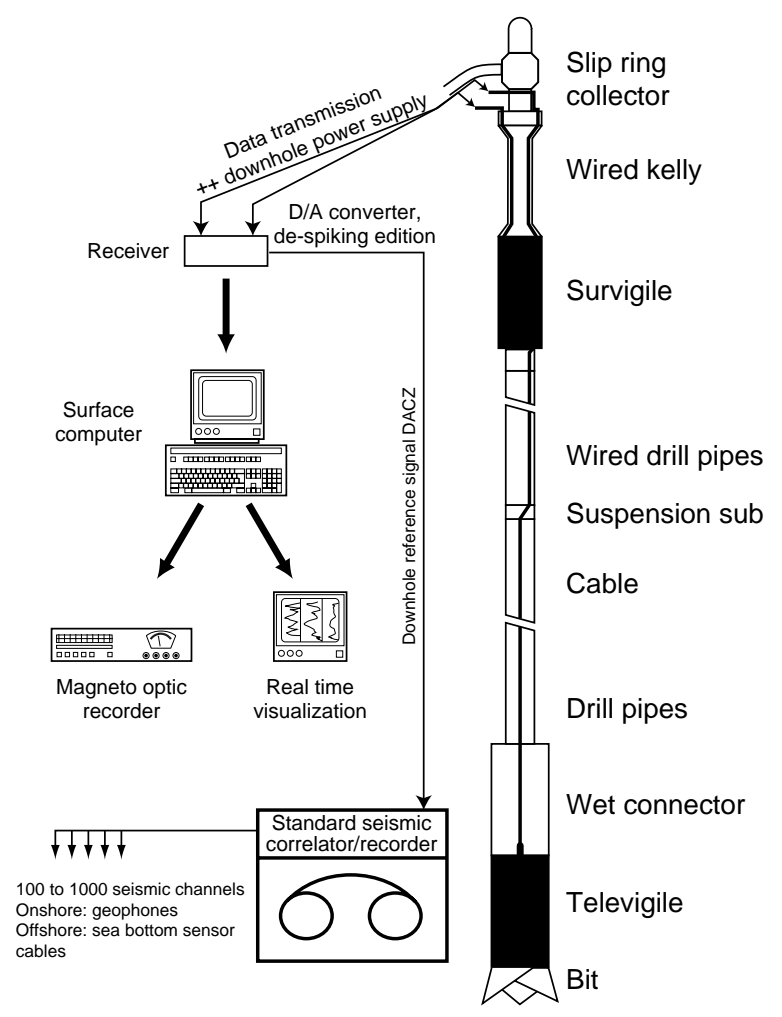

Figure 1

TRAFOR: a real time transmission system while drilling, at high rate: $30 \mathrm{kbit} / \mathrm{s}$, coupled with a real time seismic correlator.

downhole vibrations while drilling, in order to improve the safety of drilling operations. At the time, the French geophysicists naturally expressed their desire to conduct a fuller investigation of the drillbit seismic technique by evaluating the downhole vibrations generated by the drilling process and propagated through the drillstring wave guide, especially as several $R \& D$ projects of powerful post-drilling or while drilling downhole seismic sources during the 1980's had not been successful. The large apparent amount of seismic energy emitted by a roller cone under drilling kept the geophysicists motivated in pursuing their investigations, despite the development cost of any piece of downhole technology. In 1991, a drillbit seismic field test was carried out in piggyback fashion with an MWD TRAFOR field test in an eastern France $G D F$ well, already planned by the drillers in order to collect downhole drilling parameter data. The field installation was quite straightforward and efficient, as a real time Sercel SN348 recorder-correlator was used so as to immediately evaluate the seismic quality of the drillbit seismic data (Fig. 1) in the field. As a result, the first minutes of drillbit seismic data correlated either by the downhole accelerometer (labeled DACZ) or by the top of drillstring accelerometer 
SACZ, did not show very significant differences, as both correlated records were altered by a very high level of drillstring multiples: the main improvement obtained by correlation with the downhole DACZ was a higher frequency content. IFP field geophysicists (J.C. Dubois, C. Naville, Ph. Staron), acquainted with vibroseismic technology immediately felt that it would be desirable to introduce a mechanical decoupling device above the drillbit and downhole sensor, in order to drastically reduce the generation of drillstring multiples and all sorts of associated secondary seismic source effects related to the presence of the drillstring. This kind of damping element is well known by the drillers as a "shock absorber", and had been extensively developed by the drilling equipment manufacturers during the period 1950-1985.

In reference to the widely accepted vibrator model described in [5], the shock absorber would play the role of both the airbags, decoupling the hold-down force from the vibrator base plate, and the dashpot of the vibrator actuator, since the hold-down force is directly applied on the vibrating reaction mass located below the absorber in the case of the drillbit-BHA (sketch on Fig. 2a).

\subsection{Drillbit SWD with TRAFOR and One Shock Absorber in the BHA}

After filing for a patent on the drillbit SWD method using a shock absorber in the BHA and downhole measurements [6], a prospective $R \& D$ campaign of drill tests was launched by IFP in 1992 in order to:

- gain more knowledge on the downhole mechanical characteristics of the shock absorber in field conditions;

- execute new SWD tests with a shock absorber in the BHA and analyse the effects; all tests would occur in shallow vertical wells (TD around $1000 \mathrm{~m}$ ) drilled by $G D F$ for the exploration or development of gas storage, in the framework of a long term mutual agreement between $G D F$ and $I F P$ ensuring access to the $G D F$ wells under drilling, and with partial funding of the CEPM (Comité d'Exploitation Pétrolière et Marine), an extension of the French Ministry of Industry supporting R\&D initiatives.

Most of the drillbit SWD field tests were carried out with roller cone bits, preferred to PDC bits by GDF drillers as the borehole walls drilled with roller cones are more rugged and

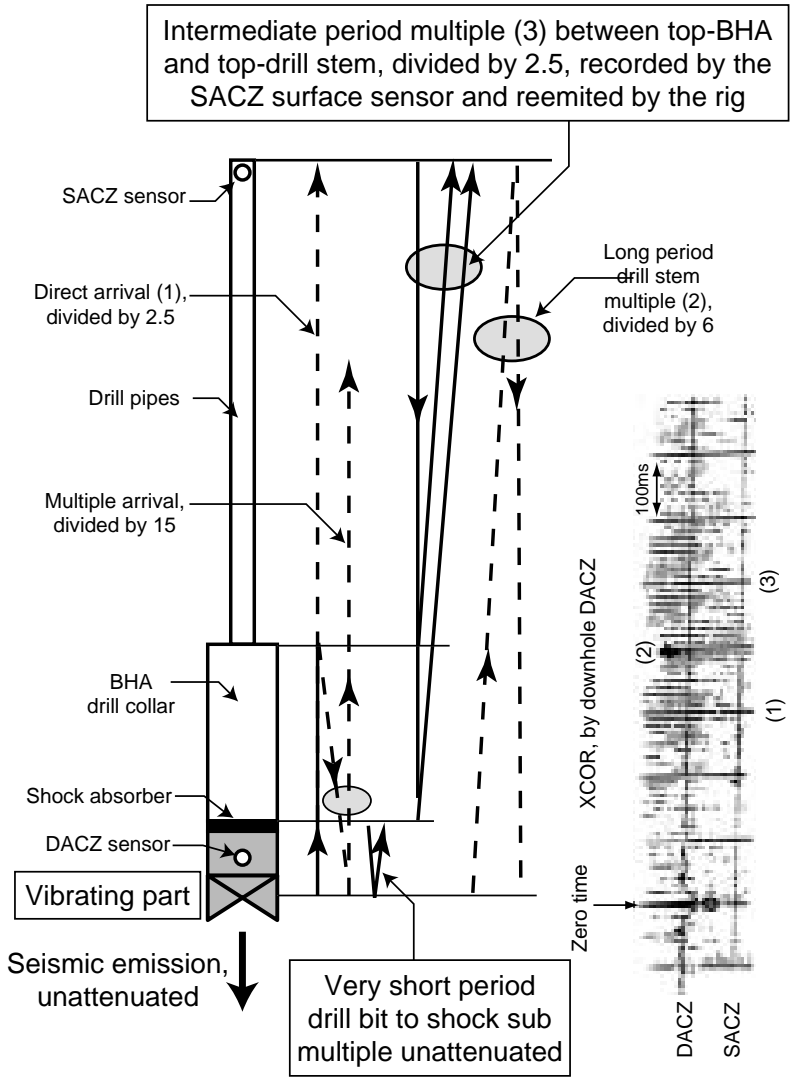

Figure 2a

Pressure guided wave mode propagation in the drillstring, with shock absorber.

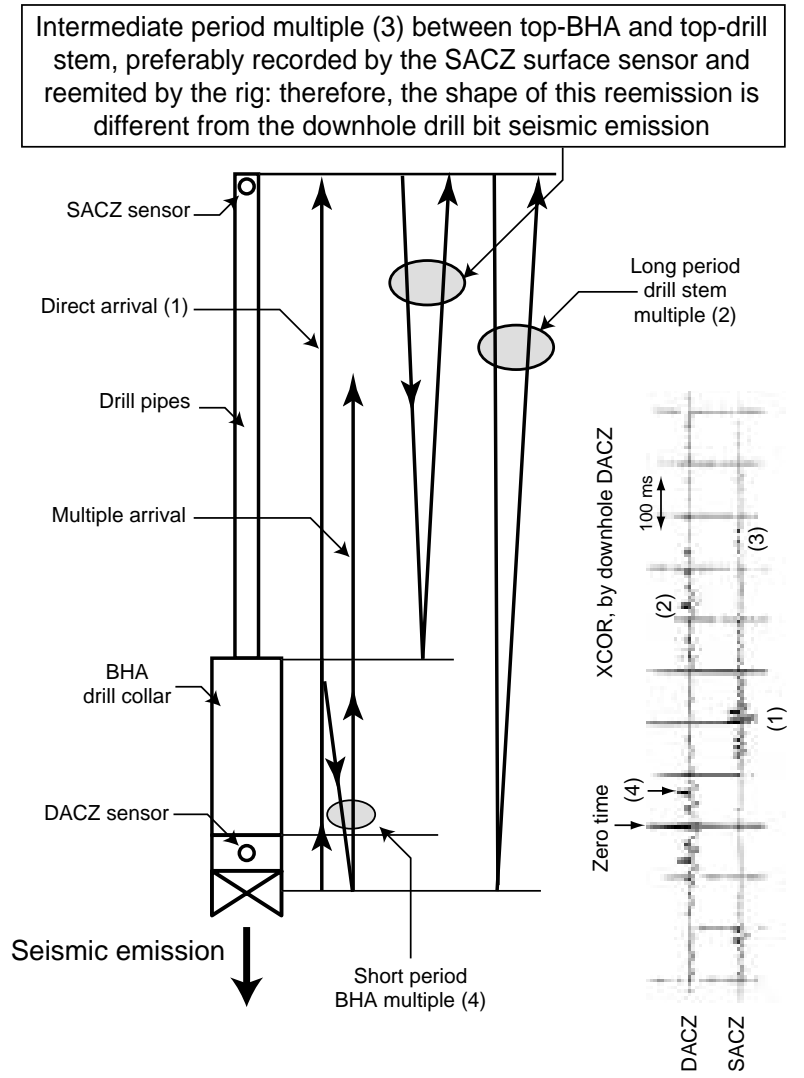

Figure 2b

Pressure guided wave mode propagation in the drillstring, without shock absorber. 
favor the quality of the cement job around the casing. Moreover, as drilling with roller cone bits favor the quality of the SWD results, the GDF wells appeared as excellent drillbit SWD test well candidates.

The presence of a shock absorber in the BHA induces the total extinction of the long top to bottom drillstring multiples otherwise reemitted into the formation through the rock bit (compare Fig. $2 a$ with Fig. 2b, and Fig. 3a with Fig. 3b). The first experiment related in [7] allowed the geophysicists to verify that the BHA architecture including a shock absorber, constitutes a clean and efficient random vibrator source, as the drillstring mechanical ensemble above the shock absorber is sufficiently decoupled from the vibrating element below it (Fig. 2a). The fundamental proof of the previous statement is supported by the spiked character of the autocorrelation of the downhole accelerometer DACZ signal, when placed below the shock sub (see the DACZ autocorrelation, right side of Fig. $2 a$, versus Fig. 2b). Although the presence of a shock absorber reduced peak amplitudes of the rock bit to about $80 \%$ of the peak amplitudes observed without shock sub, the signal-to-noise ratio and the readability of the field correlated seismic records are drastically improved (see Fig. $3 a$ versus Fig. 3b). The improvement brought by the downhole pilot accelerometer DACZ is obvious when comparing the field correlated monitor exhibited on Figure 4a (correlation by DACZ obtained at the end of a drilling phase with shock absorber in the BHA) versus Figure $4 \mathrm{~b}$ (correlation by SACZ obtained immediately after removing the absorber). Figure $4 \mathrm{~b}$ clearly shows the presence of undesired coherent forerunner line-ups parallel to the direct arrival and generated by the drillstring multiples (from top drillstring to top BHA and top of shock absorber) propagated above the shock absorber and still present in the SACZ-correlated signal. As a result, the introduction of a shock absorber located above the roller cone bit and the downhole reference accelerometer reduces drastically, although not totally, the undesirable emissions of seismic energy radiated from the drillstring into the formation, identified by $[8,9]$, and illustrated in Figure 5. Additionally, the shock absorber insures that the rock bit keeps in contact with the formation, so that the reference signal measured above the bit represents more realistically the seismic signal imparted into the formation.

The first example of drillbit SWD image in a gentle geological context obtained using one shock absorber in the BHA are shown on Figure 6, where three independent results
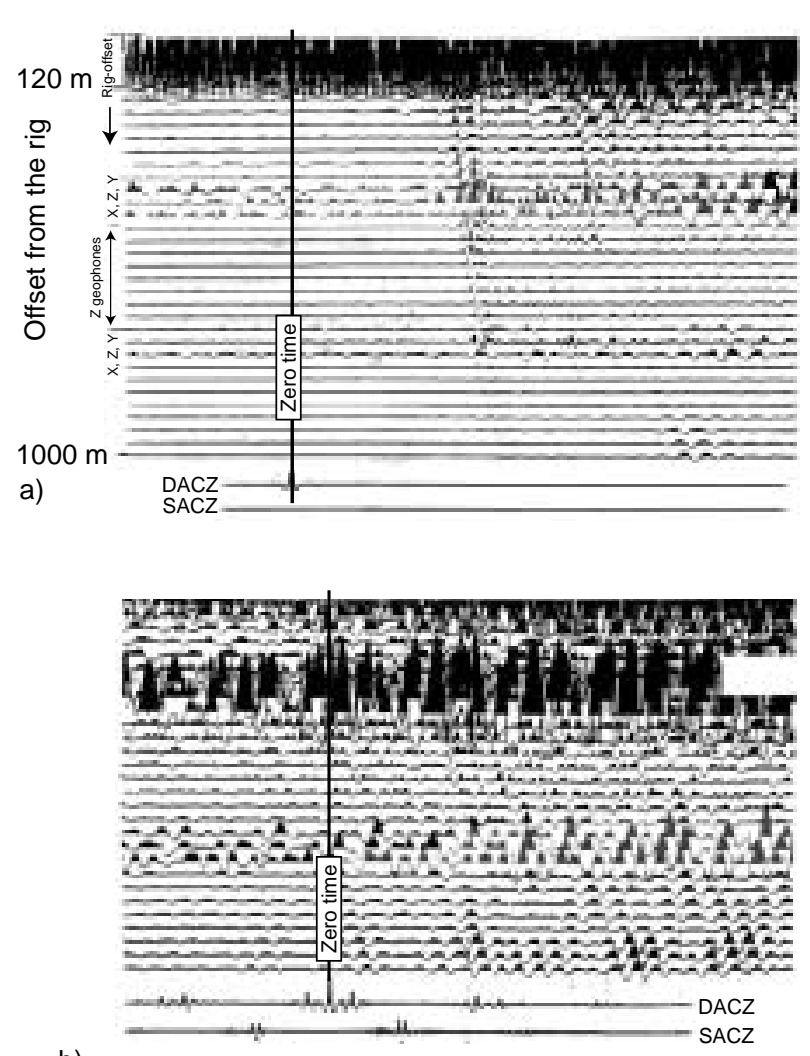

b)

Figure $3 a$ and $3 b$

a) field XCOR, by DACZ with shock absorber.

b) field XCOR, by DACZ without shock absorber.

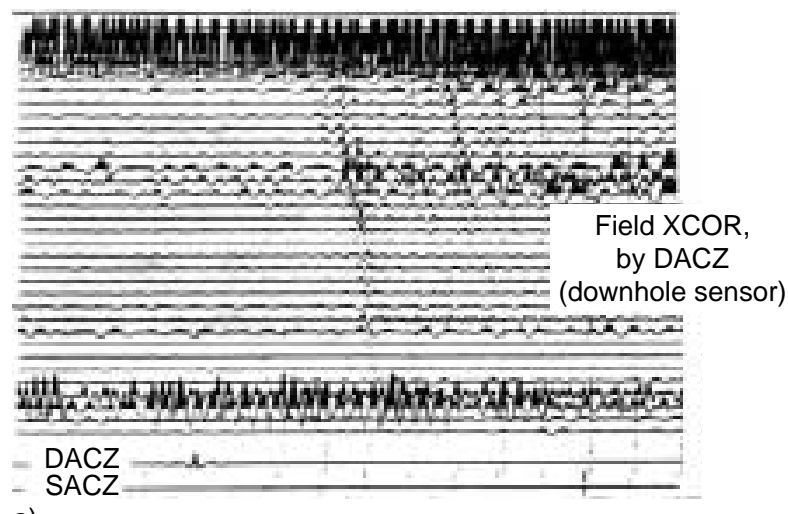

a)

b)

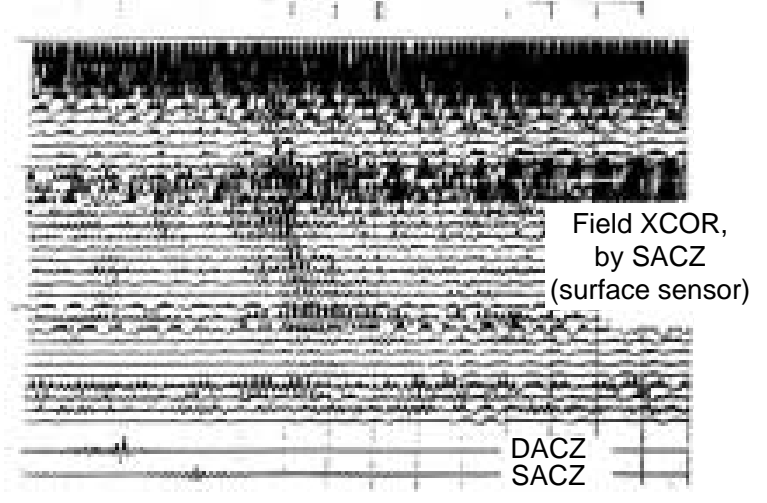

Figure $4 \mathrm{a}$ and $4 \mathrm{~b}$

Comparison of field XCOR, by DACZ versus SACZ both with shock absorber in the BHA. 


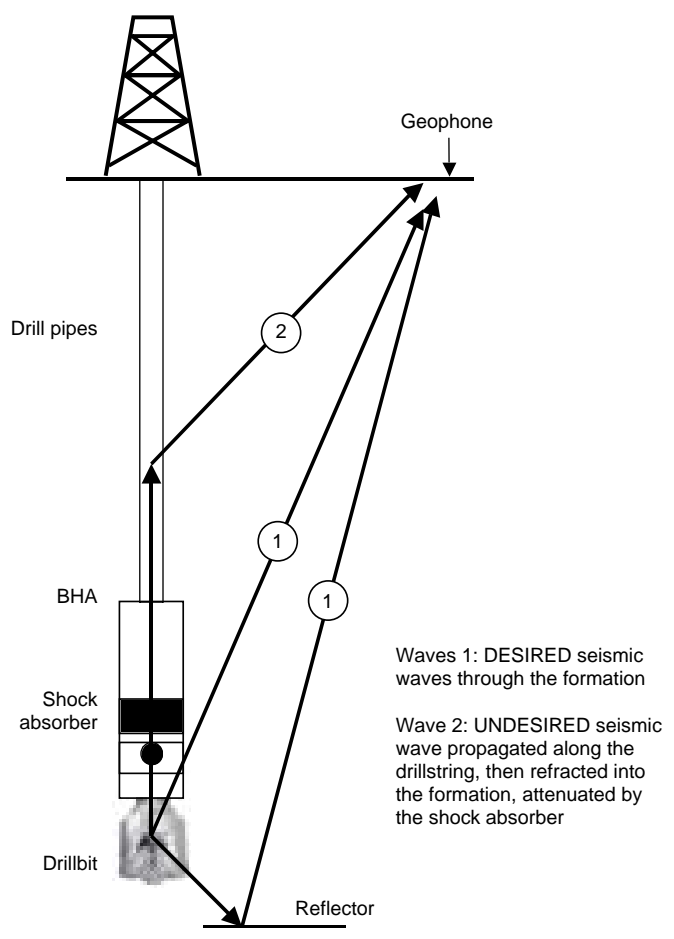

Figure 5

Mechanical principle of decoupled drillbit to enhance the seismic S/N quality.

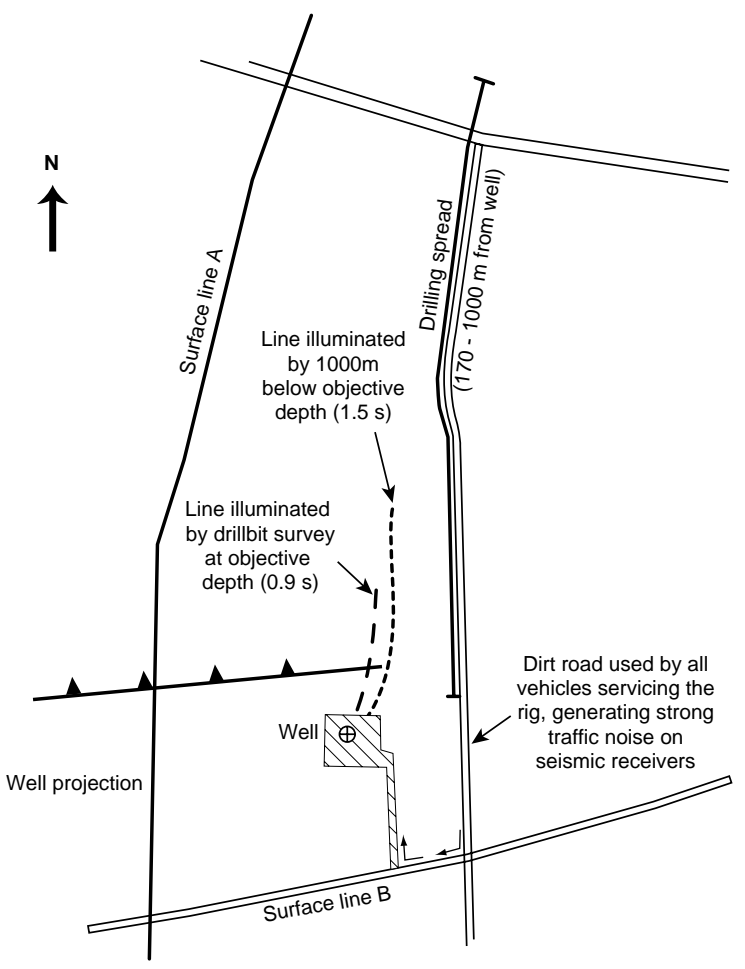

Figure 7

Sketch of location (courtesy of Gaz de France).

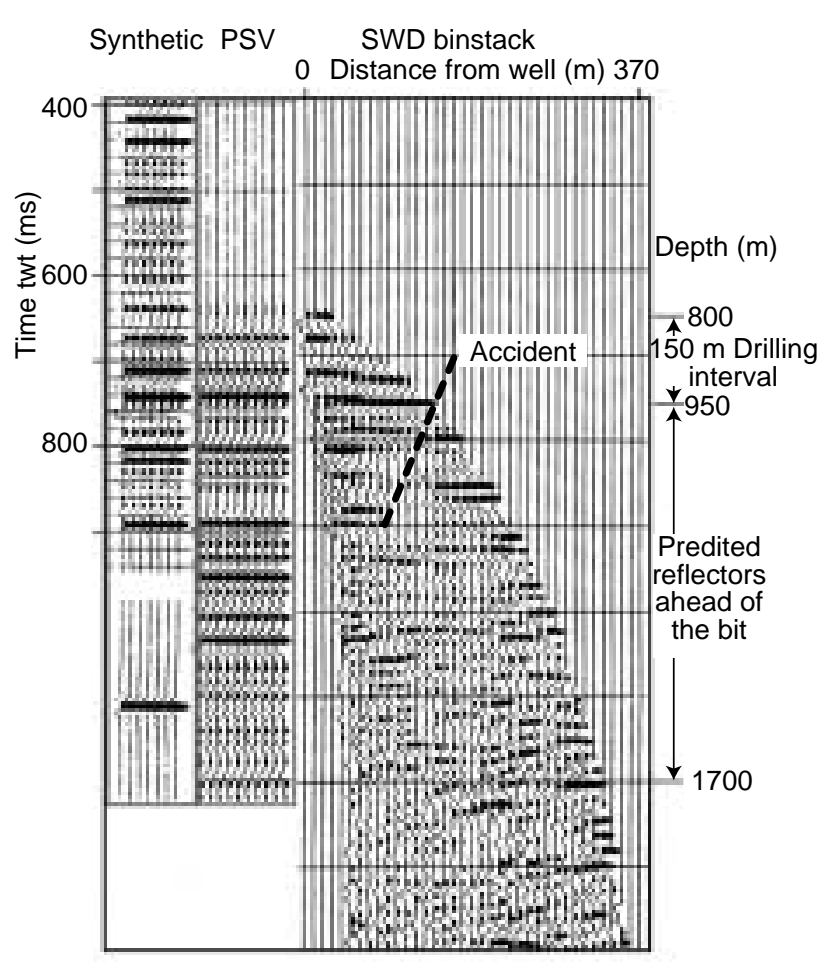

Figure 6

Reflectivity along the well from three independent methods: synthetic seismogram, VSP, and drillbit SWD with one shock absorber in the BHA (courtesy of Gaz de France).

of the Earth seismic reflection response at the well are represented, from left to right:

- synthetic seismogram computed from wireline calibrated sonic log and density log, zero phase display;

- VSP corridor stack, zero phase deconvolved;

- drillbit SWD reflection results ahead of the bit. The short $150 \mathrm{~m}$ logged depth interval is indicated, as well as the offset from the well (10 $\mathrm{m}$ trace interval, zero phase).

Although the seismic drillbit image shows a few accidents, there is an excellent resemblance between the three independent earth responses in the immediate well proximity, within 5 traces $/ 50 \mathrm{~m}$ from the well: this fact indicates the reliability of the new drillbit technique using an appropriate BHA. In spite of the short drilling interval from 800 to $950 \mathrm{~m}$, one can observe the basement reflection around depth $1700 \mathrm{~m}$ (1.2 s twt, two way time), about $700 \mathrm{~m}$ ahead of the bit.

\section{Comparison of Drillbit Seismic Image with Nearby Seismic Lines}

The drillbit SWD image was compared with the surface seismic section line A: Figure 7, sketch of surface location; Figure 8, zone illuminated by the drillbit SWD walkaway, projected on the seismic section (shot about 1978); Figure 9, SWD walkaway image superimposed on seismic section. 


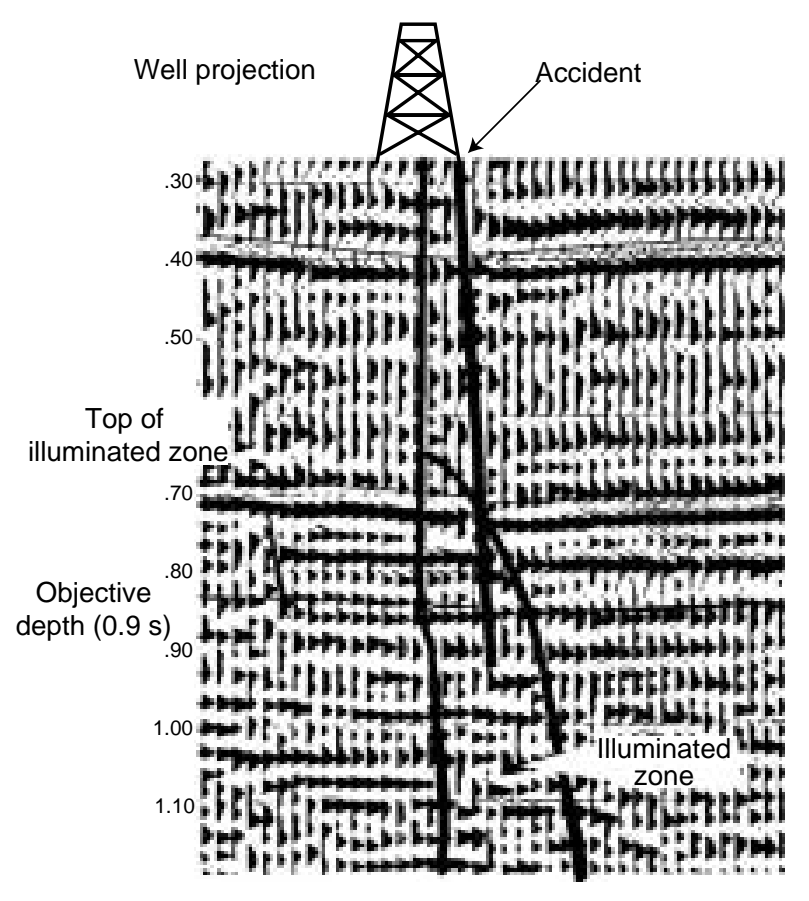

Figure 8

Surface line-A (1978), marked with drillbit image projected domain (courtesy of Gaz de France).
The frequency content of the SWD image, up to $75 \mathrm{~Hz}$ (Fig. 10) is higher than the frequency content of the old seismic line A. The flexural accident on the seismic section (Fig. 8 ) is well marked by the lateral reflectivity variations on the SWD walkaway VSP-CDP binstack image (Fig. 9, Fig. 6), although the two imaged lines are parallel and about $300 \mathrm{~m}$ apart (Fig. 7). At processing, it had been necessary to apply velocity filters, or preferably wave filters rejecting seismic events "parallel" (in the convolution sense) to the undesired conical waves plus multiples illustrated as arrivals (2) on Figure 5, which could still damage the final SWD image. The result of this rejection filtering applied in receiver collection is displayed on Figure 11a, and in bit depth collection on Figure 11b. Interestingly, the near offset receiver collections (ex. Fig. 11a) express a high level of low frequency guided tube wave most probably propagated in the mud column at about $1500 \mathrm{~m} / \mathrm{s}$ and seismically reemitted by the drilling apparatus and mud pipes/pump at surface.

Additionally, an equivalent of the SNAP Log [1], obtained from the downhole measurements and compensated by the drilling parameters, was labeled pseudo-impedance log while drilling, and matches quite well with the post drill impedance $\log$ built from the wireline sonic and density logs (Fig. 12). Technical details on building the pseudo-impedance log while drilling can be found in [10] and [11].

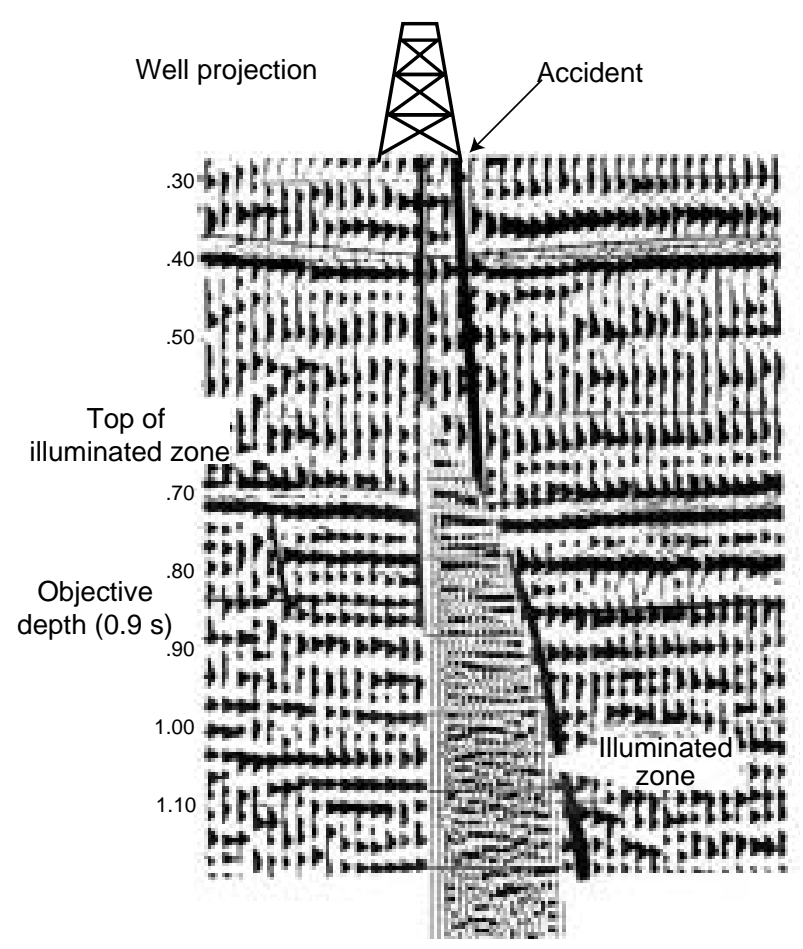

Figure 9

Surface line-A (1978), superimposed with projected drillbit image (courtesy of Gaz de France).

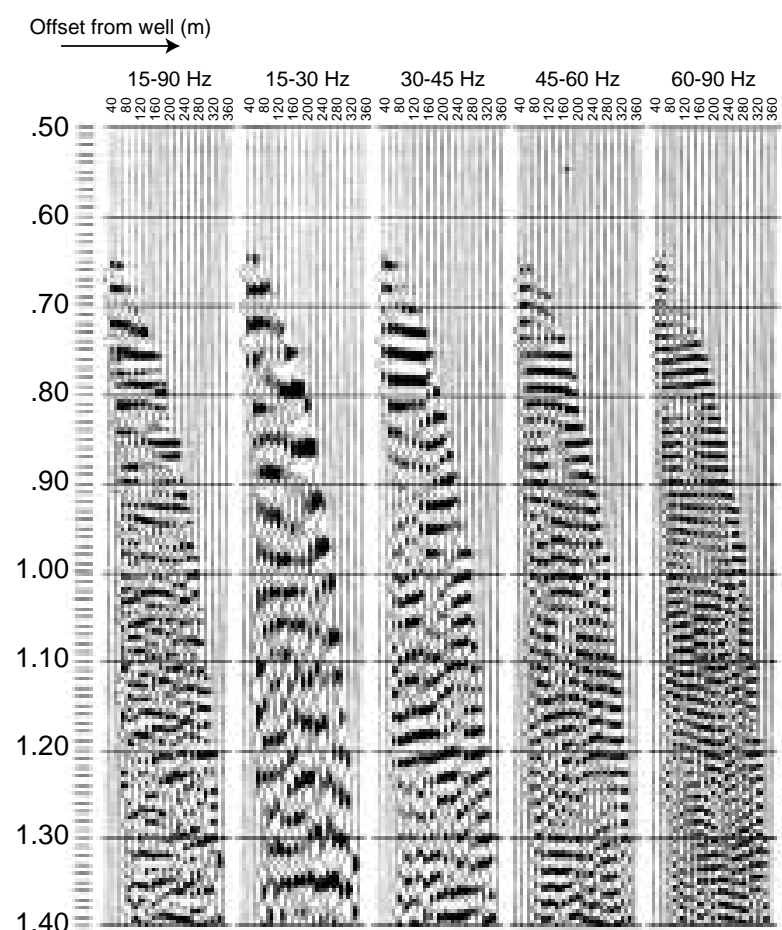

Figure 10

Frequency analysis on drillbit Binstack. Correlation by downhole acceleration below shock sub. The frequency content extends up to $70 \mathrm{~Hz}$. 


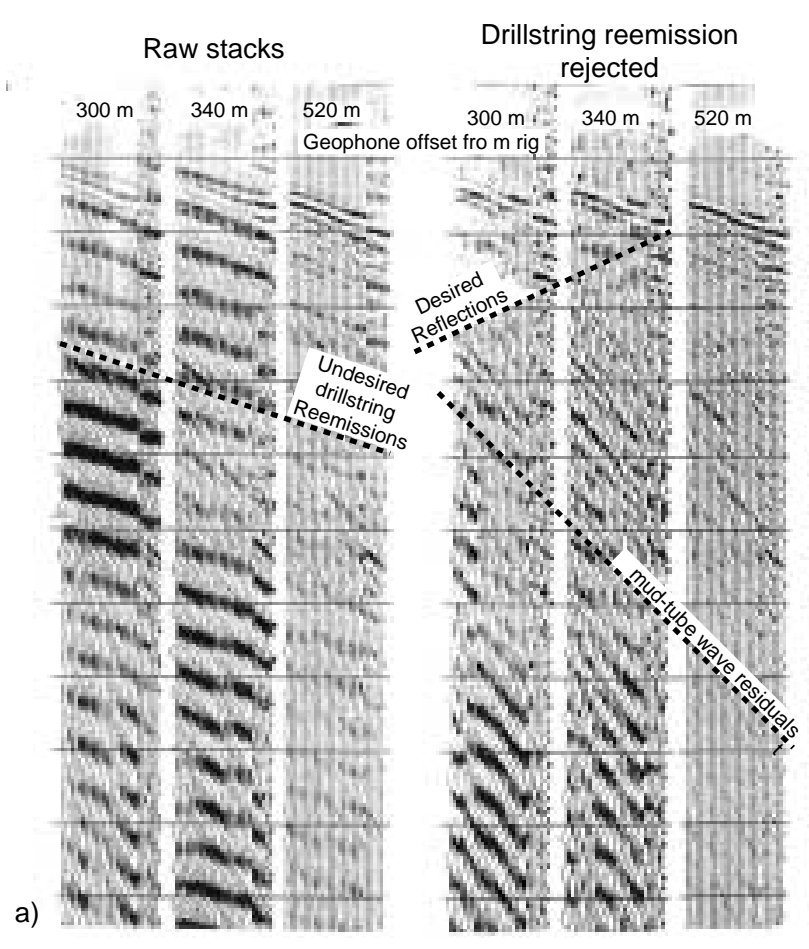

Figure 11a

Geophone collections of drillbit vertical stacks over each drill pipe.

Impedance from sonic and density wireline logs, obtained post drill. Unit: $0.01 \mathrm{~m} / \mathrm{s} \cdot \mathrm{g} / \mathrm{cm}^{3}$

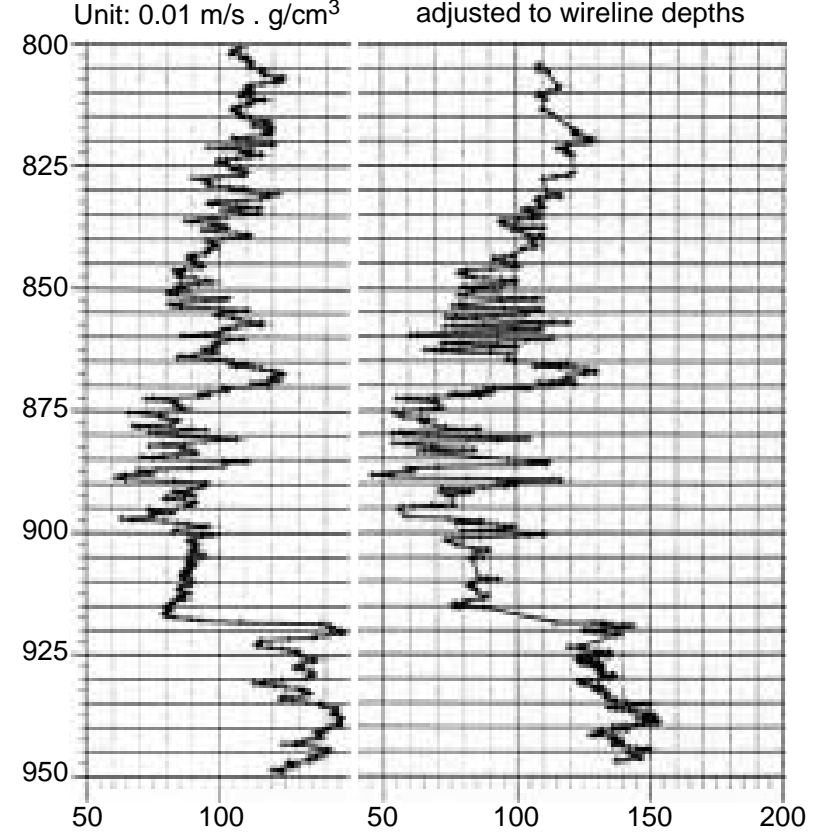

Figure 12

Formation parameter LWD (courtesy of Gaz de France).

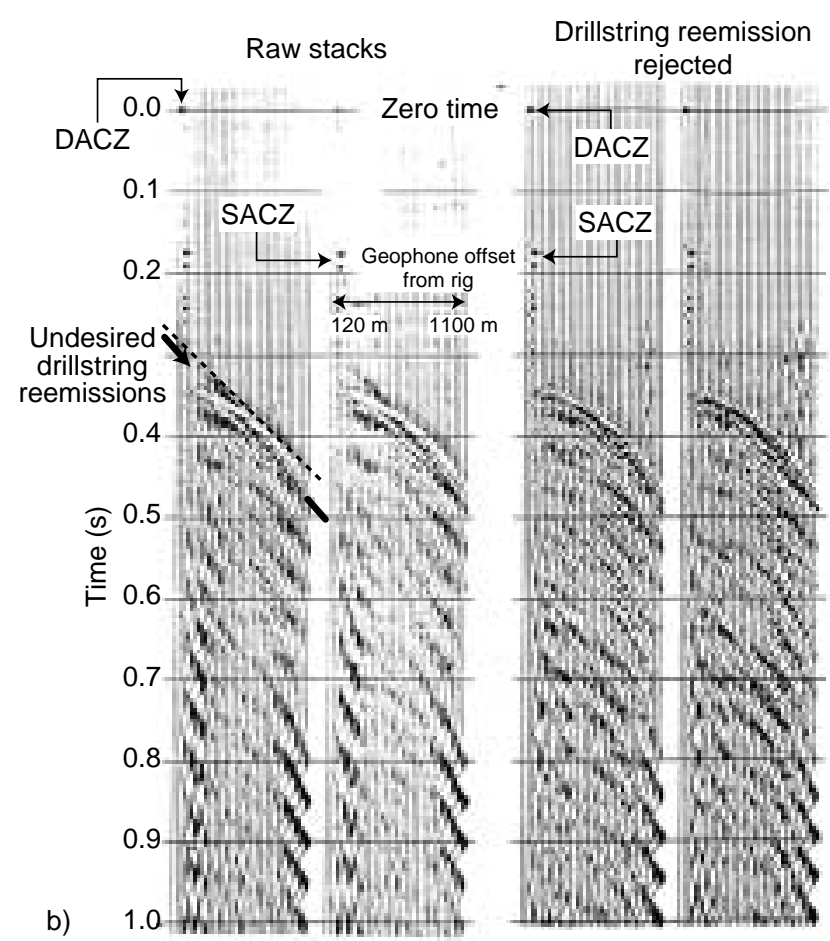

Figure 11b

Common depth collections of drillbit vertical stacks over each drill pipe.

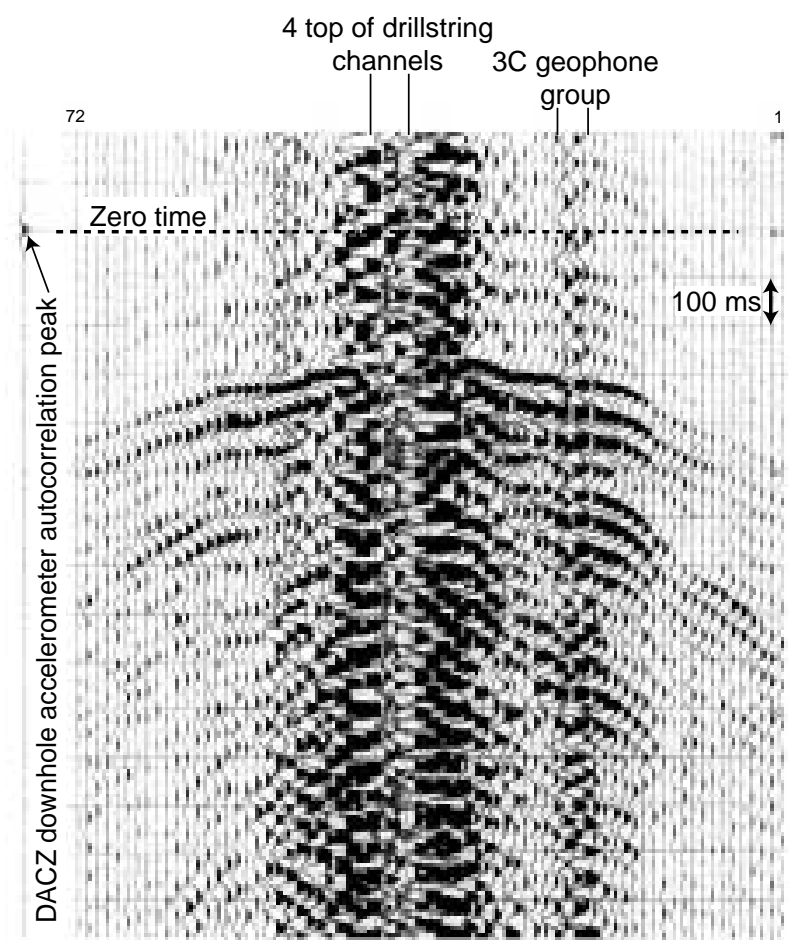

Figure 13

Field drillbit SWD monitor display BHA with two shocks subs. Real time field correlation over $40 \mathrm{~s}$. The DACZ downhole acceleration reference signal measured in real time with TRAFOR feeds the surface seismic recorder-correlator. 


\subsection{Drillbit SWD with TRAFOR and Two Shock Absorbers in the BHA}

In order to further improve the drillbit seismic emission quality, the geophysicists carried out an additional SWD experiment with two shock absorbers of different mechanical characteristics mounted in the BHA. This resulted in a total attenuation of audible vibrations on the drill floor when drilling the very hard Dogger limestone formation encountered in the Paris Basin, which positively surprised the field drillers. This observation is confirmed by the exceptionally low level of seismic noise on the near rig geophone signals on the raw field correlated record: the field monitor on Figure 13 was obtained by correlation over $40 \mathrm{~s}$ of raw drillbit data only. The residual field statics are adjusted from the deeper DP trace collection (Figs. 14a and 14b). Interestingly, the lateral coherence from one seismic trace to the other looks excellent on the first arrivals of the raw data (Fig. 14b), before any deconvolution. The final SWD walkaway image, displayed in both polarities on Figures 15a and 15b, matches reliably with the synthetic seismogram from sonic and density logs at well location, and shows reflected events down to the top basement reflector, about $800 \mathrm{~m}$ ahead of the drillbit and laterally to the well. A nearby well located at offset $400 \mathrm{~m}$ on the right branch of the walkaway, shows a

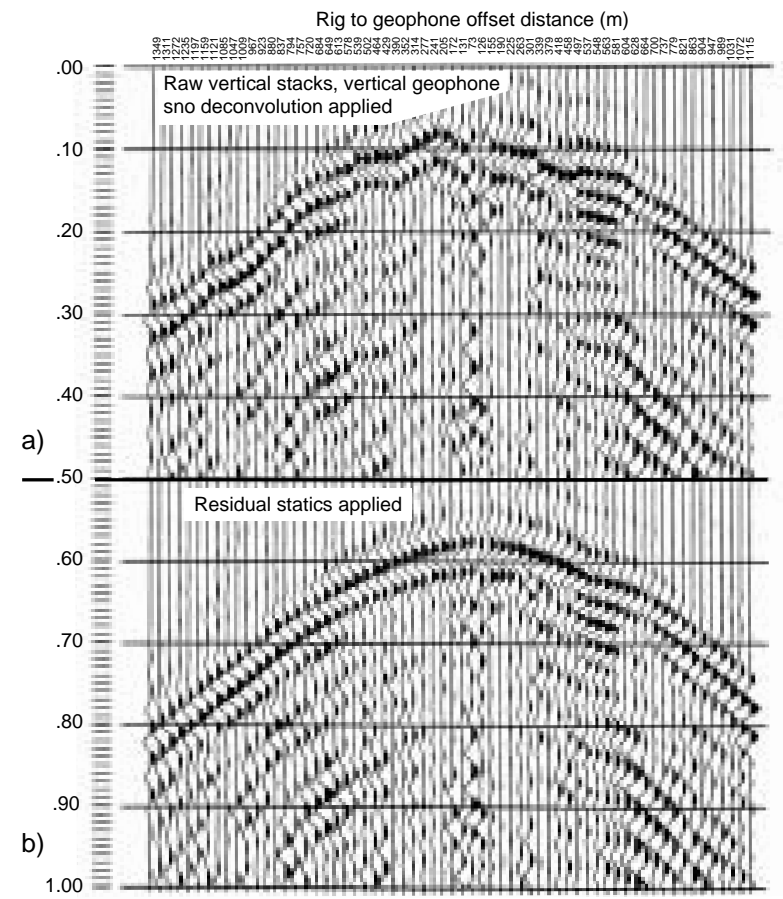

Figure $14 \mathrm{a}$ and $14 \mathrm{~b}$

Bit source collection of correlated data, vertical stacks over the deep drill pipe.

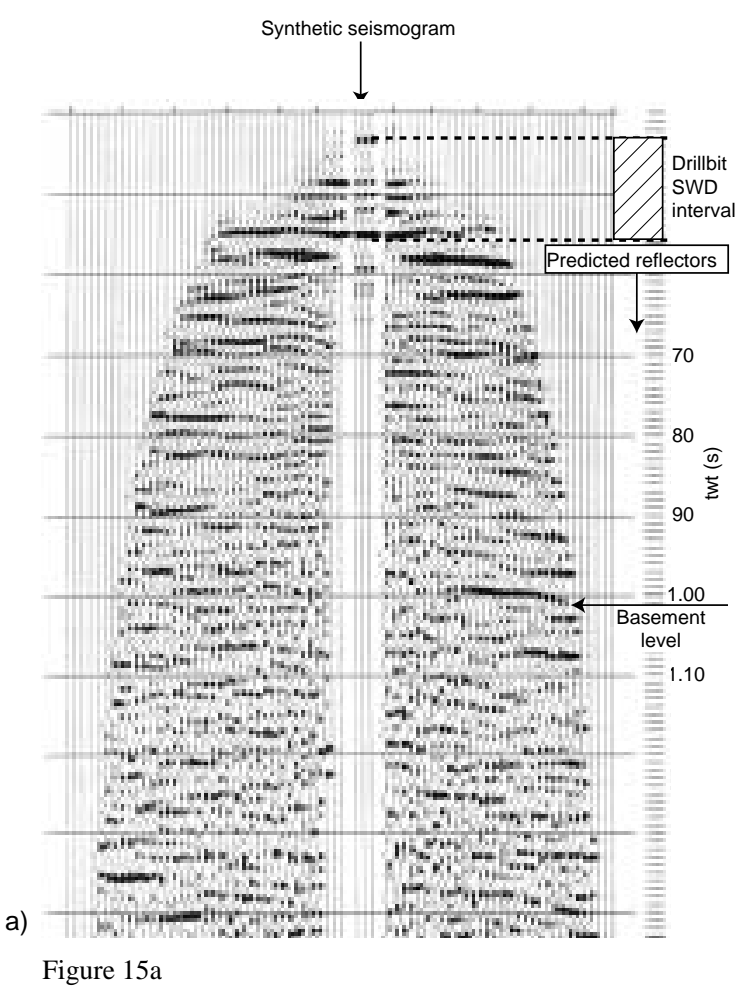

Field drillbit walkaway binstack BHA with two shock subs. White through $=$ increase of impedance $($ courtesy of Gaz de France).

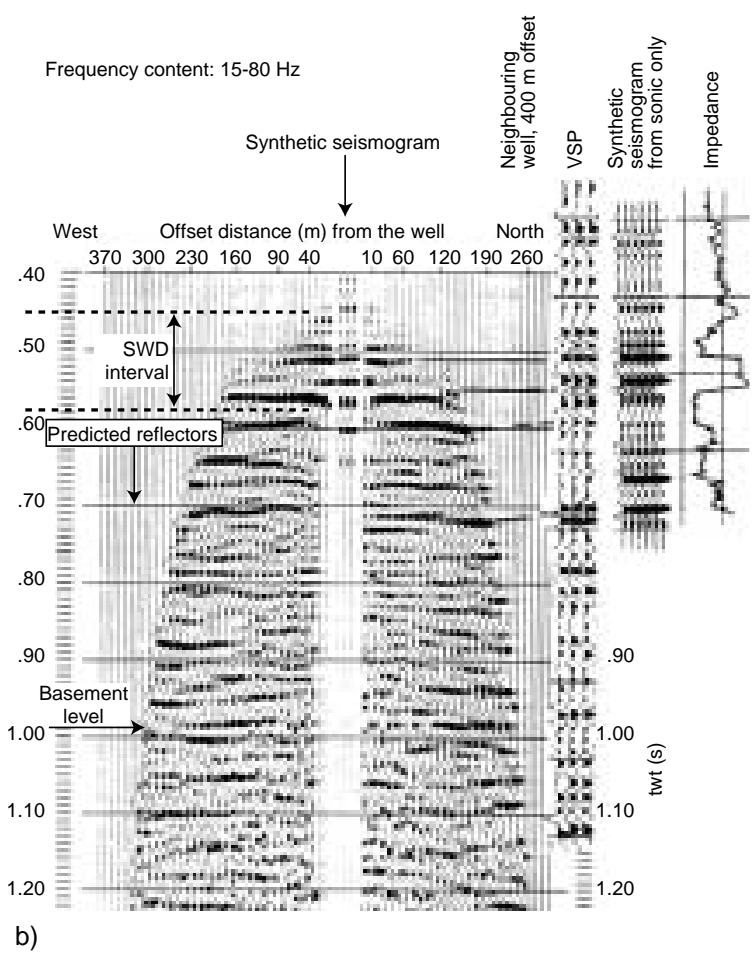

Figure $15 b$

Field drillbit SWD walkaway binstack. Black peak $=$ increase of impedance (courtesy of Gaz de France). 
fair resemblance with the walkaway image (right side of Fig. 15b). Remarkably, this reverse walkaway SWD image was obtained with no more processing effort as for a conventional direct walkaway recorded post drilling with a surface source and a multilevel string of downhole seismic receivers clamped on the borehole wall. Financially, the rental cost of a shock absorber is lower than the processing cost of heavy filtering the raw data, and the final walkaway SWD reflection image is cleaner and more reliable.

\subsection{Transfer Function of a Shock Absorber}

We describe here the measurement of the transfer function of a shock absorber with TRAFOR in drilling conditions.

The mechanical engineers in IFP desired to conduct a field experiment in order to improve the general knowledge of the shock absorber characteristics and behavior in true downhole drilling conditions. Therefore, a Drilco-Smith rubber spring absorber was chosen, with the 9 inch outer diameter (9" OD) recommended by the manufacturer for making up a BHA with a 12"1/4 diameter rock bit. This type of shock absorber dampens both the axial and rotational vibrations (simplified sketch on Fig. 16). Full mechanical and technical characteristics can be found in [12]. It is interesting to observe that this kind of rustic and efficient shock sub has been commercialized since about 1955, and did not evolve much over the years. As a matter of fact, the stiffness and damping characteristics of shock absorbers are commonly measured in the surface workshop by the manufacturers, often in a static manner, but no dynamic measurements are available in drilling downhole conditions of pressure and temperature.

A sketch of a BHA with shock sub instrumented with two downhole accelerometers is shown in the bottom part of Fig. 17:

- DACZ and DEBF axial accelerometers are placed on each side of the shock sub to be tested, DACZ and DEBF are strictly identical, and their analog circuits are the same before input into the multichannel downhole digitizer.

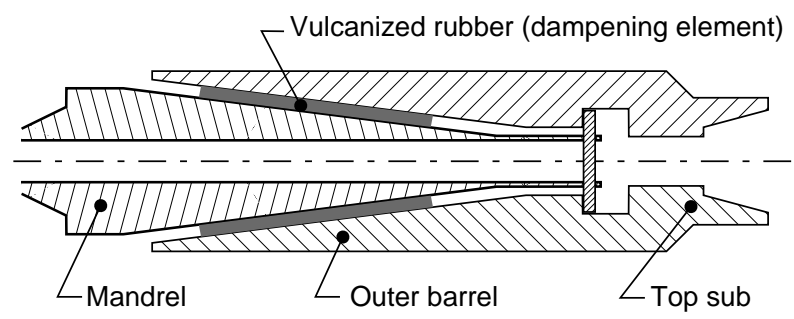

Figure 16

Simplified sketch of the Drilco/Smith rubber spring shock sub vibration dampener.

[Ref: The Composite Catalog 1986-87, pp 1751-1753].

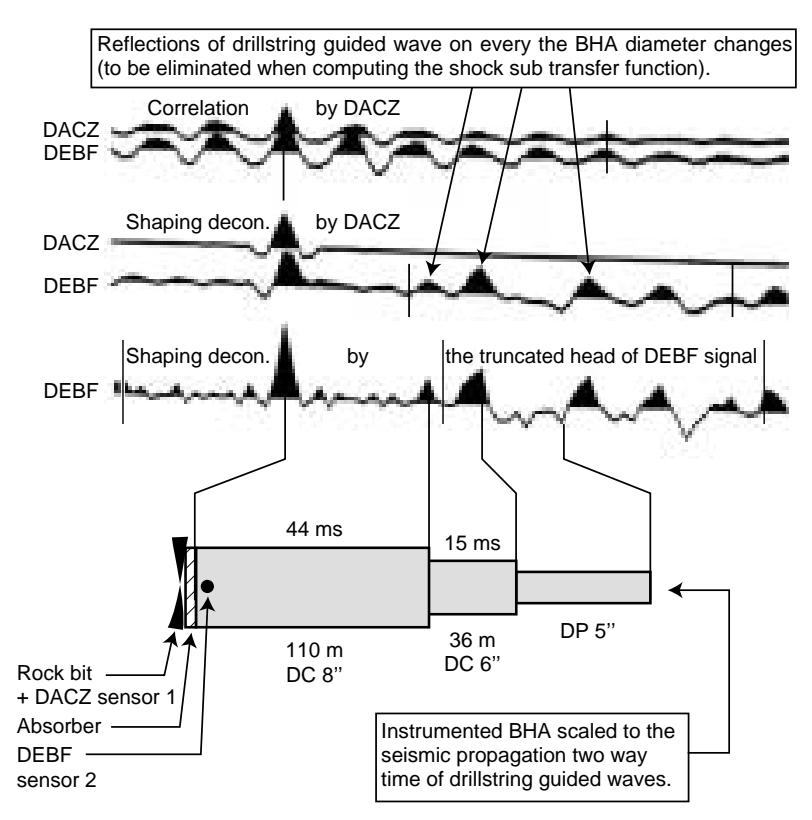

Figure 17

Sketch of the BHA instrumented for measuring the transfer function of a shock sub.

DACZ and DEBF are identical accelerometers, located below and above the shock sub, recorded with same gain, same digitization parameters.

- DACZ accelerometer is located on the rock bit below the shock absorber, with the downhole Televigile digitizer.

- DEBF accelerometer is located above the shock absorber, connected to the digitizer through a pigtail insulated wire running inside the shock sub element.

The top part of Figure 17 shows signals obtained by processing the downhole measurements, with, from top to bottom (five signal traces):

- Autocorrelation of DACZ random reference bit signal.

- Cross correlation of DEBF by DACZ reference bit signal.

- Shaping deconvolution (also called signature deconvolution) of the DACZ random reference bit signal: this signal is a Dirac delta function band limited to $6-116 \mathrm{~Hz}$, with flat amplitude spectrum (also represented as trace $\mathrm{T} 1$ on top part of Fig. 18).

- Shaping deconvolution of the DEBF signal by DACZ reference signal, also represented as trace $\mathrm{T} 2$ on Figure 18: this signal restitutes the shock absorber transfer function, in the first $30 \mathrm{~ms}$ following the DACZ autocorrelation peak time, followed by the reflections of the BHA guided wave on every diameter change, plus multiple reflections at a later time. Note on Figure 18 the amplitude drop of trace $\mathrm{T} 2$ (in true amplitude) relatively to trace $\mathrm{T} 1$, due to the attenuation of the vibrations transmitted through the shock absorber. Trace T3 on Figure 18 and the $4^{\text {th }}$ trace 
from the top on Figure 17, both represent the same signal as trace $\mathrm{T} 2$, but with normalized amplitude (peak amplitude equals unit amplitude).

- Shaping deconvolution of the previous DEBF signal by the shock absorber transfer function signal (same signal restricted to its head wavelet by truncation of the signal tail). This operation enhances the readability of the BHA multiples: the sketch of the BHA on the bottom is transformed into seismic time scale by division of the BHA length by the $5000 \mathrm{~m} / \mathrm{s}$ velocity factor corresponding to the acoustic velocity of BHA guided waves in the borehole.

The transmission transfer function and spectra of the 9"OD. Drilco-Smith rubber spring shock absorber are shown on Figure 18.

Trace T4 on top part of Figure 18 is obtained by truncation and tapering of the tail signal of the above deconvolved BHA response on trace $\mathrm{T} 3$, therefore trace $\mathrm{T} 4$ truly represents the transfer function or impulse response of the shock absorber element, about $30 \mathrm{~ms}$ long: the amplitude and phase spectra computed from impulse response $\mathrm{T} 4$ are displayed on Figure 18 (middle and bottom parts).
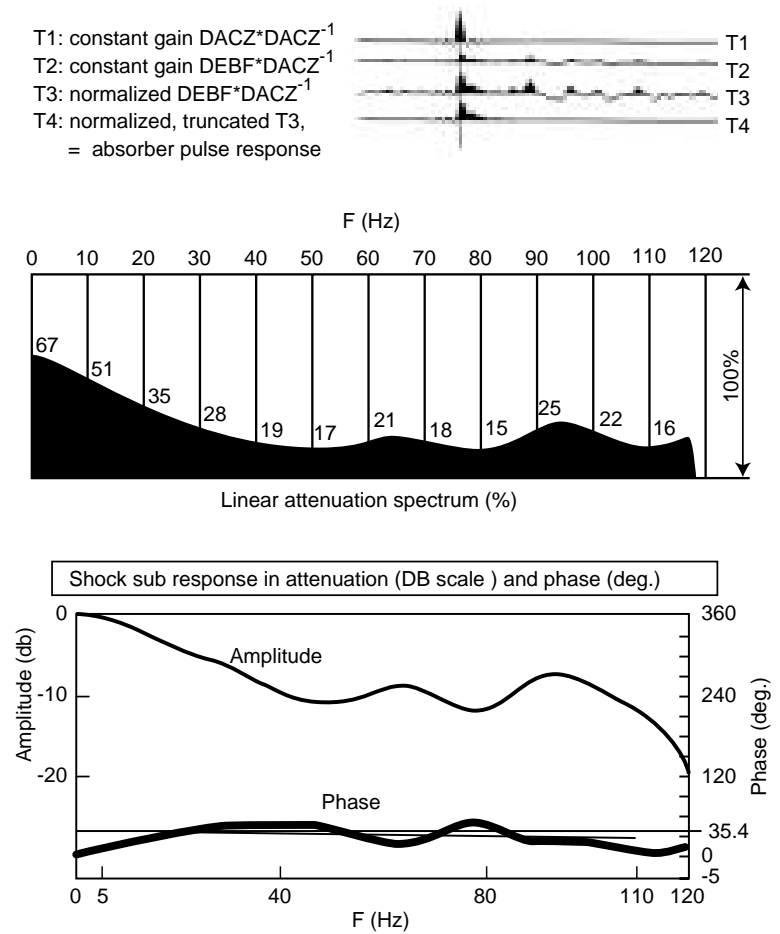

Figure 18

Transfer function of the Drilco/Smith 9"OD shock sub in downhole drilling conditions.
The linear attenuation (displayed in percent) is larger at high frequencies (a dividing factor 5 for frequencies above $40 \mathrm{~Hz}$ ) than for low frequencies (dividing factor 2 at $5 \mathrm{~Hz}$, 3 at $25 \mathrm{~Hz}, 4$ at $35 \mathrm{~Hz}$ ). Interestingly, when the bit bouncing resonating regime is not active (i.e. when the rock bit remains in permanent contact with the formation), there is no resonance peak in the transfer function amplitude spectrum around $3 \times \mathrm{rpm}$, a result potentially very different from the transfer function inferred from the mechanical parameters of shock absorbers measured in the workshop and a simplified bit-formation interaction model [13].

The phase shift of the shock absorber considered is found almost constant at about $35^{\circ}$ (linear regression of the phase spectrum between $5 \mathrm{~Hz}$ and $110 \mathrm{~Hz}$ ).

The transit time through the shock absorber (propagation from input DACZ to output DEBF accelerometers) is about $1.3 \mathrm{~ms}$, compatible with the $5 \mathrm{~km} / \mathrm{s}$ velocity through a $6 \mathrm{~m}$ long shock sub element ( $+2 \mathrm{~m}$ for half the digitizer length).

\subsection{Feasibility of VSP While Drilling}

\subsubsection{Shock Tests}

Shock tests of downhole geophone sensors and electronic equipment were carried out from 1996 to 1999. The downhole conditions of vibrations and shocks impose that all sensors, every electronic element, and subassemblies be drastically shock tested in order to insure that any downhole electronic ensemble can yield reliable measurements while drilling and withstand tough downhole drilling conditions for long periods of time. The validation shock test criterion defined by Guy Pignard in IFP consists in imparting 10 shocks of $1600 \mathrm{~g}$ 's as a half millisecond sine wave, on any piece of downhole equipment, preferably in several shock directions.

The shock test table sketched on Figure 19 was used to test several kinds of standard SM-15 rotating coil geophones from input/output $I / O$ Sensor manufacturer in Holland, who participated in the sensor validation program with $I F P$, by testing the characteristics of the geophones after each shock. Several types of geophones (SM7-10 Hz natural frequency, vertical and horizontal axis) as well as omnitilt SM7-30 Hz geophones have been positively submitted to in axis and off axis shocks.

After the tests, the design engineers from I/O Sensor went back to their workshop, tested again the electric response of all geophones, then cut open the case of the defective geophones in order to analyse the reason for failure, so as to subsequently determine how to further improve the reliability of their products. As a matter of fact, many I/O Sensor geophones were shock tested positively up to 5000 g's (as a $0.5 \mathrm{~ms}$ sine wave) without damage or any significant change in their response or sensitivity. 


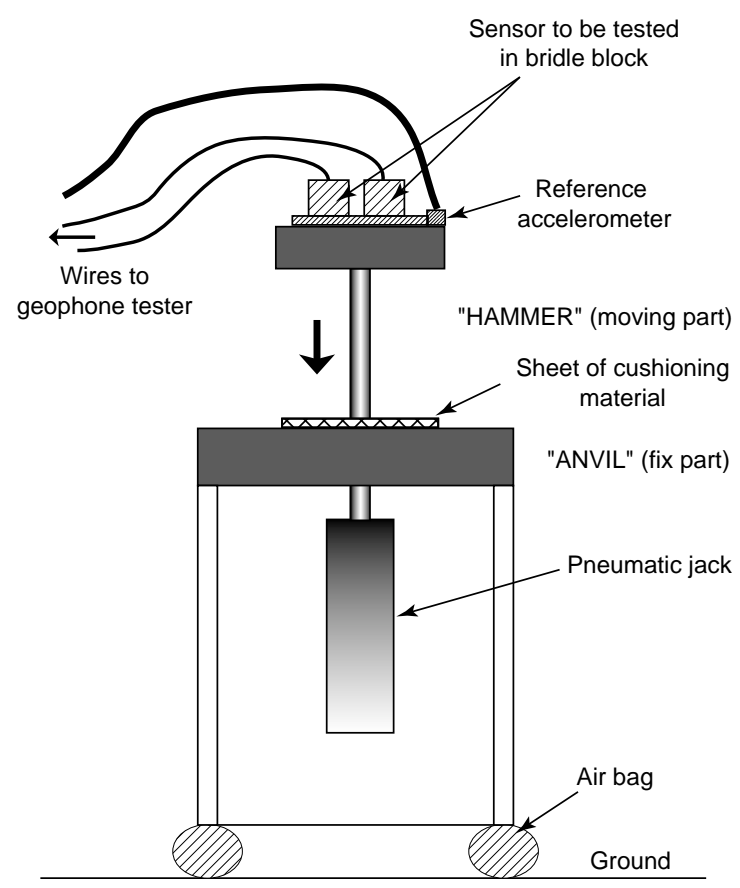

Figure 19

Sketch of a shock test table used to validate sensors and electronic parts for operations in downhole drilling conditions.

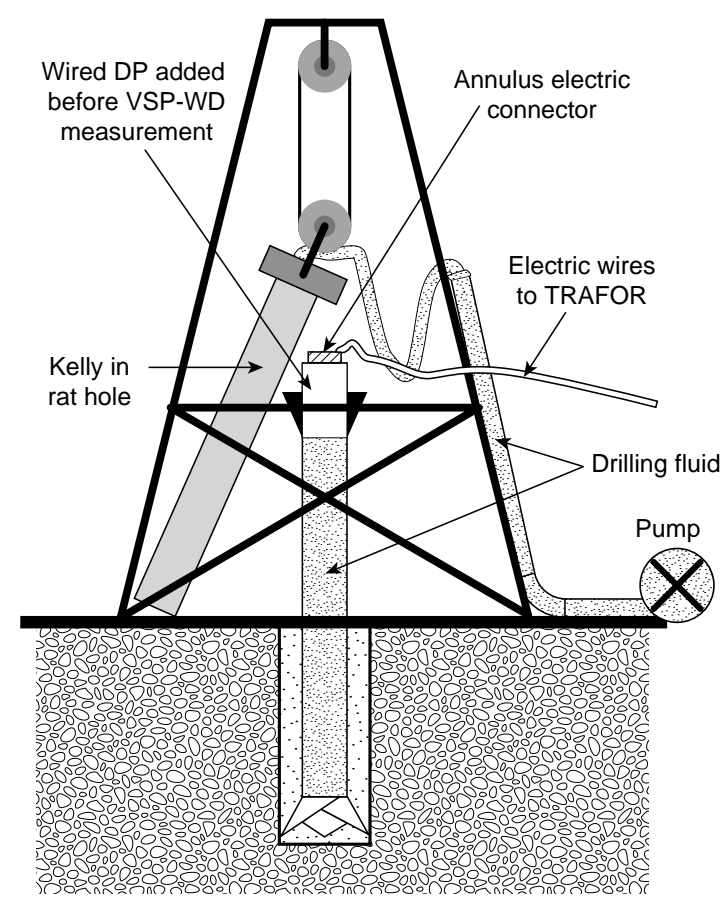

Figure 21

VSP-WD: rig configuration for recording limited WOB (5 t) applied; kelly disconnected. This recording configuration is preferred.

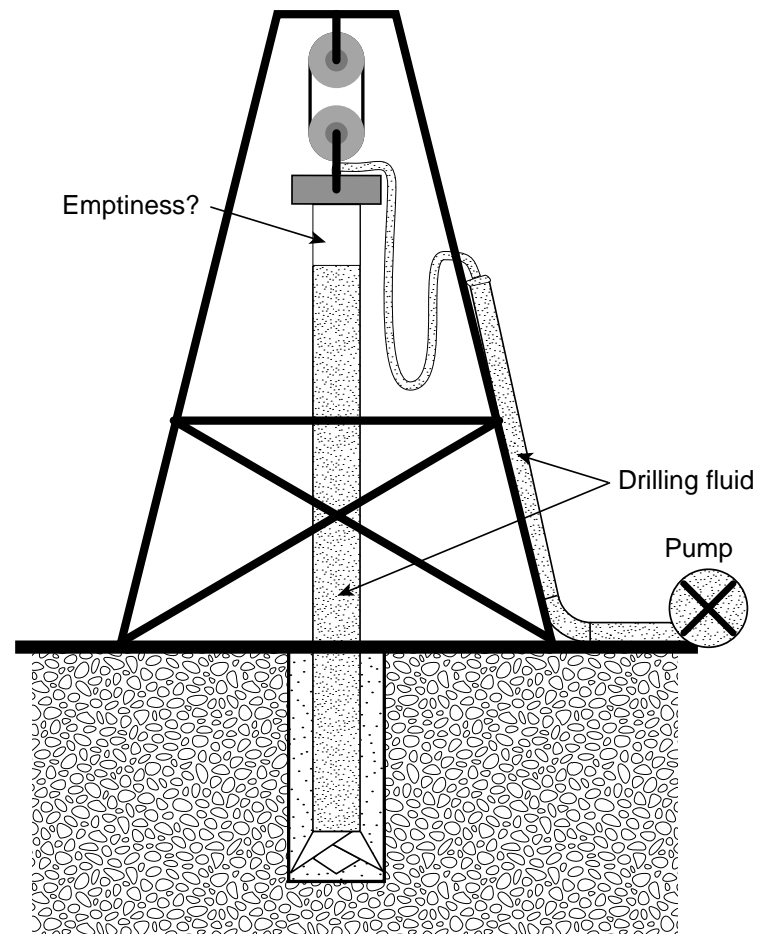

Figure 20

VSP-WD: rig configuration for recording limited WOB (5 t) applied so as to insure geophone coupling to the formation; kelly connected.
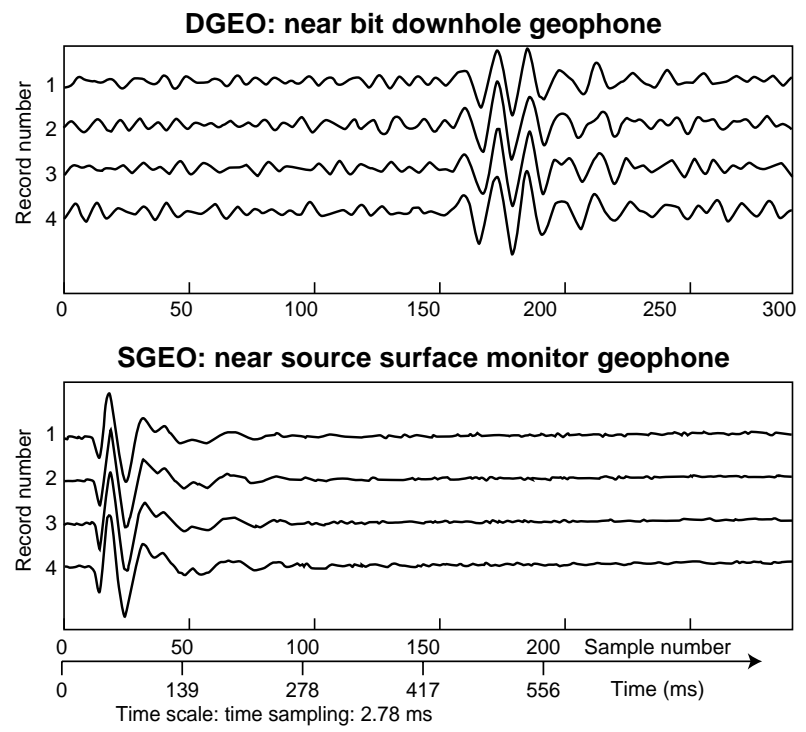

Figure 22

VSP-WD: series of unit records at same level. Simultaneous recording of downhole geophone (DGEO) and monitor surface geophone near the air-gun source (SGEO).The displayed data are filtered $\mathrm{HC} 45 \mathrm{~Hz}$. 
Given the proven sturdiness of the geophone receivers, a VSP test program could be pursued by IFP on one hand, and the miniaturisation of the geophones could be envisaged by I/O Sensor on the other hand.

\subsubsection{First Field Test}

The first field test of VSP-WD using the TRAFOR system was in 1997. The TRAFOR system was equipped with a SM15-14 Hz axial vertical downhole geophone (DGEO), and the signal of a surface geophone (SGEO) recorded simultaneously for the time reference, so as to execute a VSP test in the vertical portion of a $G D F$ well. The drilling apparatus configurations for VSP-WD recording in vertical well are illustrated on Figure 20 (kelly pipe connected), and on Figure 21 (kelly disconnected), for which the $G D F$ drillers agreed to rest the drillstring on the slips for a few minutes while applying a limited Weight On Bit (WOB) of about $5 \mathrm{t}$, in order to insure a good mechanical coupling between the formation and the downhole geophone located $7 \mathrm{~m}$ above the drillbit.

The seismic source was a 120 cubic inch airgun in a shallow water pit, which was rapidly activated several times in succession as the TRAFOR system was recording continuously. Figure 22 shows a few unit VSP shot traces, in downhole and surface receiver collection, time shifted and synchronized with a field computer before vertical stack (Fig. 23), built with the Matlab software.

A final display of the all the vertically stacked downhole signals versus depth was produced on the field (Fig. 24): the direct arrival is quite clean, the signal-to-noise ratio is variable; on the upper levels (1137-1152 m), strong tube wave arrivals are visible, in correspondence with the rig configuration of Figure 20, in which the drillstring is connected to the kelly during the VSP measurements. In contrast, below $1211 \mathrm{~m}$, the Kelly was disconnected during the VSP measurements (as on Fig. 21): as a result, the tube wave vanished, and the general noise level was significantly decreased on the downhole signal. The first VSP level, at $1137 \mathrm{~m}$, was recorded with and without application of any weight on the bit: signal distortion occurs when the BHA is suspended as the rock bit is off contact with the well bottom.

After processing the above VSP-WD test data, a few reflections appeared in the lower part of the conventional frequency spectrum, and with less coherency of signal shape (i.e. lower quality coupling conditions to the formation) in comparison with the standard wireline VSP data recorded later in the same well.

In addition, another high quality pseudo-impedance log was recorded and produced from the TRAFOR measurements of the above VSP-WD test: Figure 25 shows the comparison of the velocity derived from the wireline sonic log, after application of a $3 \mathrm{~m}$ shift between the wireline depth scale and the driller depth: the upper section with alternate shale and sandstone beds shows an excellent correlation between the two logs; near $1330 \mathrm{~m}$ the $6 \mathrm{~km} / \mathrm{s}$ hard shaley dolomite bed is not marked by the pseudo-impedance log derived from drillbit vibration level, probably due to the microfracturation of this formation which makes it easy to drill.

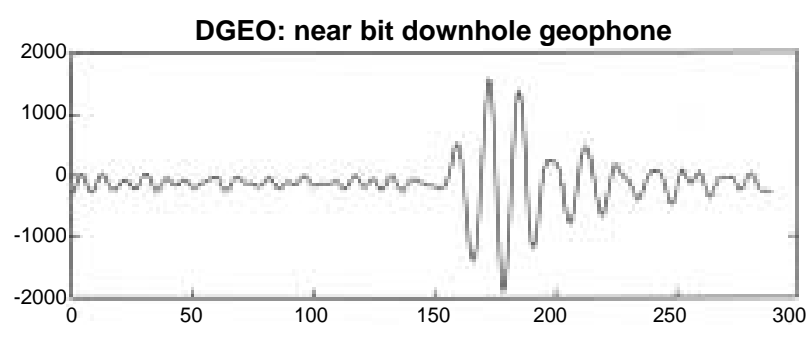

SGEO: near source surface monitor geophone

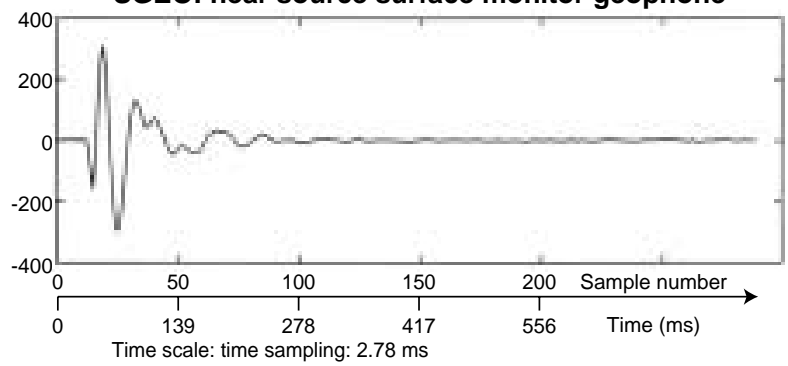

Figure 23

VSP-WD preprocessing. Vertical stack at a given depth level. Downhole geophone (DGEO) and surface geophone (SGEO). The displayed data are filtered $\mathrm{HC} 45 \mathrm{~Hz}$.
All measurements are done with $5 \mathrm{t}$ WOB (Weight On Bit), except first $1137 \mathrm{~m}$ record. 1137-1152 m: kelly connected during seismic recording: undesirable tube wave present. 1211-1285 m: kelly disconnected during seismic recording: tube waves are eliminated. The displayed data are filtered $\mathrm{HC} 45 \mathrm{~Hz}$

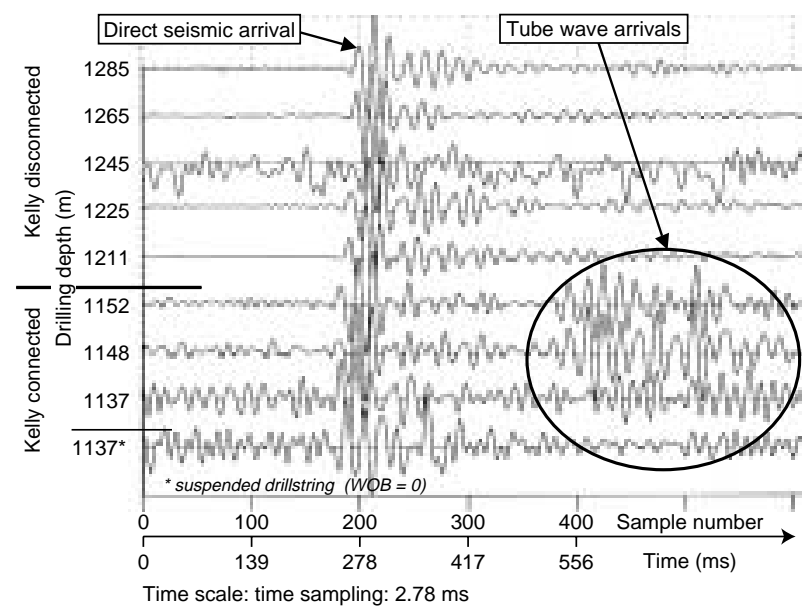

Figure 24

VSP-WD: DGEO field vertical stacks at every depth level, synchronized with the surface signal (SGEO) direct arrival for time origin (October 1997). 


\subsection{Industrialization}

We describe here an industrialization approach of the drillbitSWD and VSP-WD techniques using wireless downhole measurement technology.

The experimental drillbit SWD tests run by IFP in the Paris Basin with the TRAFOR wireline transmission system allowed two conclusions to be drawn. Firstly, reliable drillbit seismic reflection results can be obtained up to $70 \mathrm{~Hz}$ using a roller cone bit (with teeth/insert length not too small) with one or two shock absorbers in the BHA and a downhole reference sensor in between, provided that the formation under drilling is not too tender. Secondly, in practice, the P-wave velocity $V p$ should, in practice, exceed $2500 \mathrm{~m} / \mathrm{s}$ in order to have enough drillbit seismic energy. Reliable seismic reflections have been recovered up to $1000 \mathrm{~m}$ or more ahead of the bit.

Moreover, as the TRAFOR system is more intrusive and heavy-to-operate for the drilling teams in comparison with existing wireless MWD systems, other transmission and data transmission avenues needed to be explored in order to approach the industrial drilling sites with SWD applications including downhole measurements. With this in mind, IFP geophysicists investigated the technical capabilities of the electromagnetic (EM) transmission system developed by Geoservices, in terms of transmission performance versus terrain resistivity, and in terms of synchronization precision of the downhole recorder clock with a surface clock.

The absolute precision of the EM synchronization seemed to be compatible with seismic requirements; in addition, for drillbit SWD applications, some drift of the downhole clock with temperature, relatively to a highly stable surface clock, could be tolerated as the guided wave propagation in the drill string would allow the appropriate corrections to be made. Therefore, the EMWD technique commercially operated by Geoservices, [14], presented a good perspective for the SWD applications, starting with the drillbit-SWD reverse walkaway method to be applied while drilling a limited depth interval, as it had been previously done with TRAFOR.

For VSP-WD, the TRAFOR system was adequate to carry out a feasibility test as only a limited amount of wired drill pipe is available. For a wireless downhole recorder, the

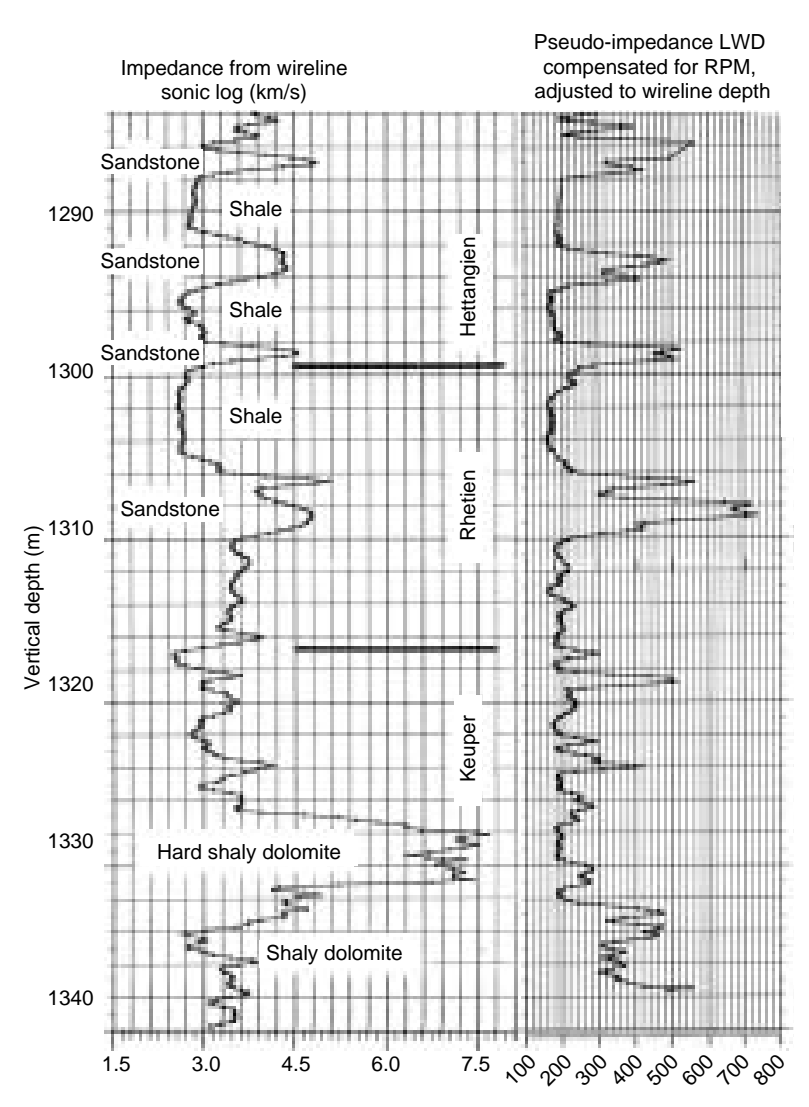

Figure 25

Formation parameter LWD.

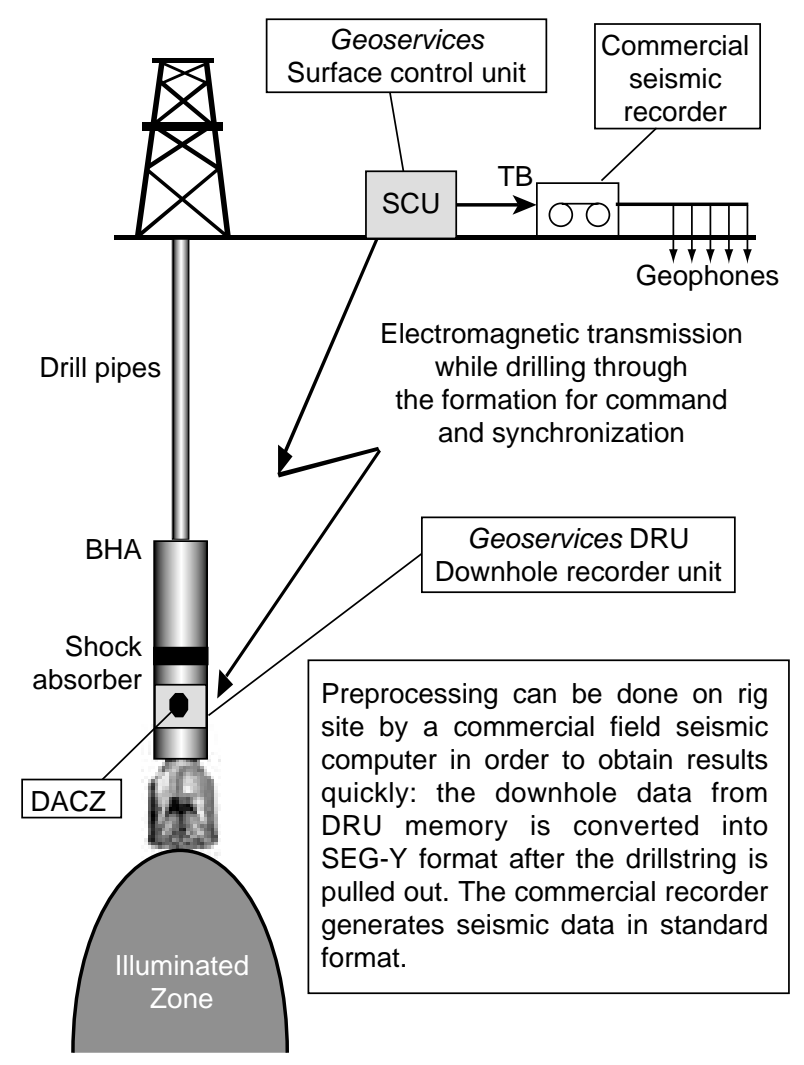

Figure 26

Sketch of the drillbit EM-SWD recording chain. 
tolerance on the downhole clock drift would be much more severe than for the drillbit-SWD method, of the order of $1 \mathrm{~ms}$ over 5 or 10 days, and this point would have required an additional technological improvement of its own.

Another economical argument was in favor of developing a drillbit-SWD prototype first, rather than an VSP-WD prototype: a commercial drillbit-SWD downhole recorderWD can be built as a central tool to be used only over a depth interval of 200 to $400 \mathrm{~m}$ in a vertical to low deviated well, around mid target depth. In contrast, a VSP-WD downhole recorder would have to work in the deep section of all kinds of borehole, vertical to horizontal, therefore it must be built in the steel crown of a drill collar, resulting in higher costs.

The above reasons lead IFP and Geoservices to develop a wireless SWD prototype for the drillbit-SWD method in the first instance. Depending on the success of this first cooperation project, the more challenging VSP-WD method would be engaged in a second stage.

\section{WIRELESS DRILLBIT EM-SWD}

This method was implemented by a demonstrator downhole MWD recorder prototype in the framework of an ENELGeoservices-IFP project carried out in 1997-2000 with partial funding of the EC (project GE 019/96).

The Bottom Hole Assembly (BHA) includes a roller cone bit, preferably a shock absorber and a downhole reference accelerometer axial to the well (sketch of the field set-up in Fig. 26). The downhole source signal from the accelerometer is recorded and stored downhole.

Geoservices built a new Downhole Recorder Unit (DRU) to be integrated in the BHA in order to record the random axial drillbit vibrations in synchronization with the surface and controlled by a Surface Command Unit (SCU). The SCU transmits "start recording" orders to the DRU through a one way EMWD wireless transmission surface to downhole only. In order to simplify the equipment and remain within reasonable budget limits, no data transmission downhole to surface was implemented.

\subsection{Downhole}

Downhole, the DRU (Fig. 26) records and stores the drillbit pilot accelerometer signal in synchronization with and under command of the SCU. While drilling, only a limited time window per drill pipe is recorded downhole on order from the surface operator. The preamplification gain was preadjusted so as to optimize the dynamic range of the data to be retained and stored, requiring a memory capacity of 48 Mbytes only, which proved to be operationally sufficient. The DRU prototype is outlined on Figure 27, showing the general design, the central electronics and its main characteristics. The EMWD transmission can be operated even in case of total fluid loss while drilling, which is an advantage over the mud pulse transmission technique in Italian geothermal wells for instance.

\subsection{On surface}

On surface, a commercial seismic recorder can acquire as many channels as desired, and store the uncorrelated data on magnetic cartridges. Laying out the receivers in radial lines extending away from the wellhead is a practical pattern. Most of the commercial surface seismic recorders can be easily interfaced with the SCU. The SCU generates periodic time pulses (time break, "TB" on Fig. 26) in order to automatically start the seismic recorder, accompanied by a coded TB number on a separate serial line.

\subsection{Downhole Data Recovery}

Downhole data recovery is illustrated in Figure 28. After the drillstring is pulled out of the well, the downhole signal is transferred from the DRU memory to the SCU, then QC'ed (Quality Controlled) and segmented according to the instants of the TB orders sent periodically by the SCU to the seismic recorder during the effective drilling periods. After recovery, the segmented downhole reference data are output in standard SEG-Y seismic format. The segmented and reformatted downhole data and surface data are then sent to a processing center in order to be merged and correlated using a commercial seismic processing software.

As the drillers would not accept to drill with a roller cone bit and a shock absorber all along the borehole, the EMSWD method is well suited to reverse walkaway SWD field operations, for which the recorded depth interval is limited (for instance: 300-500 m), around mid target depth, preferably in vertical or low deviation wells: thus a typical drillbit SWD survey would last for one or two drilling runs only.

\section{PREOPERATIONAL EM-SWD FIELD TEST}

In October 1998, a preoperational SWD field test was carried out (in the framework of EC project GE 019/96) in a low temperature Gaz de France well near Paris with the objective to validate the new wireless downhole equipement developed by Geoservices and the whole EM-SWD acquisition chain including a Sercel SN388 surface seismic recorder interfaced with the SCU (Fig. 26).

Full technical details on this field test can be found in [15].

\subsection{Field Operation}

A short single surface line of 12 geophone groups, $50 \mathrm{~m}$ apart, was recorded on surface. The SCU (Fig. 26) generated a time break (TB) every $54 \mathrm{~s}$ to start automatically the SN388 seismic recorder. The SN388 recorder stores the first $50 \mathrm{~s}$ on magnetic cartridge, then stops and resets itself waiting for the next TB order from the SCU. 


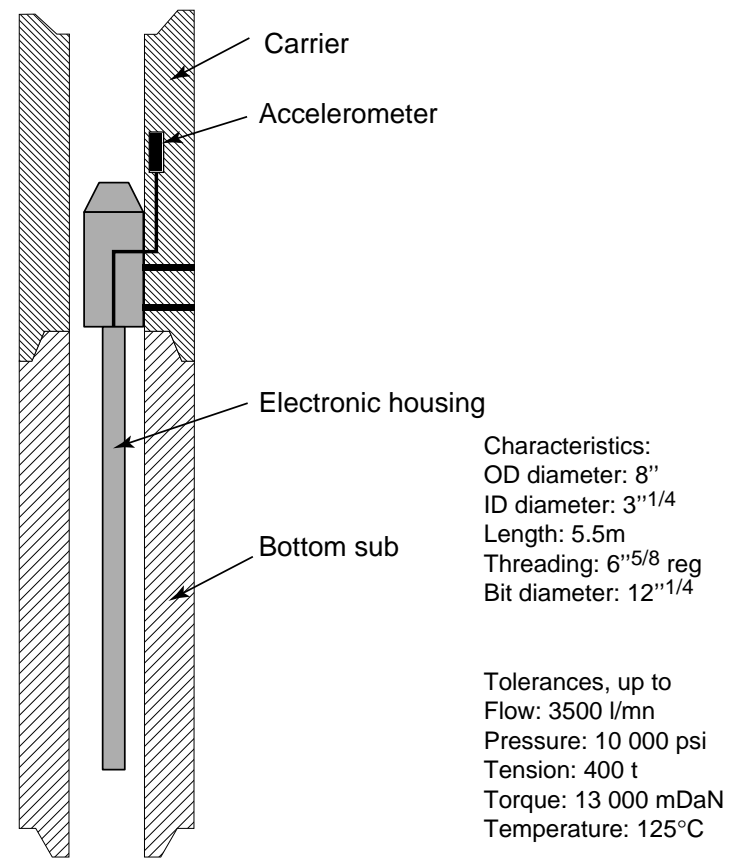

Figure 27

Drillbit EM-SWD recording sub manufactured and operated by Geoservices.

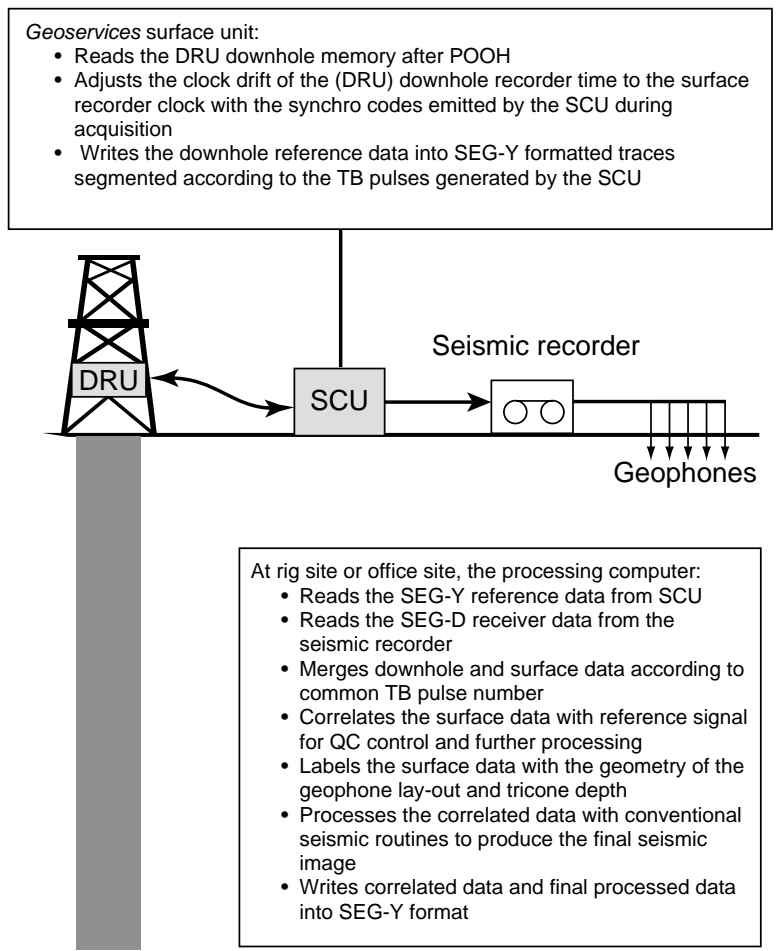

Figure 28

Data recovery procedure applied when the BHA is pulled out of the hole.
After Pull Out Of the Hole (POOH), all the downhole data were correctly recovered: 1000 time segments of $54 \mathrm{~s}$ were extracted with 8 bits sample, per $4 \mathrm{~ms}$ sample rate, and 1300 time segments in sign bit ( 1 bit per sample), all converted into SEG-Y format. On surface, 2400 seismic records of $50 \mathrm{~s}$ with 16 channels were stored by the SN388 on IBM 3490 cartridges in SEG-D format. Downhole and surface channels were almost continuously recorded during the effective drilling periods.

Two vertical accelerometers SACZ were placed at the top of the drill string and connected to the seismic recorder. The seismic acquisition occurred during the drilling of the deviated part of a Gaz de France well, up to $25^{\circ}$ incidence, in the 12 "1/4 diameter, from 620 to $880 \mathrm{~m}$ depth, as illustrated by the well trajectory Figure 29. The downhole EM-SWD recording sub (Fig. 27) was placed above the directional mud pulse MWD system in the BHA sketched on Figure 30, about $25 \mathrm{~m}$ above the rock bit. The mud pulse transmission was not altered by the presence of the EM-SWD sub.

Although the presence of a shock absorber in the BHA is recommended to attenuate undesired drill string head waves [2-4], GDF drilling operators did not wish to have any shock absorber in the deviated well part. During the operation, the EM orders were sent downhole during the drill pipe connec- tion manoeuvre while the drill string is seated on the slips. Thus, the EM signal is optimal and no rig downtime is necessary for the surface to downhole transmission of EM start orders.

\subsection{In House Preprocessing}

The preprocessing phase addresses the questions of merging control of the downhole and surface data, synchronization control and correction of the clock drift between the downhole and surface recorders. The TB pulse number labelling of surface and downhole records facilitates the merging of surface records and corresponding downhole reference time segments. First, the top drill string accelerometer SACZ signal is correlated by the downhole reference accelerometer DACZ corresponding to the same time segment and TB number, in order to insure the following quality control actions:

- Check of the exactitude of the downhole and surface TB pulse number correspondence, from correlated records.

- Edition of the single surface (resp. downhole) seismic records without correspondence with downhole (resp. surface) record, and during the drilling interruptions.

- Evaluate and compensate the downhole clock drift relative to the surface clock: as the propagation time from DACZ 


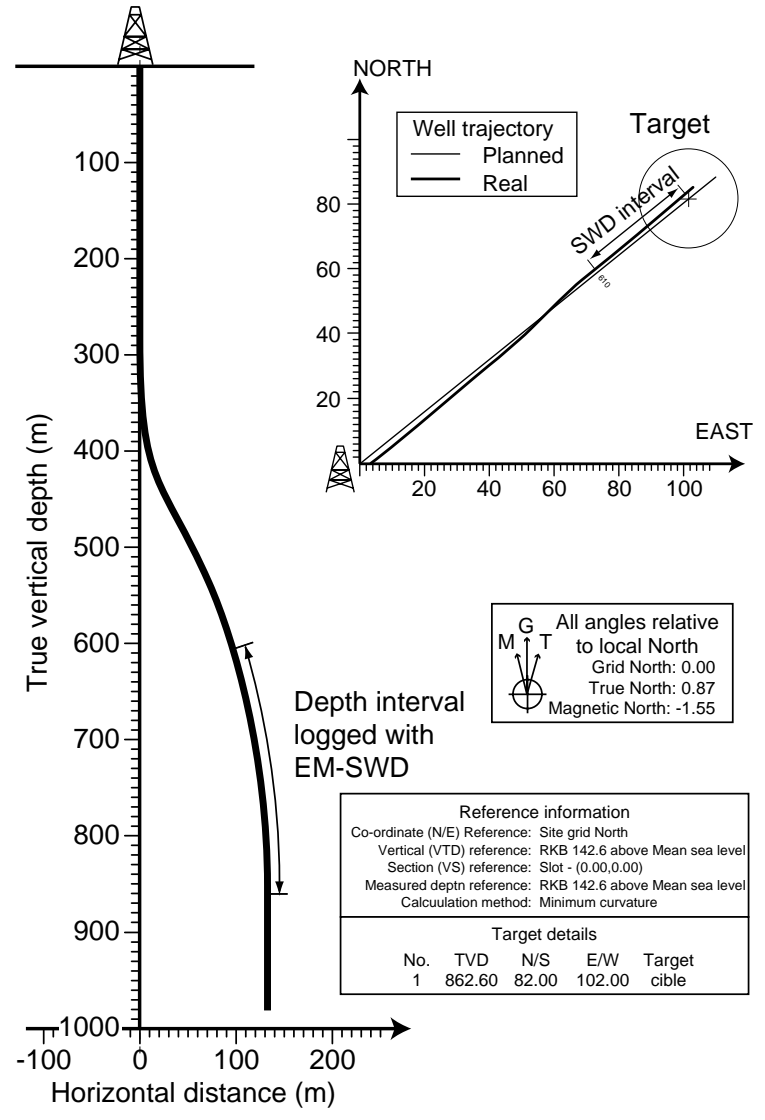

Figure 29

Well trajectory and interval logged by SWD.

\begin{tabular}{|c|c|c|c|c|c|c|}
\hline & \multirow{3}{*}{$\begin{array}{c}\text { NEYRFOR } \\
\text { Fanse }\end{array}$} & $\cos a x$ & 3 & sum & \multicolumn{2}{|c|}{ PEOWनI } \\
\hline & & $\operatorname{sen}$ & & & & \\
\hline \multirow[b]{2}{*}{ osahes } & & \multicolumn{2}{|c|}{ Eatsea } & \multicolumn{3}{|c|}{ ass } \\
\hline & Descerrot & Colinit & Dimen: & & $A=$ & $\operatorname{sech} \pi$ \\
\hline & 1 & & & & & \\
\hline$\varphi$ & $p \infty$ & $r$ & $r$ & & & COESR \\
\hline & cross oves & ive & 2 ser & 283 & 19.3 & consh \\
\hline & $4 \infty$ & evr & aner & ma & 18th & corsh \\
\hline & Cress oven & evt & $r$ & $2 \pi$ & $10 \mathrm{ng}$ & esron \\
\hline & $a b c$ & $r$ & $2127 \%$ & an & tent $n$ & coston \\
\hline & DUnEY SAR & $r \mathrm{vr}$ & an & 1200 & tas & taven. \\
\hline & 100 & $r$ & atare & has & $\tan 3$ & CEFSA \\
\hline & sono & $r$ & a 12 & sat & an & GEOSERVICES \\
\hline ais & stkos stas & the & $212 \mathrm{me}$ & $\pi$ & 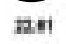 & 46004 \\
\hline & krosen & $r$ & งหน & La & $m=$ & जeca \\
\hline & WNo & $r$ & 3 & $\mathbf{s}$ & 13.4 & steon \\
\hline & knover. & $\mathrm{r}$ & I 12 & en & 125 & basenes \\
\hline & Festheta & $r$ & $\operatorname{sen}$ & asi & $\mathrm{cn}$ & \\
\hline & poert ounL + hat sabe & $r$ & $n$ & 20 & 10 & esten \\
\hline & 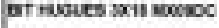 & & & $2 x$ & 28 & Arrs \\
\hline
\end{tabular}

Figure 30

BHA used for drillbit EM-SWD field test EM-SWD sub located about $25 \mathrm{~m}$ above the rock bit.

Near well geophone collection (VSP). Equalized display in raw time $\begin{array}{lllllllll}0.20 & 0.30 & 0.40 & 0.50 & 0.60 & 0.70 & 0.80 & 0.90 & 1.00\end{array}$ Spread of 12 geophones, $50 \mathrm{~m}$ apart, 100 to $650 \mathrm{~m}$ from the well. Bottom channel corresponds to top of drill string accelerometers, SACZ.

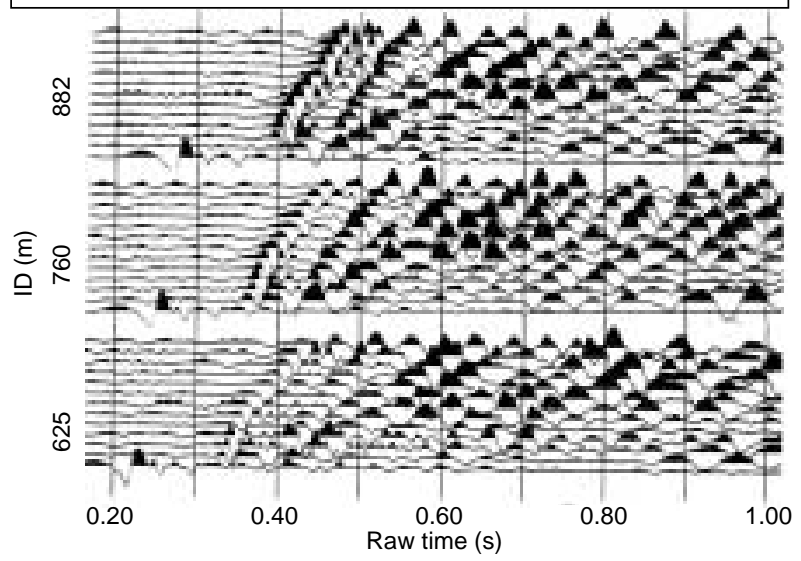

Figure 31

EM-SWD: source collections.
Figure 32

EM-SWD: geophone collection. 


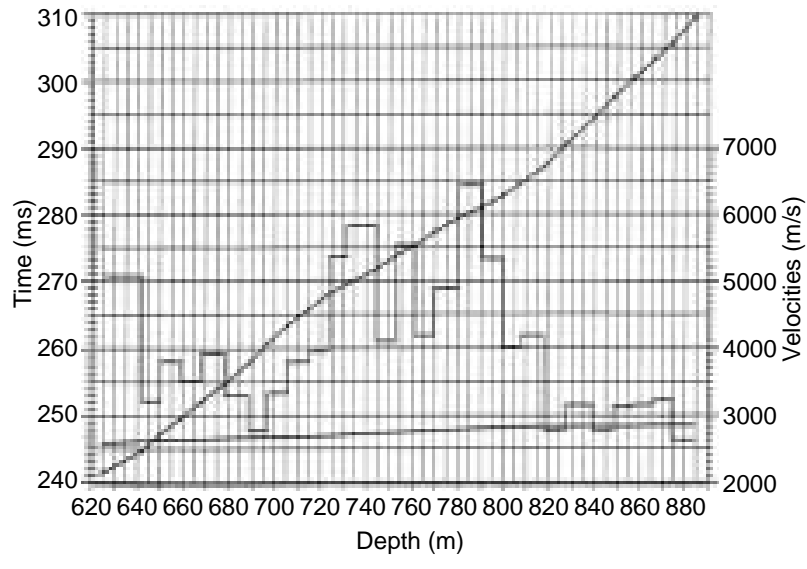

Figure 33

EM-SWD: time-depth and velocity curves.
Reflected wavefield deconvolved on near well geophone collection. VSP-type processing applied. Equalized display in two way times (twt) $\begin{array}{lllllll}0.40 & 0.50 & 0.60 & 0.70 & 0.80 & 0.90 & 1.00\end{array}$

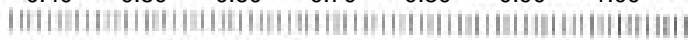

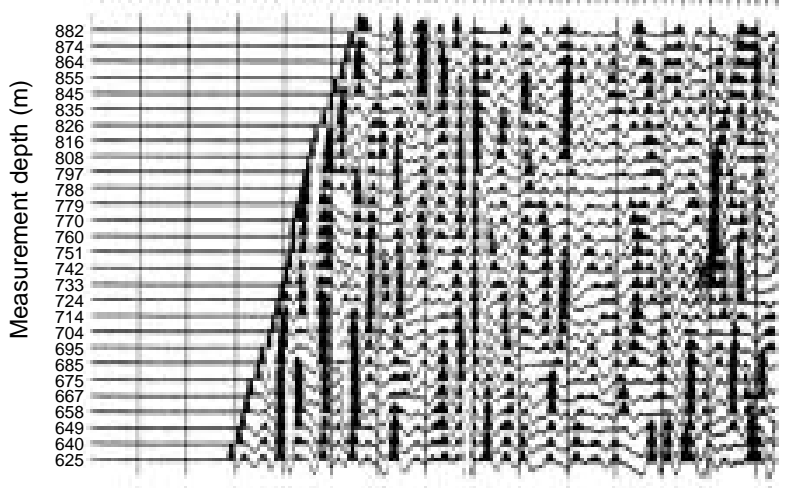

Figure 34

EM-SWD: geophone collection.

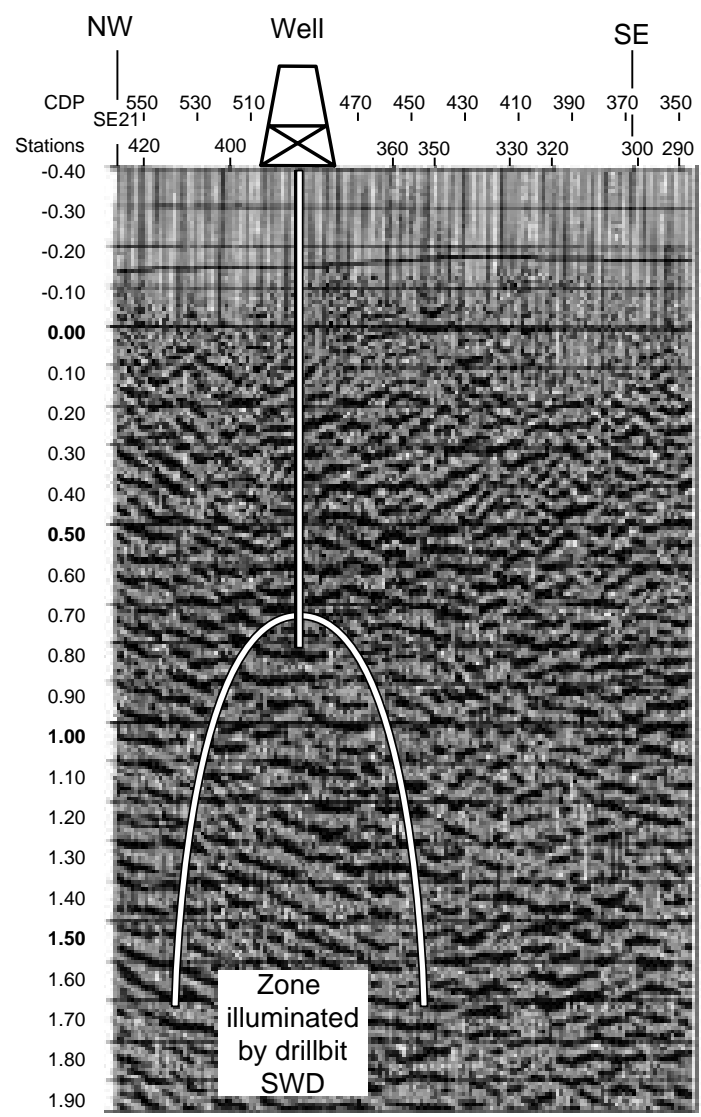

Figure 36

Surface seismic section across the geothermal well: image totally blurred.
SWD reflection images, (10-65 Hz), compared with Binstack of standard vibrator walkaway $(10-100 \mathrm{~Hz})$ on nearby well equiped with permanent downhole geophone on tubing. Courtesy of Gaz de France

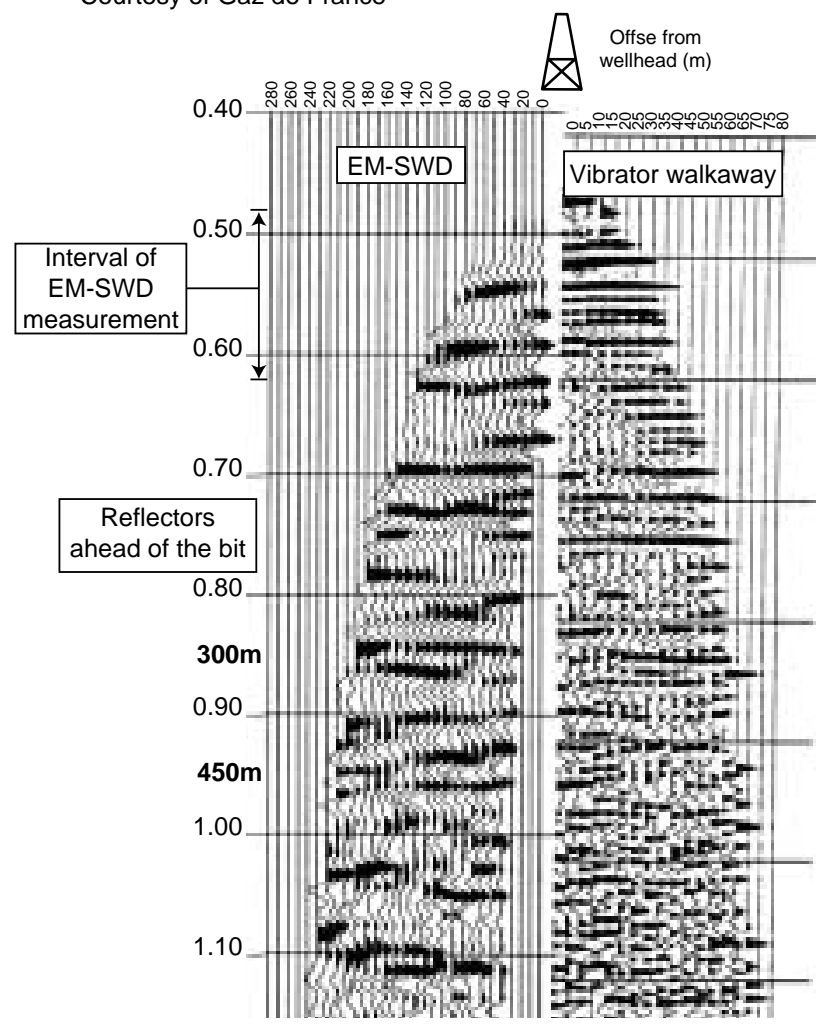

Figure 35

EM-SWD survey: Binstack image (courtesy of Gaz de France). 
to SACZ accelerometers must remain constant during the drilling of each DP interval, the clock drift can be estimated: it remains linear with time since the downhole temperature does not vary significantly over a $10 \mathrm{~m}$ drill pipe interval (unless fresh mud is circulated).

After application of all compensations and corrections, the preprocessing output is a vertical stack after shaping deconvolution of the surface records by the downhole pilot signal, illustrated by the displays in source collection (Fig. 31), and in geophone collection (Fig. 32), on which the signal is stacked over $20 \mathrm{~min}$ of drilling time for each drill pipe.

The final correlated data is excellent (low noise level before direct arrival, compressed wavelet with short peglegs), even in the absence of shock absorber in the BHA, due to the partial attenuation of drill string guided waves provoked by the drillstring drag against the walls of the deviated borehole. In contrast, experience shows that in vertical wells in the same area, SWD surveys run without shock absorber in the BHA yield stacked records blurred by undesired drill string head waves or rig noises (see above Paragraphs 1.1 and 1.2).

\subsection{VSP Processing}

VSP processing was carried out on a near offset geophone collection, $150 \mathrm{~m}$ away from the well. The direct arrivals show a high apparent frequency content $(>70 \mathrm{~Hz})$ in Figure 32. Figure 33 shows the time-depth curve obtained by SWD, yielding good precision on interval velocities. Figure 34 shows the reflected VSP wavefield results from the geophone collection. Refining the alignment of the two way time reflections by a standard trim static routine allows one to compensate for potential remaining residual EM synchronization errors (up to $+/-1 \mathrm{~ms}$ ).

\subsection{D Walkaway Processing}

A conventional processing procedure was applied to the SWD walkaway data, including:

- wave separation and shaping deconvolution by downgoing wavelet, on each geophone collection;

- normal move-out corrections, trim statics, eventual filtering in source collection, Binstack and migration imaging.

In order to process the set of 12 geophones, residual geophone statics have been computed from a hyperbolic regression on the deepest source collection, then applied.

NMO velocities are estimated from the VSP interval velocities, then adjusted so as to have a good direct arrival horizontalization of the reflections after NMO correction.

Figure 35 (left side) shows a final time image within and below the depth interval logged by EM-SWD, far ahead of the bit. Reflections are visible down to $1450 \mathrm{~m}$, far below the deepest SWD measurement level $(880 \mathrm{~m})$.

For comparison with conventional direct well seismic, a vibrator walkaway image is displayed on the right side of
Figure 35. It was obtained using a permanent downhole geophone array located in a nearby well. The maximum frequency reaches around $65 \mathrm{~Hz}$ on the drillbit reverse walkaway versus $85 \mathrm{~Hz}$ for the vibrator direct walkaway image.

\subsection{First Preoperational EM-SWD Field Test}

The successful first EM-SWD field test confirmed the choices made for the technological design and the field acquisition procedures. Surprisingly, the absence of shock absorber in the BHA did not have severe consequences on the processing efficiency and output data quality, as the well deviation resulted in a substantial attenuation of the undesired waves guided then radiated by the drillstring. During the operation, the EM orders were sent downhole during the drill pipe connection manoeuvre when the drillstring was on slips. Therefore, no rig downtime was necessary for the EM transmission associated to the SWD operation. The seismic frequencies observed on the final reverse walkaway drillbit seismic image reach $65 \mathrm{~Hz}$, higher than the SWD results obtained without downhole measurements, although lower than the frequencies observed on a nearby conventional direct vibrator walkaway (Fig. 35). The new downhole equipment, synchronized and interfaced with a commercial surface seismic recorder, behaved successfully on the field. The field procedure for data recovery after $\mathrm{POOH}$ was easy, fast and successful.

The encouraging processing results allowed us to proceed to larger scale SWD operations, after correcting for the technological glitches revealed by this first EM-SWD field test.

\section{LARGE SCALE EM-SWD DRILLBIT}

A large scale EM-SWD drillbit demonstration test for seismic imaging on a geothermal site was carried out within the EC project GE 019/96. In 1999, a full scale SWD reverse walkaway was recorded around an $E N E L$ well in a "no seismic result" area, near Larderello, Italy, using a surface seismic recorder rented from OGS-Trieste, Italy, with 170 channels deployed over 6 radial lines of geophones on surface, $75 \mathrm{~m}$ intertrace, each line extending from $350 \mathrm{~m}$ to $2 \mathrm{~km}$ from the well. A near well 2D time migrated surface seismic section is shown Figure 36, with well projection and indication of the domain illuminated by the drillbit SWD survey. In the well vicinity, the surface seismic image is totally blurred. Full technical details on this experiment can be found in [16].

The Italian geothermal fields of Larderello and Monte Amiata are characterized by a complex geological structure. The downhole temperature can reach and exceed $350^{\circ} \mathrm{C}$ in metamorphic rocks, around 3500-4000 m. The use of conventional wireline well seismic technique is restrained by the temperature and by the high seismic noise present in Italian geothermal wells. Therefore, the reverse seismic walkaway 


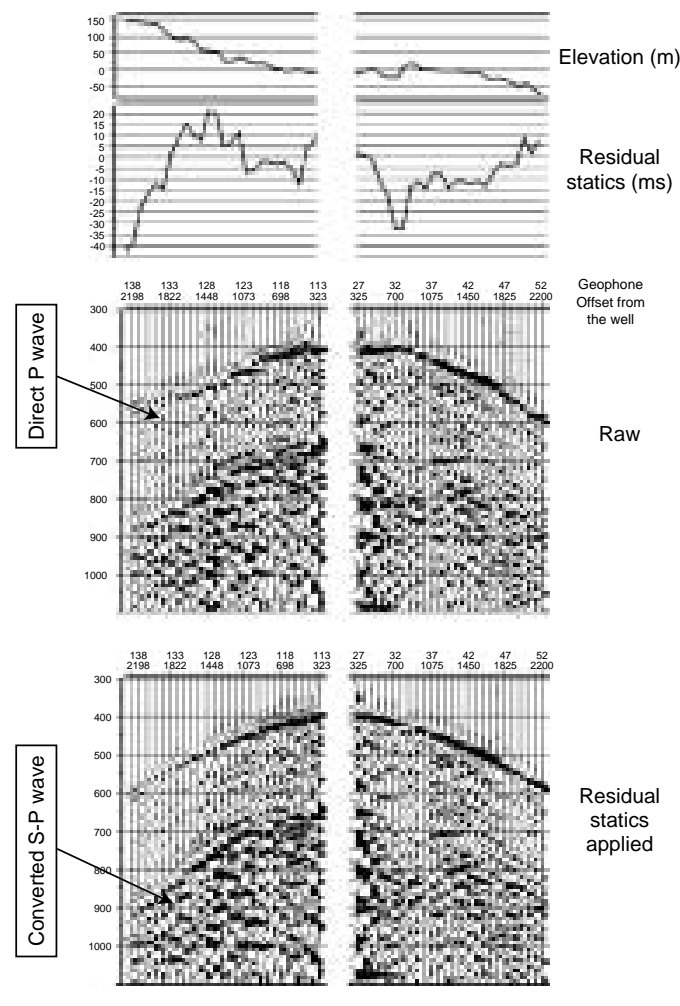

Figure 37

Line 3: application of residual statics on a deep (1758 m) source depth collection. The statics do not correlate with the elevation.

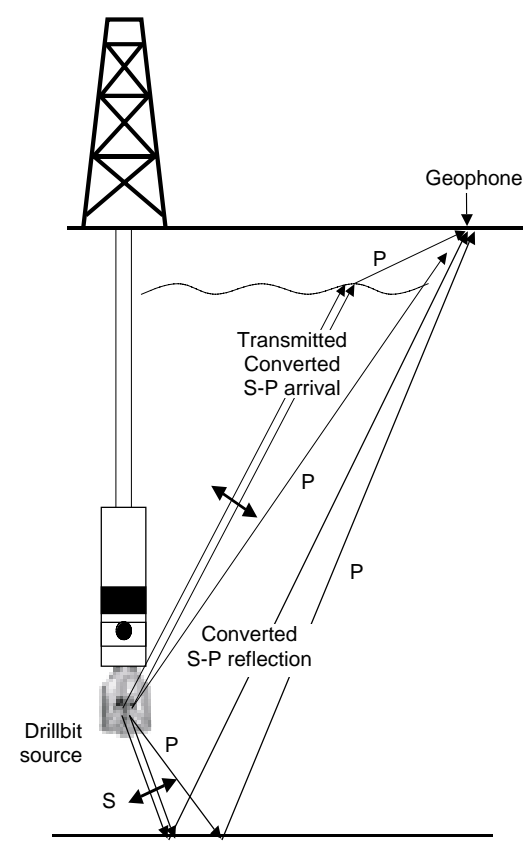

Figure 38

Sketch of propagation.

${ }^{*}$ Direct $\mathrm{P}$ and transmitted-converted S-P arrivals are clear on the raw data (Fig. 37).

${ }^{* *} \mathrm{P}-\mathrm{P}$ reflected and S-P converted-reflected arrivals can be separated from their differing apparent velocities in receiver collections, and on the binstack Figure 39a. technique using the drillbit noise as seismic source looks attractive; additionally, the temperature in the well while drilling is substantially lowered by the drilling fluid circulation. As the formations to be drilled are hard, only roller cone bits can be used, which is most favorable to the generation of drillbit seismic vibrations. Moreover, the unfavorable conditions of surface accessibility such as rugged relief, forest cover, sensitive permit and environmental constraints make it difficult to operate surface seismic sources. Actually, similar exploration difficulties are encountered in many oil and gas field areas worldwide, locally or regionally.

\subsection{Acquisition and Preprocessing}

170 surface channels were recorded over two drilling runs, about 35 Gbytes of raw uncorrelated surface data was collected and stored on IBM 3490 magnetic cartridges. The surface data were acquired in $2 \mathrm{~ms}$ sampling/4 bytes per sample, then the data volume was reduced by a factor of 1500 after correlation by the downhole reference data and stacking over the top $5 \mathrm{~m}$ interval of each DP: the raw data recorded continuously while drilling (about $1 \mathrm{~h} / \mathrm{DP}$ ) is compressed into $3 \mathrm{~s}$ of correlated/stacked seismic data for each surface receiver channel. The whole chain of field equipment behaved successfully and a shock absorber was integrated into the BHA.

\subsection{Processing and Results}

An example of the preprocessed surface data in source collection is shown in Figure 37 after correlation with the downhole reference signal and vertical stacking over each drill pipe interval. The surface data are displayed in preserved amplitude before and after application of static corrections. Strong S-P converted transmitted arrivals are present (see the propagation sketch Fig. 38), which need to be removed by careful processing in order to extract the desired P-P reflections.

Additionally, strong interfering S-P converted reflected waves (downgoing $\mathrm{S}$-wave generated by the rock bit, followed by upgoing P-wave reflection) were observed during the processing stage, as illustrated by the propagation sketch Figure 38, and required appropriate velocity filter rejection (details in [16]). The efficiency of the S-P reflected wave cancellation can be appreciated on the final binstack images Figures 39a and 39b: the S-P reflected events appear on the top binstack Figure 39a as line-ups showing arrival time 
increasing with distance from the well, and abrupt apparent dip variation directly below the well location. The bottom Binstack on Figure 39b shows an enhanced P-P reflection wavefield and a more reliable subsurface image, as desired by the interpreter.

Interestingly, as the bulk of signal processing and filtering is achieved independently on each geophone collection, the deep reflection line-ups observed on the stacks in geophone collections and the final VSP-CDP binstack insure that these line-ups represent real primary reflections. Deep P-P reflections appear on Figure $39 \mathrm{~b}$ at 1.4 to $1.5 \mathrm{~s}$ twt on the right side of the well, corresponding to events located $1.8 \mathrm{~km}$ ahead of the bit, around $3.6 \mathrm{~km}$ deep. On the left side, deep reflected events at 1.3 and $1.75 \mathrm{~s}$ are observed in spite of the high energy direct S-P waves present on this line on the raw data, which is quite encouraging for the future applications of the drillbit SWD surveying.

\subsection{Influence of BHA Abnormal Vibrations}

Interestingly, the BHA abnormal vibrations regimes such as stick-slip or bit bouncing are perfectly obvious on the downhole DACZ accelerometer: on Figure 40 (left to right), the displayed traces represent successive $54 \mathrm{~s}$ long time segments of DACZ signal, illustrating that the BHA vibrations can naturally change quite fast from a regime of normal drilling (random signal) to a vibration regime of stick-slip, followed a few minutes later by a vibration regime of bit bouncing. There were no shock absorbers in the BHA corresponding to the data on Figure 40.

The stick-slip pattern is characterized by a cycle including a temporary stop of the downhole rotation, followed by a very fast rotation of the BHA and intense vibrations; the period of this cycle depends on the length of the drillstring, which oscillates as a torsion pendulum (Fig. 40, central a)

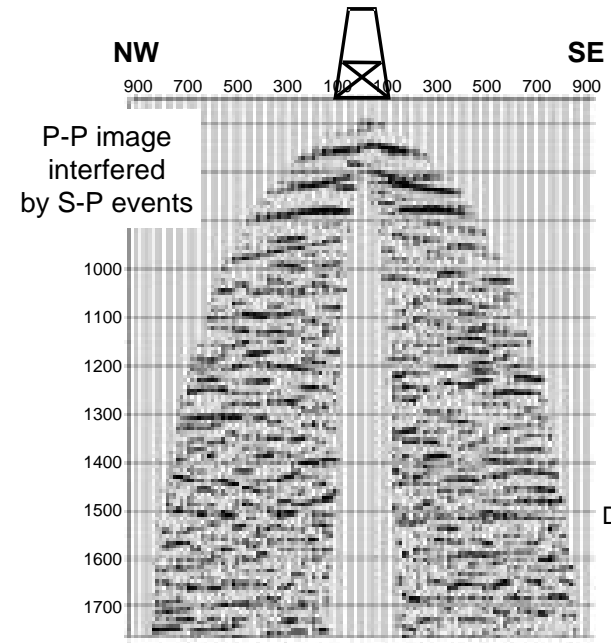

Distance from the well (20 $\mathrm{m}$ trace interval)

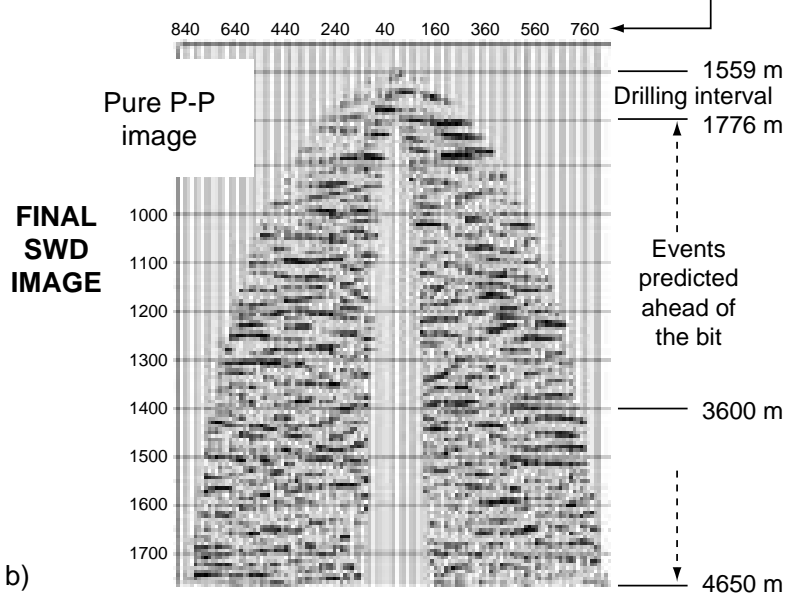

Figure 39a and 39b

Binstack seismic images of P-P reflections on line 3.
Display of $12 \mathrm{~Hz}$ low cut filter applied to raw DACZ signal - Normal drilling = random vibration

- Stick-slip regime = long period bursts separated by null signal. - Bit bouncing $=$ dominant frequency around 3 times the rpm

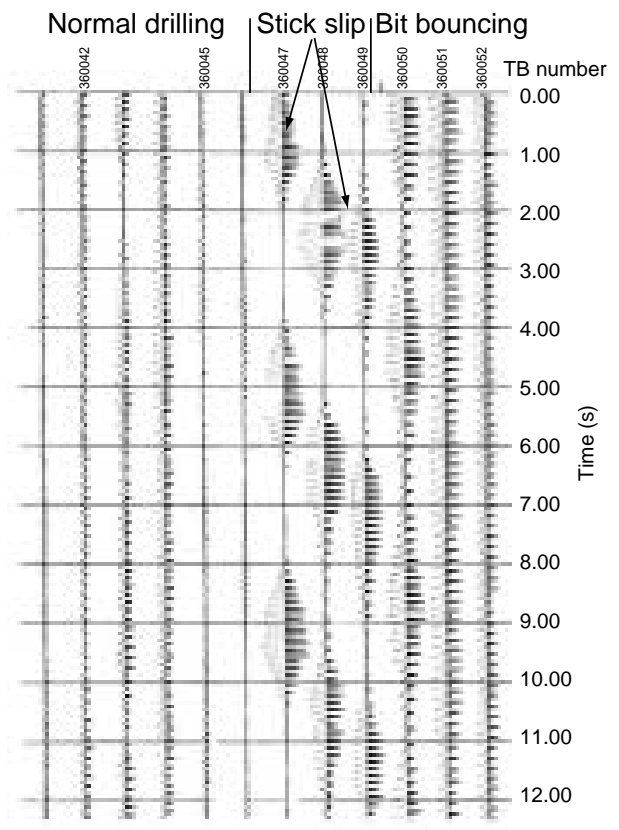

Figure 40

Examples of downhole BHA vibration patterns. 
traces). The BHA stick-slip resonance pattern can often be seen on the correlated drillbit records by an apparent repetition of the low frequencies, such as the ground roll events (Fig. 41), with a period equal to the stick slip period. This phenomenon does not alter the quality of the seismic walkaway drillbit image as the prediction seismic time of interest ahead of the drillbit is generally shorter than the stick-slip cycle duration.

The bit bouncing pattern is characterized on the seismic records by a powerful dominant frequency close to three times the RPM frequency, due to the tri-lobed pattern of the formation surface right under the roller cone bit. The frequency content is very low and barely extends over $30 \mathrm{~Hz}$. The bit bouncing pattern is generally mitigated when a shock absorber is present in the BHA.

\section{TIME SYNCHRONIZATION}

This section describes time synchronization of the downhole seismic measurements, at seismic precision.

\subsection{Synchronization Using Guided Waves}

Details of this method can be found in IFP patent in [17].

The guided waves in the drillstring are of three types:

- P-waves in the guide constituted by the drillstring, the earth formation and the drilling fluid inside the drill pipes and in the annulus between drillstring and borehole wall. Typical velocities fall in the range $4800-5200 \mathrm{~m} / \mathrm{s}$, and sometimes vary with depth within the same drillstring (Fig. 42 and Fig. 43 right side).

- Torsional waves in the drillstring, which propagate only in the metallic drillstring: they can be recorded by torque sensors, by tangential accelerometers on the drillstring, or by a shunt current on the power line of the rotating table electric motor. The propagation velocity of torsional waves in the drillstring is slightly higher than half the Pwave velocity, around 2800 m/s (Fig. 42 and Fig. 43 middle display, Stor sensor).

- Tube waves propagated in the drilling fluid inside the drillpipes, which can be recorded by a pressure sensor

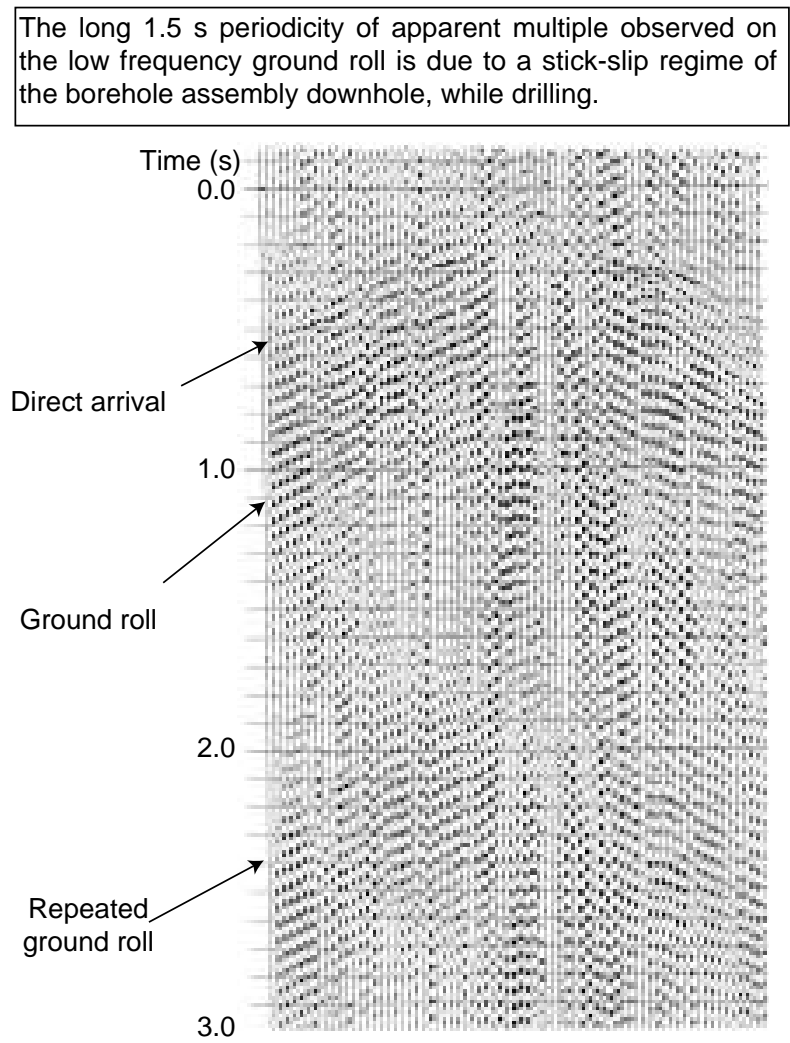

Figure 41

Correlated drillbit record.
The direct and multiple arrivals of the drillstring guided waves can help controlling the exactitude of the downhole clock. With a shock absorber in the BHA, the DACZ autocorrelation is spiked, which insures that the seismic emission into the ground is a simple spike as well.

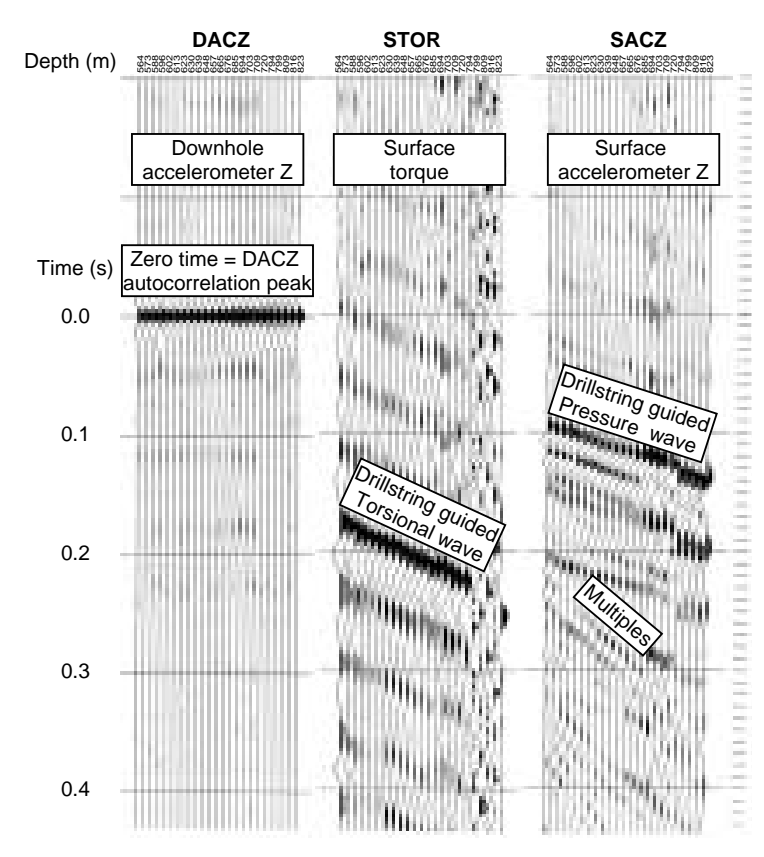

Figure 42

Vertical stack over each drill pipe after correlation with DACZ, from TRAFOR measurements. 


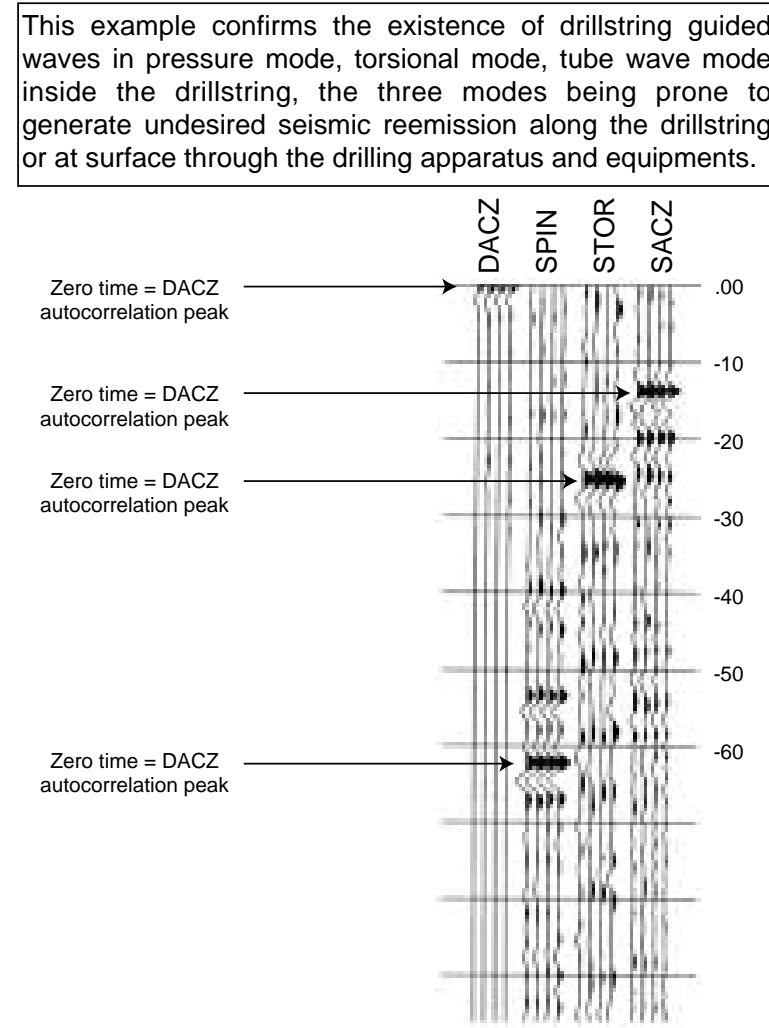

Figure 43

Vertical stack over each drill pipe after correlation with DACZ from TRAFOR measurements.
The correlation of a random signal, i.e. drillbit signal, recorded by two independent recorders, can be used at processing to compensate for an eventual drift between master clocks. Below, at $20^{\circ} \mathrm{C}$, the downhole clock drift was about $77 \mathrm{ppm}$, and was compensated at processing stage. As a result, for real field drillbit operations, the correlation of SACZ by DACZ is an excellent clock and timing control.

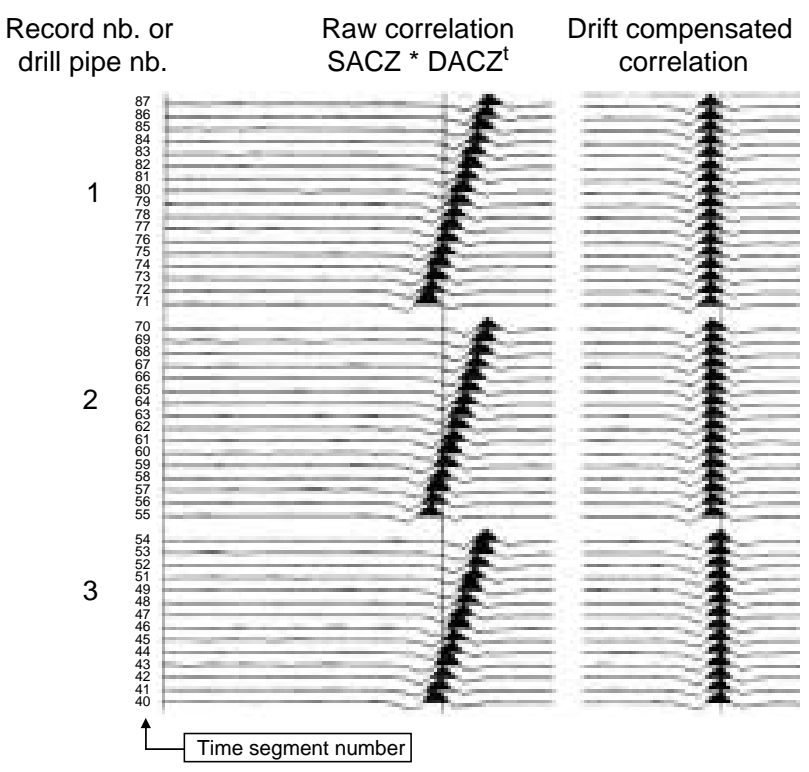

Figure 44

Example of clock drift compensation. located in the fluid column internal to the drillstring. The propagation velocity of tube waves is close to the sonic velocity in water, i.e. $1350-1500 \mathrm{~m} / \mathrm{s}$, and can vary with the drilling fluid composition (see Fig. 43, Spin sensor). Actually, the pressure signal of tube waves guided inside the drillstring mud column had been successfully used as a pilot signal for correlation in a few SWD experiments conducted in the mid 1980's by ENI, Italy.

The propagation properties of guided waves in the drillstring can be used in several ways.

Firstly, for determination of the clock drift between the clock of the surface recorder which handles the guided wave sensor located at the top of the drillstring or on surface around the drilling apparatus, and the clock of the downhole recorder which handles the downhole guided wave sensors: while drilling the depth interval corresponding to the same drill pipe, the propagation time between the two above mentioned sensors must be constant, as the distance between the sensors is constant, as long as the wave guide keeps its characteristics while drilling. A laboratory example of this man- ner of correcting the drift is presented on Figure 44: the cross-correlation of the same random signal recorded by two recorders with drifting master clocks has been represented before and after linear corrections easily estimated and applied using simple seismic processing operations available in all the commercial processing software packages. The drift correction applied is linear with time, and it is technically sound to assume that the velocity of the drillstring guided wave is constant over the drilling duration of a given drillpipe (about $30 \mathrm{~min}$ to $3 \mathrm{~h}$ ) and quite insensitive to the drilling fluid temperature variations. Although the value of the clock drift may change with the downhole clock temperature, the geophysicist can easily compensate for this effect using the consistency of the drillstring travel time picked up on the successive correlations of the SACZ signal by the DACZ signal at processing stage: this technique is practical mainly for drillbit SWD with roller cone bit, but becomes useless for the VSP-WD technique.

A second use is for determination of the absolute one way propagation time between the two wave guide sensors 


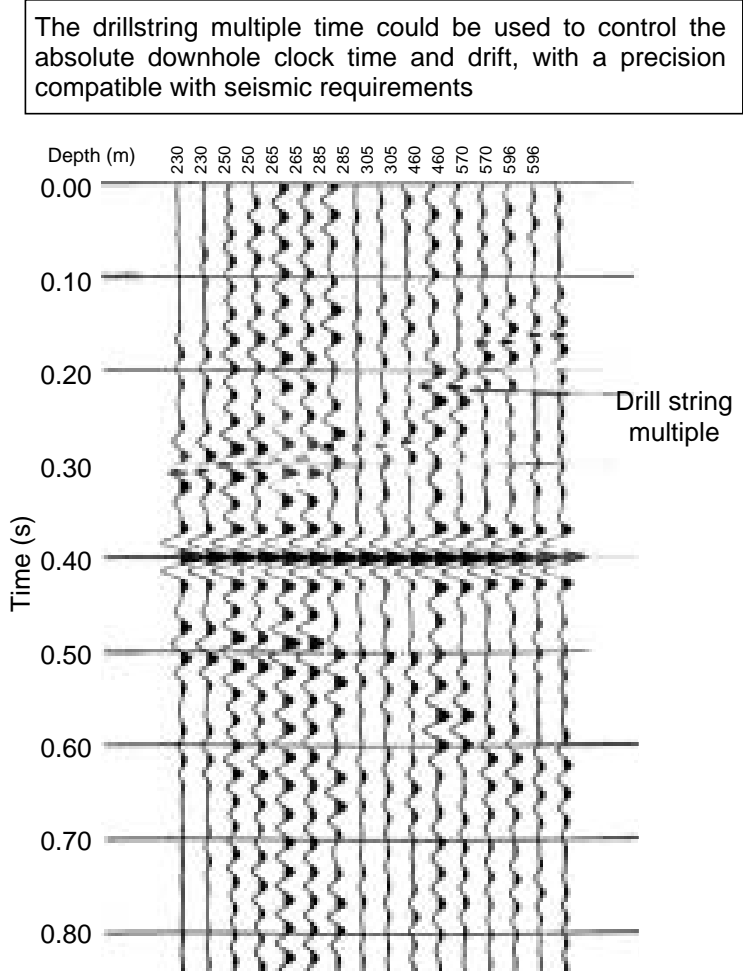

Figure 45

VSP-WD: autocorrelation of downhole geophone signal while drilling.

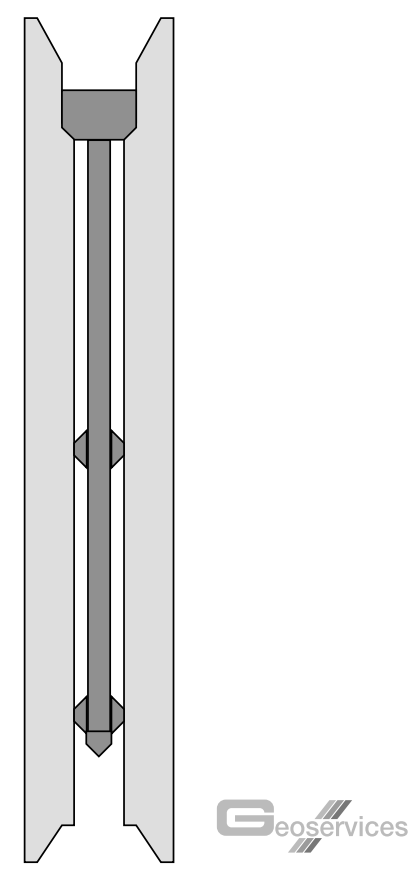

Sketch 1

The 3C-VSP-WD. Downhole Recorder Unit (DRU). Manufactured and operated by GEOSERVICES. located on top and bottom of the drillstring, as the half time of the first drillstring multiple: the time of the first drillstring multiple can be picked on the autocorrelation of the downhole or top of drillstring reference signal, as is usually practiced in the drillbit SWD method without downhole reference measurements [3].

Lastly, during a VSP-WD field experiment in a vertical well of the Paris Basin, good autocorrelation functions and drillstring multiples have been obtained from the saturated signal recorded while drilling by a standard $14 \mathrm{~Hz}$ vertical geophone mounted inside an EM-VSP-WD prototype (see Fig. 45). This sort of drillstring guided wave signal might help calibrate and correct an eventual downhole clock drift of a wireless VSP-WD downhole tool at processing stage, or in implementing some independent controls on the time precision of the downhole clock.

\subsection{Synchronization by a New Electronic Clock}

In order to simplify all types of additional measurements while drilling and subsequent processing, it is desirable to have a downhole clock stabilized relatively to the shock conditions and variable temperature conditions. An innovative development has been achieved and tested by F. Cecconi and L. Soulier of Geoservices, as described in the patent in [18], in order to reach a higher precision of 1 to $10 \mathrm{ppb}$ (part per billion) in a wide range of downhole drilling conditions (temperature and shocks), which is absolutely necessary to meet the technical requirement for the VSP-WD method.

\section{WIRELESS EM-VSP-WD EXPERIMENTS}

In 1999, after the successful technical achievements obtained with the downhole recorder built by Geoservices to implement and improve the technique of drillbit EM-SWD reverse walkaway, a joint project was launched with Total, Geoservices and IFP, in order to develop the VSP-WD technique with partial funding of CEPM (Comité Exploitation Pétrolière et Marine, R\&D extension of French Ministry of industry). $C G G$ joined the project in 2000, after the first downhole prototype was built. IFP encouraged the geophone manufacturer Sensor-I/O in Holland to build the SM-45 high temperature miniaturized geophones, with natural frequency 
around $15 \mathrm{~Hz}$ in order to insure a good omnitilt response. These geophones offer good perspectives for VSP-WD application in small diameter wells, and will successfully endure the rough shock tests described in Paragraph 1.4.1.

\subsection{Geoservices EM-VSP-WD Equipment}

As shown in Sketch 1 in page 395, the 3C-VSP-WD tool, is built as a central electronic shuttle (dark gray) inside the tool carrier (light gray), and comprises a 3C orthogonal set of geophones, with no hydrophone, and sufficient memory capacity. The shuttle appears can be easily removed from the carrier on the drill floor.

The main specifications of the 3C-VSP-WD tool (DRU on Fig. 46) are listed below in Tables 1 to 3 .

TABLE 1

Mechanical specifications of the 3C-VSP-WD tool

\begin{tabular}{l|r|r}
\hline & \multicolumn{1}{|c|}{$\mathbf{6}^{\prime \prime 3 / 4}$} & \multicolumn{1}{|c}{$\mathbf{4} \mathbf{3 / 4}$} \\
\hline Tool carrier OD & $6 " 3 / 4$ & $4 " 3 / 4$ \\
Typical hole size & $8^{\prime \prime} 1 / 2$ & $6 "$ \\
Tool carrier ID & $100 \mathrm{~mm}$ & $83 \mathrm{~mm}$ \\
Shuttle OD & $60 \mathrm{~mm}$ & $60 \mathrm{~mm}$ \\
Tool carrier length & $3.5 \mathrm{~m}$ & $3.5 \mathrm{~m}$ \\
Tool carrier weight & $400 \mathrm{~kg}$ & $175 \mathrm{~kg}$ \\
Upper connection & $4 " 1 / 2 \mathrm{IF} \mathrm{box}$ & $3 " 1 / 2 \mathrm{IF} \mathrm{box}$ \\
Lower connection & $4 " 1 / 2 \mathrm{IF} \mathrm{box}$ & $3 " 1 / 2 \mathrm{IF} \mathrm{box}$ \\
Make-up torque & $3840 \mathrm{mdaN}$ & $1200 \mathrm{mdaN}$ \\
Max. torque & $6960 \mathrm{mdaN}$ & $3100 \mathrm{mdaN}$ \\
Pulling load & $260 \mathrm{t}$ & $140 \mathrm{t}$ \\
Max. working pressure & $15000 \mathrm{psi}$ & $15000 \mathrm{psi}$ \\
Maximum temperature & $100^{\circ} \mathrm{C}$ & $100^{\circ} \mathrm{C}$ \\
Dog leg sliding & $18^{\circ} / 100 \mathrm{ft}$ & $25^{\circ} / 100 \mathrm{ft}$ \\
Dog leg rotating & $13^{\circ} / 100 \mathrm{ft}$ & $16^{\circ} / 100 \mathrm{ft}$ \\
Maximum flow rate & $30001 / \mathrm{min}$ & $14501 / \mathrm{min}$ \\
\hline
\end{tabular}

TABLE 2

Seismic specifications of the 3C-VSP-WD tool

\begin{tabular}{l|r}
\hline Geophones & $30 \mathrm{~Hz}$ omni-tilt X,Y and Z-axis \\
Digital conversion & $16 \mathrm{bit}$ \\
Bandwith & $7-150 \mathrm{~Hz}$ \\
Sampling rate & $500 \mathrm{~Hz}$ \\
Data format & SEG-Y \\
\hline
\end{tabular}

TABLE 3

Other features of the 3C-VSP-WD tool

Tool autonomy

DC steel

Temperature measurement
10 days

Non magnetic DC

Yes

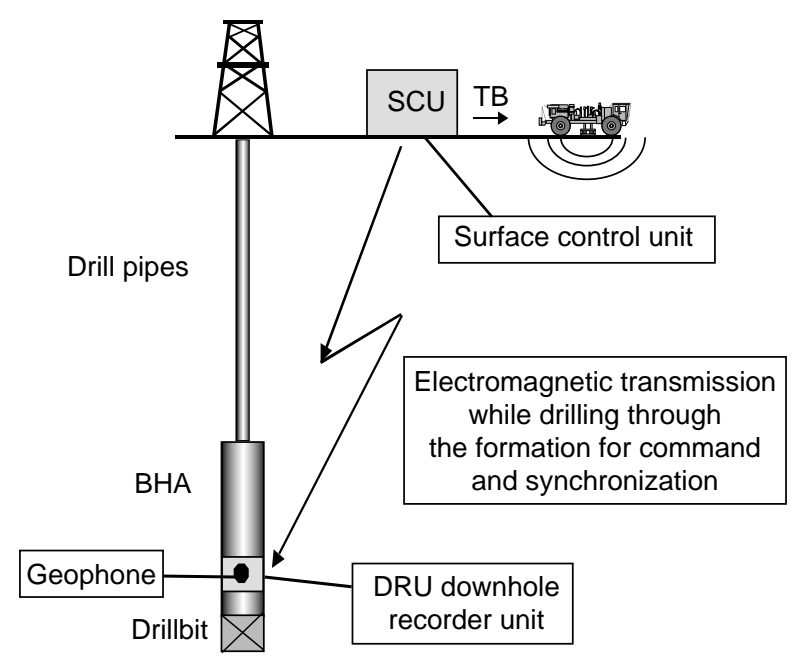

Figure 46

The EM-VSP-WS recording chain.

The Surface Command Unit (SCU on Fig. 46) insures the EM transmission of start orders from surface to downhole, so that the synchronization between independent downhole and surface clocks falls into a precision range inferior to $1 \mathrm{~ms}$, in order to meet standard requirements.

Simultaneously to the order sent to the DRU, the SCU generates a time break (TB) to the surface seismic recorder and firing box manager which in turn actuates the seismic source(s) (airgun and/or vibroseis, etc.). The DRU records and stores the downhole signals over a period of time preset on surface before making up the BHA. After the drilling run and the VSP-WD recording, the drill string is pulled out of the hole, and the downhole data are transferred from DRU memory to the SCU, then QC'ed and output in standard SEG-Y seismic format in a manner identical to the one described on Figure 28. The surface and downhole data are then merged, edited and vertically stacked at each depth level on the field VSP processing computer provided by $C G G-B S D$.

\subsection{Preliminary Field Test}

The shallow experimental well of Downhole Technology Limited (DTL, Aberdeen, United Kingdom), in the deviated and horizontal part (Fig. 47) was selected to qualify and validate the downhole VSP-WD tool and check the vector fidelity of the tool coupling. This test well is drilled entirely in massive granite altered with a few permeable fractures: therefore, the seismic propagation in this medium should be quite isotropic and the VSP test can be focused on the study of direct arrivals in order to optimize the vector fidelity and the mechanical coupling of the WSP-WD downhole DRU recorder. Advanced applications of isotropic mechanical 


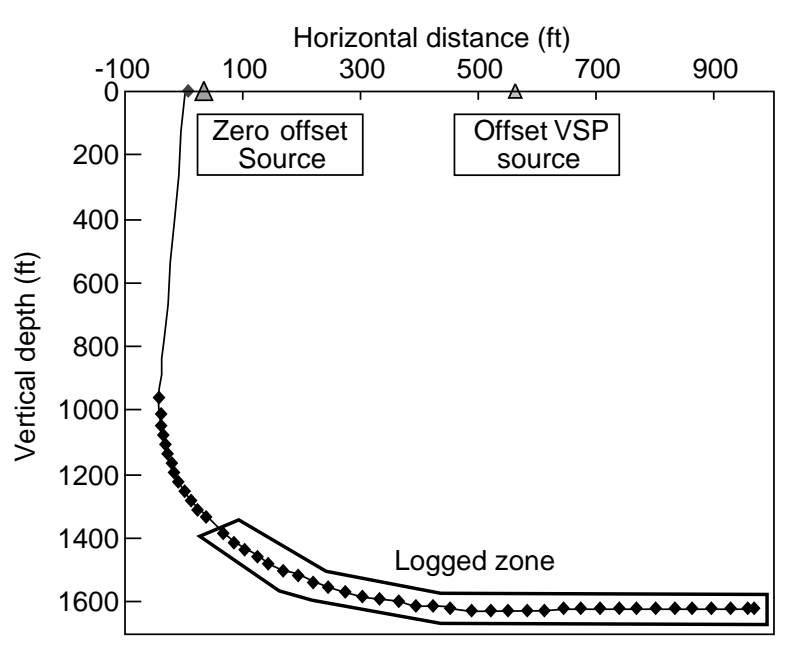

Figure 47

Well trajectory projection in azimuth $\mathrm{N} 222^{\circ} \mathrm{E}$.

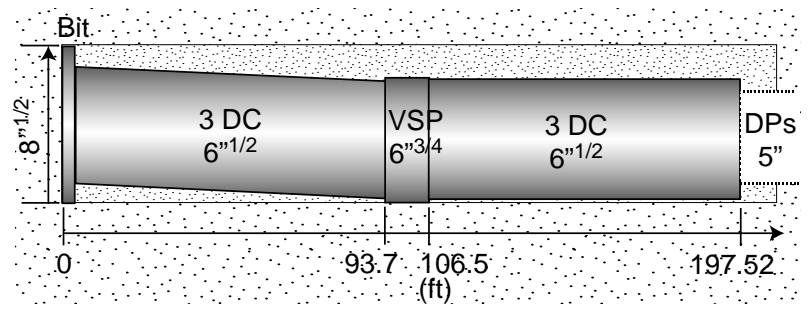

Figure 48

Sketch of BHA1.

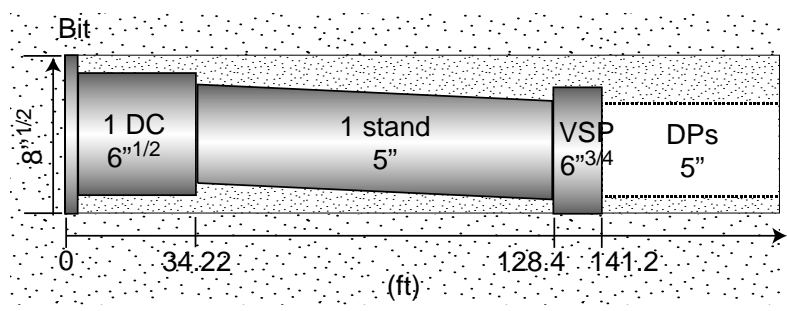

Figure 49

Sketch of BHA2. response of the $3 \mathrm{C}$ VSP tools include the possibility to determine the dip and azimuth of seismic reflectors under the well trajectory, as explained in [19] for instance.

Two architectures of Bore Hole Assembly (BHA) were tested, as the mechanical coupling of the sensors to the formation is insured by gravity only:

- For the first test run (BHA1 sketch on Fig. 48), the coupling was mainly insured by the heavy $6^{11 / 2}$ diameter drill collars (DC) located below and above the 6"3/4 diameter VSP-WD tool: the DC weight of the adjacent DC was expected to provide a firm contact with the formation.

- For the second test run (BHA2 sketch on Fig. 49), the $6^{13 / 4}$ diameter VSP tool is quite larger than the 5" diameter adjacent drill pipes (DP): the net extra diameter of the VSP tool was expected to provide an improved local contact with the formation and constitute a vibration node right at the level of the geophone sensors.

Two sources were actuated for both runs: a zero offset airgun in a shallow water pit and a truck mounted land air gun in an offset position above the horizontal drain (Fig. 47). Once the bit reached the total depth (TD $2370 \mathrm{ft}$ ), the drill string was moved up every $15 \mathrm{~m}$ (half a $3 \mathrm{DP}$ stand) for the VSP acquisition: 5 shots per level for each source, resulting in less than 5 min recording duration per level.

\subsection{Processing}

A standard VSP preprocessing was applied on the recorded data, including:

- edition of the few noisy traces;

- vertical stack at each level for each source;
- orientation of (X- and Y-axes) by maximization of the direct P-wave.

On operational drilling sites, an easy and accurate way to orient the $3 \mathrm{C}$ signals in a geographical system of coordinates consists in using the directional MWD measurements (tool face and well deviation and azimuth angles) made when the BHA rests in a still position at each VSP level, a procedure successfully applied previously. On Figure 50, the tool face angle is labeled "Relative bearing" $(\mathrm{Rb})$ in reference to the same angle denomination used in wireline logging.

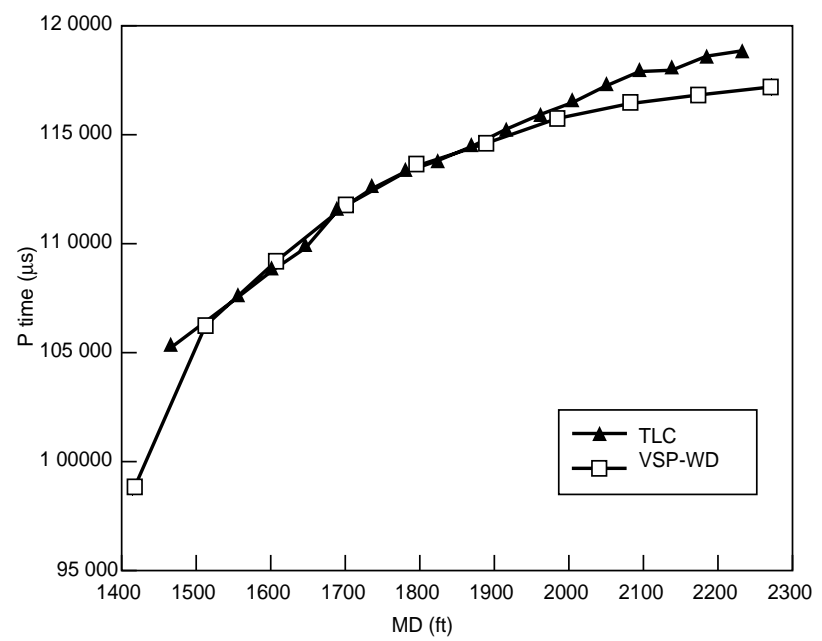

Figure 50

Time picks of 3C VSP-WD versus TLC-VSP on direct P-wave arrivals. Same zero-offset/rig source for both VSP runs. 


\subsection{Results}

\subsubsection{Time Pick Comparison}

The time picks of the direct P-wave of the VSP-WD prototype versus a TLC tool used in the same drillstring with the same source, but not at the same measured depth (MD) levels, are compared on Figure 50. The two curves are similar within less than $1 \mathrm{~ms}$ between MD 2000 and $2230 \mathrm{ft}$. These results show the good accuracy of the seismic times, which validates the EM synchronization technique versus the conventional wireline reference.

\subsubsection{Reorientation Angle Comparison}

If the DRU coupling to the formation is isotropic for the two runs, the difference between relative bearing angles (RB) computed by maximization of the off-axis $\mathrm{X}$ and $\mathrm{Y}$ components of direct arrival signals on the offset source and rig source should be equal for both runs at the same depth level. The difference of angle is limited to within about $5^{\circ}$, which means that the two BHA architectures tested yield fair coupling conditions. Above MD $450 \mathrm{~m}$, where the well is almost vertical, the dispersed values obtained on the BHA1 curve (Fig. 5l) are due to the loose mechanical coupling in this part of the well.

\subsubsection{C Data Quality and Trace to Trace Coherency}

Figures 52 to 54 show the oriented $3 \mathrm{C}$ data for BHA1, Figures 55 to 57 for BHA2 The oriented VSP-WD data show an excellent $\mathrm{S} / \mathrm{N}$ ratio for both BHA architectures as the noise before the first direct $\mathrm{P}$-wave arrival is minimal.

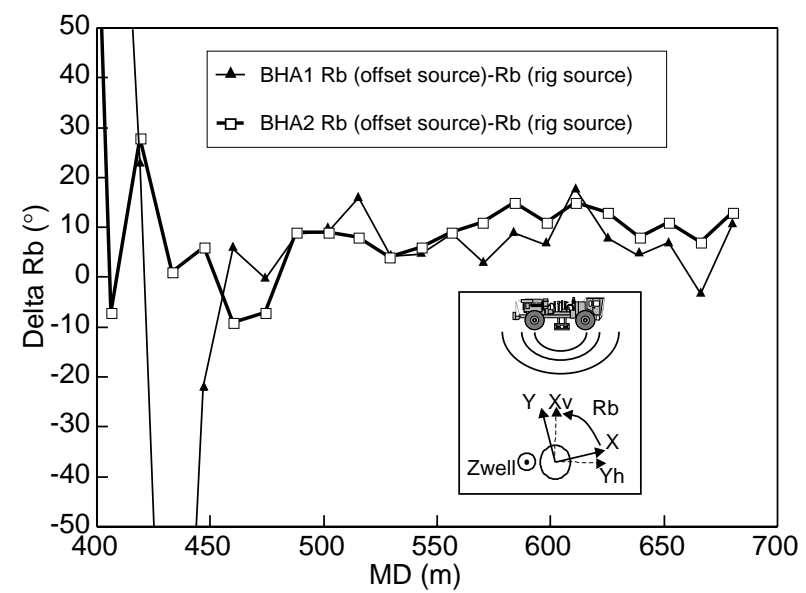

Figure 51

Reorientation of $(\mathrm{X}, \mathrm{Y})$ by maximization of the direct arrival.

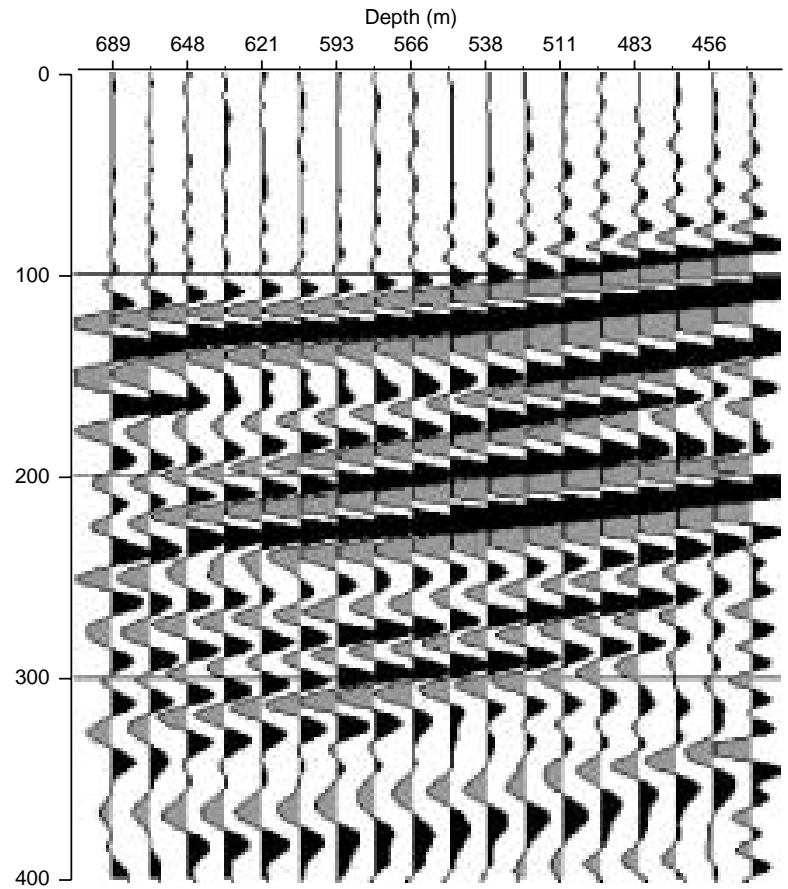

Figure 52

BHA1. Zwell component. Rig source collection.

Figs 52, 53 and 54: isotropic 3C displays, filtered (2, $65 \mathrm{~Hz})$. Constant gain.

Observation: components $X V$ and $Y H$ do not show a good trace to trace coherency.

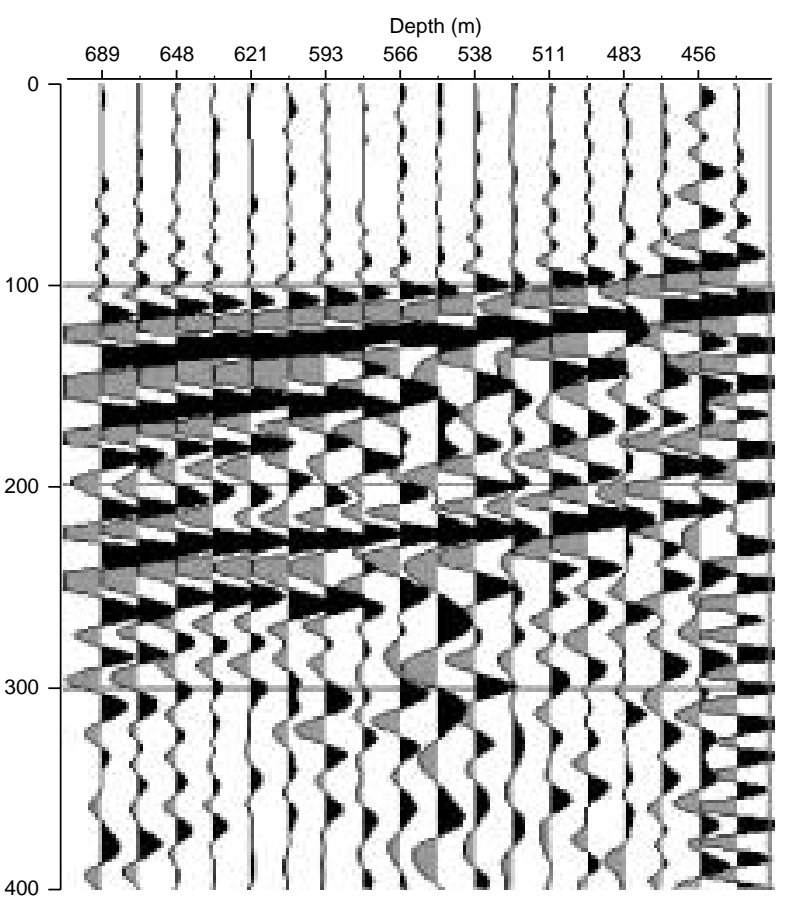

Figure 53

BHA1. XV component. 


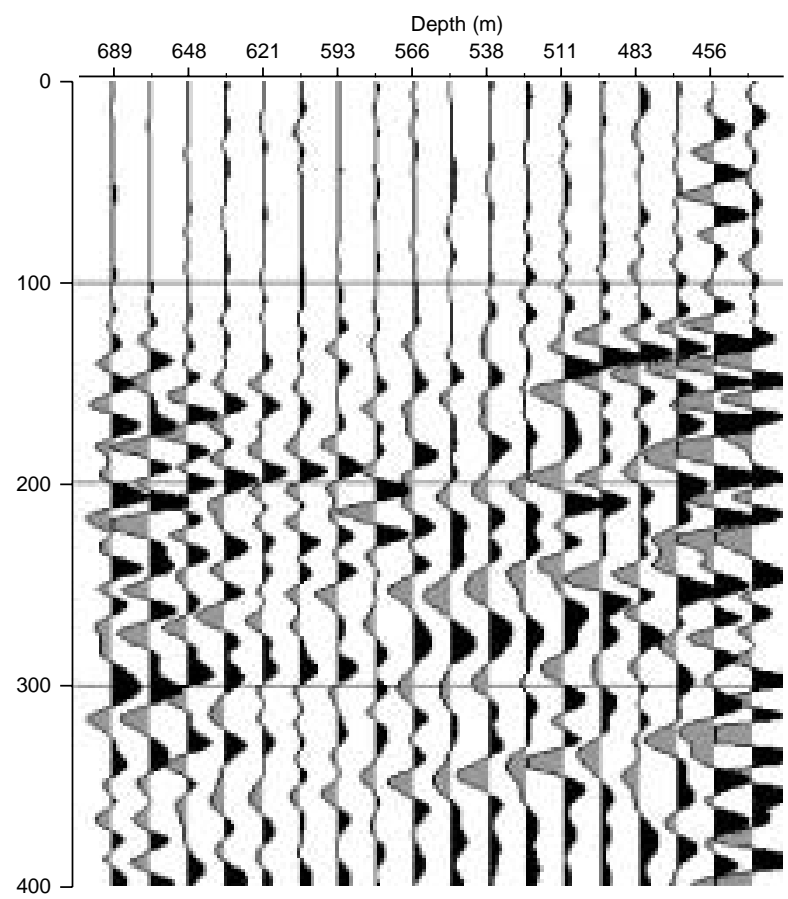

Figure 54

BHA1. YH component.

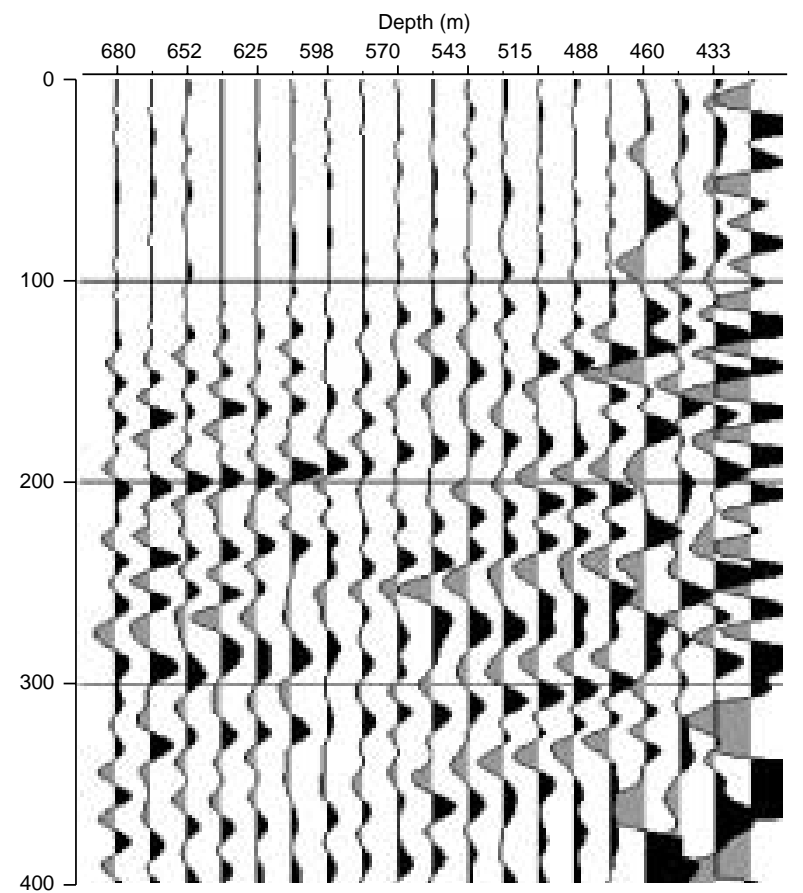

Figure 57

BHA2. YH component.

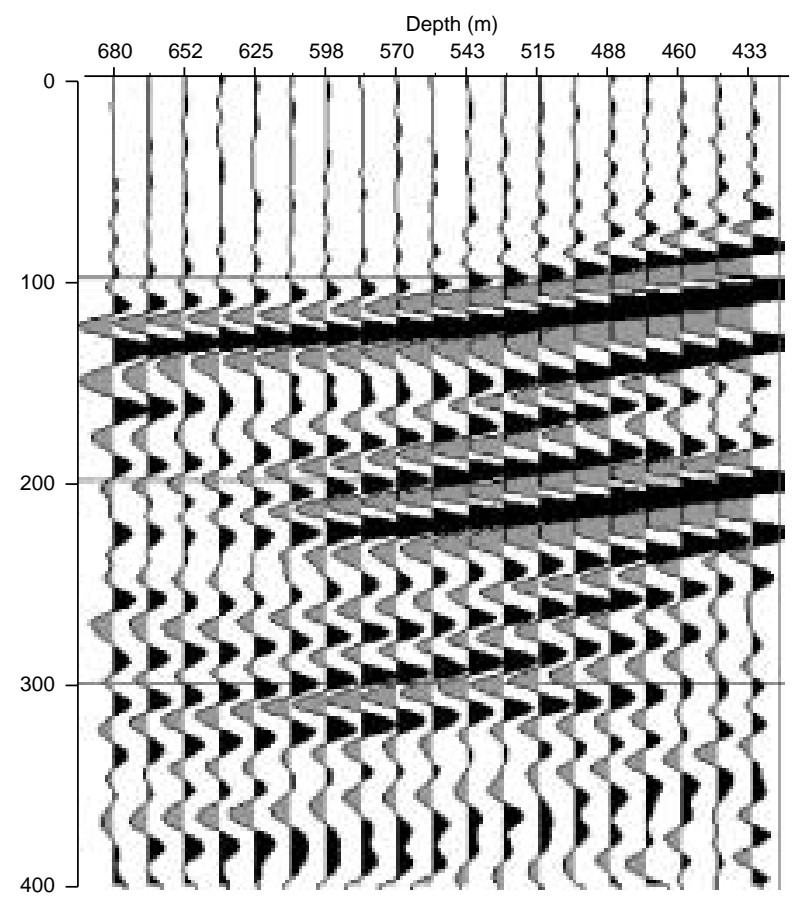

Figure 55

BHA2. Rig source - Zwell component-filtered $(2,65 \mathrm{~Hz})$.

Constant gain.

Figs 55, 56, 57: isotropic 3C displays, filtered (2, $65 \mathrm{~Hz})$.

Constant gain.

Observation: components $X V$ and $Y H$ show an execellent

trace to trace coherency, on $P$-wave peglegs ( $X V$ component) and on downgoing $S$-wave residuals (YH component).

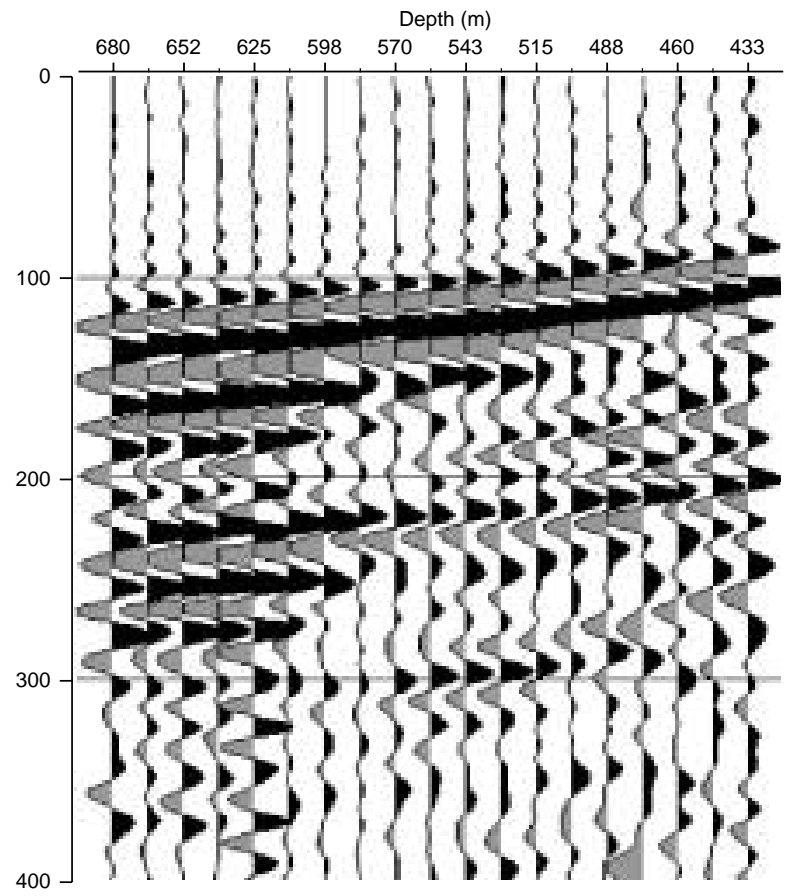

Figure 56

BHA2. XV component. 
However, after orientation of the off-well axis components $\mathrm{X}$ and $\mathrm{Y}$, the 3 component wavefields are much more consistent trace to trace on BHA2 than on BHA1:

- on component $X_{V}$, the direct P-wave arrival and its peglegs are more coherent on Figure 56 than on Figure 53;

- on the transverse component $Y_{H}$, the weak downgoing S-wavetrain is much more coherent on Figure 57 than on Figure 54. The P-wave direct arrival energy have been nicely minimized on component $Y_{H}$ for both BHA's, indicating a fair vector fidelity;

- on well axis component $Z_{\text {well }}$, the downgoing P-wavetrain is very consistent for both BHAs, which means that the mechanical coupling to the formation is quite good in the well axis for both BHA configurations, this result being similar with wireline VSP tools.

Therefore, the above tests show that a VSP-WD tool integrated in a BHA has an improved vector fidelity of the overall seismic response, thus isotropy of mechanical coupling, when the diameter of the VSP-WD tool is larger than the diameter of the adjacent BHA elements.

In conclusion, the 3C EM-VSP-WD prototype meets the requirements of the seismic measurement in terms of reliability, S/N ratio, 3C isotropy, and operational efficiency. The acquisition is not limited only to a check-shot. The present test validates the EM-VSP-WD technique at least for the well sites where the EM transmission works properly.

The next generation of EM-VSP-WD tool might need to be built in the crown of the BHA, in order to clear the passage inside the drill collars, in which case it will be easier to add a hydrophone sensor.

\section{DISCUSSION AND CONCLUSION}

\subsection{Drillbit-SWD Reverse Walkaway}

The objective of the walkaway SWD method is to produce a seismic image of the geological structure around the first well in order to confirm the target structure, or to indicate the drilling targets of the following directional wells. Exploration and development drilling occurs sometimes in areas where the surface seismic quality is poor, or where the subsurface objectives are very deep and difficult to illuminate with surface seismic: the drillbit SWD technique is expected to complement the surface exploration in the well vicinity in such circumstances.

In onshore areas where rough field conditions make it difficult to operate seismic sources, a reverse walkaway SWD survey might prove to be more economical than a direct walkaway survey recorded with surface source and downhole string of receivers.

Onshore, conventional walkaway surveys can be difficult to acquire depending on the access conditions for the seismic source: rugged terrain, forest and mountain areas, transition zone, etc., which increases both the source cost and the rig immobilization time necessary for the seismic acquisition. In contrast, the drillbit EM-SWD technique of 3D reverse walkaway presents a definite advantage over the conventional direct wireline WSP technique in areas of difficult terrain conditions where only 2D surface seismic profiling is economically reasonable. The drillbit EM-SWD technique can be more efficient than the conventional walkaway when deep reflections are sought for, with a large 3D surface seismic spread of geophones deployed around the well up to large distances from the rig. The drillbit source can be listened to for the whole drilling time in the depth interval of the survey, which generates large amounts of seismic energy and improves the $\mathrm{S} / \mathrm{N}$ quality, the image clarity and the penetration ahead of the bit.

The EM-SWD reverse walkaway technique does not disturb the drilling process significantly. The main constraint on drilling is to use a roller cone bit for one or two drilling runs around mid depth objective and over a limited depth interval where the rock formations are rather hard. The time delay for processing needs to be reduced in order to render the method even more attractive.

The real time availability of the downhole data obtained by means of wired drill pipe technology is ideal for drillbit SWD since the surface data can be correlated by a real time commercial correlator/stacker connected with the seismic recorder. In practice, when the wireless EM-SWD technology is used, storing large amounts of data downhole and on surface does not pose any technical problems nowadays, and this recording procedure should not delay the data processing significantly if a modest seismic processing machine and crew are brought in the immediate rig site proximity. In any case, drillbit recording over a 100 to $300 \mathrm{~m}$ depth interval is necessary to perform the full walkaway processing using velocity filters over all the recorded drillbit source interval. While acquiring the first drillbit run, many seismic preprocessing tasks and controls can be done, such as geometry acquisition, surface data reading and correlation by the secondary reference accelerometer on top of the drillstring, labeling the geometry, labeling with the drilling parameters, etc. The complete QC control and processing can start only when the first batch of downhole data is available, after the first EM-SWD drilling run.

Offshore, drillbit reverse SWD walkaways could be acquired using OBC receiver cables located on sea bottom, but this poses three problems:

- roller cone bits are seldom used in offshore drilling as formations are tender to medium hard;

- the well seismic data are not available right away and cannot be controlled in real time, in contrast with the conventional direct walkaway recorded with a long array of receivers in the well and an efficient seismic source mounted on a boat quickly accessing any desired shooting location; 
- deep offshore installation of OBC's might become difficult in deep waters. For these reasons, the conventional wireline technique remains very efficient for offshore walkaway surveys.

In conclusion (Fig. 58), the use of the drillbit SWD walkaway method offers good perspectives for onshore areas with difficult access conditions: this is an exploration-WD technique particularly interesting in areas where the surface seismic illumination is poor. The method is not well suited for continuous monitoring of the drillbit: as a matter of fact, the emitted energy generated by the roller cone bit decreases with depth, diameter, and weight on bit, while it would be desirable to have a more powerful source as the depth increases.

The downhole technology to be developed for drillbit walkaway SWD can be restrained to an electronic equipment in central position inside the drill collars, the precision and drift constrains on the downhole clock do not need to be very high, which lead to reasonable equipment cost.

\section{MAIN CONCLUSIONS}

On the drillbit-SWD technique of reverse walkaway using downhole reference measurements

Technical conditions preferred for application of the drillbit-SWD technique

(in bold, specific innovative input brought by IFP)

- Roller cone drilling, bit with milled teeth or inserts

- Weight on bit $>10 \mathrm{t}$, rpm $>90 \mathrm{tr} / \mathrm{min}$

- Shock ABSORBER in the BHA (near bit or above)

- Bit diameter preferred: 17 1/2", 12 1/4", 8 1/2"

- Formation under drilling medium to hard, preferably with P-wave velocity $V p>2700 \mathrm{~m} / \mathrm{s}$

- Downhole technology-MWD: memory recorder synchronized with surface clock or wired drill pipes

Where does thedrillbit-SWD technique apply with best chances of success?

- Vertical to low deviated wells, around mid-target depth

- Onshore areas with rugged surface conditions, in which activating a surface seismic source is costly

- Deep objectives in areas where surface layers are complex (foothills zones), or where shallow layers are very attenuating for seismic waves (ex.: Middle-East).

Figure 58

Conclusion.

\subsection{Application Domain of VSP-SWD}

The first objective of the VSP-WD method is to use the direct arrivals only in order to locate the drill bit and well trajectory on the surface seismic section, as long as this latter is readable, so as to help the drillers in making appropriate decisions mainly about the drilling program: overpressure detection often lead the drillers to set the casings at sensitive and appropriate depths. Visualizing the well trajectory on the seismic section (in time) is essential to help the drilling team management, in vertical, deviated or horizontal wells. Preferably, drillers like to visualize the well trajectory in the domain, which necessitates updating the conversion of the seismic image into depth several times during drilling, ref.: MWDC $^{\circledR}$ method (Migration While Drilling Continuously) and Dream Software (Drilling and REAl time Migration) introduced by ENI-Agip and Western-Atlas in 2000, and the DBSEIS ${ }^{\circledR}$ method of Schlumberger. In spite of considerable efforts engaged by major organizations such as Schlumberger, [20, 21], or OGS, Trieste, and ENI, Milan, Italy, [22-24], devoted to developing the drillbit SWD technique applied continuously while drilling, and without downhole reference measurement, the seismic signal-to-noise ratio of the drillbit signal is often too weak, thus impractical for sustained industrial use in all geographical areas worldwide. In contrast, the examples of VSP-WD given in [25-27] illustrate how the recorded $3 \mathrm{C}$ geophone data can be promising, and now yield systematic excellent direct arrivals; however, the coupling quality and the vector fidelity of the $3 \mathrm{C}$ response of VSP-WD tools still need to be improved in comparison with the wireline VSP tools.

The second objective of the VSP-WD is to use the reflection response and look ahead of the bit: in vertical wells, early detection of overpressure is always desirable; in deviated wells, the VSP is able to produce an image below the well deviation, provided the mechanical coupling of the VSP to the borehole wall is excellent (this point needs to be investigated and improved in the VSP-WD tools, which further adds to the technological challenge of VSP-WD tools). In horizontal wells, the direct arrival surface to downhole should provide at least the well trajectory in seismic time, to be drawn on the seismic section, so as to guide the drilling navigation (see [26] for example).

The VSP-WD method looks quite appropriate to operate a basic well-tie operation while drilling. In the horizontal part of the wells, it looks like the only method to record VSP-type data, since the drillers are extremely reluctant to reenter the borehole with the drillstring pushing a wireline VSP tool, for reasons of borehole wall instability and security.

In vertical wells, the coupling of the $3 \mathrm{C}$ geophones to the formation would be improved by adding to the VSP-WD tool an anchoring pad similar to the ones used on the fluid sampler tools-WD, which would further increase the complexity and rental price of the VSP-WD tool. 
A practical and economical way to record VSP-WD is to record while tripping out $(\mathrm{POOH})$, as in this manner, the seismic source mobilization is minimized.

Presently, the only alternative way to operate VSP measurements in a horizontal drain remains the slim wireline VSP tools pumped inside the drillstring (for instance the PIPESEIS $^{\circledR}$ method of CGG-Baker).

In conclusion, the SWD technology and reliability still need to be improved to fully reach the industrial stage. The drillbit SWD method using a downhole reference signal has not yet been fully industrialized by any major MWD contractor, and VSP-WD represents a very challenging technique.

The economical impact of the VSP-WD method is expected to be important in deep offshore wells, for the well tie of horizontal drains to the surface seismic images and for real-time model updating.

The preferable downhole technology to develop for VSPWD is with an electronic equipment built in the crown of a drill collar, for all possible drill collar diameters, since the VSP-WD measurements are needed continuously in the deep half of vertical, deviated and horizontal wells. The precision required on the downhole clock, the autonomy of the downhole VSP-WD recorder in terms of real time software, the difficulty to insure a good mechanical coupling of the VSP seismic sensor to the formation, lead to highly sophisticated technological developments due to the high level of reliability required, and high equipment costs.

A difficulty inherent to all the SWD techniques is that a high level of dialog and confidence need to be established between the specialists of different disciplines working around the drilling process itself, the exploration in general, and the well tie with seismic images. The views expressed above are under the responsibility's of the authors only. These views are subject to change as innovative technological elements appear in the fast evolving domain of MWD, and as the geophysicist and geologist end users will gather more experience with the emerging SWD techniques.

\section{ACKNOWLEDGEMENTS}

The authors greatly appreciate the constructive contribution of each participant in the above mentioned projects and thank the management of the collaborating organizations for their encouragement and approval to publish the obtained results.

In particular, MM. Jean-Luc Joron, Yann Terras and their drilling supervisor colleagues in the GDF Drilling Department, have facilitated the access to many $G D F$ drill sites to the IFP personnel for the set-up and operations with the TRAFOR system, within the framework of a long term cooperation agreement between $G D F$ and IFP. MM. François Verdier, Fredéric Huguet and Mme Hélène Giouse, in the GDF Geological Department, gave access to all geological, seismic and log information and documents nec- essary for the well tie and the evaluation of the new SWD results and reliability. In IFP, Guy Pignard and his electronics and mechanical engineering colleagues designed, operated and improved the Trafor system, in order to achieved all the mechanical and seismic tests desired by Jean-Baptiste Faÿ, Jean Guesnon and Claude Mabile, mechanical engineers and project leaders in the Drilling Department.

For the drillbit SWD EC project GE 019/96, Fausto Batini and the personnel of the Mining Department of ENEL, as well as ENEL drilling supervisors and many staff of the Larderello Laboratory have greatly contributed to the preparation and operational success of the large SWD field operations on the Tuscany geothermal drill sites.

During the VSP-WD French CEPM projects, the active participation of the following people has been quite helpful: Stéphan Crépin and Michel Erbetta of TFE (now Total), Nick Randall and Steve Wellens of CGG-BSD (now Baker-Atlas), Namic Klioua of Geoservices, Renate Bary and Gérard Thierry of the IFP Seismic Instrumentation Department.

The prompt cooperation of $I / O$ Sensor engineers, namely Kees Faber, Peter Maxwell, Steve Burden facilitated the preliminary phase of validation of sensors for the VSP-WD application.

Last, the partial funding brought by the French CEPM and by EC have been helpful in the decisions to engage the above described development projects.

\section{REFERENCES}

1 Lutz, J., Raynaud, M., Gstalder, S., Quichaud, C., Raynal, J. and Muckelroy, J.A. (1972) Instantaneous logging based on a dynamic theory of drilling. Journal of Petroleum Technology, 24, June, 750-758.

2 Staron, Ph., Arens, G. and Gros, P. (1986 and 1988) Method for instantaneous acoustical logging in a bore well. UK Patent $N^{\circ} G B / 2,173,596 A,(1986)$ and US Patent No. 4,718,048 (1988).

3 Rector, J.W. III and Marion, B.P. (1991) The use of drillbit energy as a downhole seismic source. Geophysics, 56, 5.

4 Guesnon, J. and Pignard, G. (1992) IFP tests its new TRAFOR MWD system. Ocean Industry.

5 Sallas, J.J. (1984) Seismic vibrator control and the downgoing P-wave. Geophysics, 40, 6, 732-740.

6 Naville, C., Staron, Ph., Pignard, G. and Wittrich, C. (1994) Seismic prospecting method and device using a drill bit working in a well. US. Patent No. 5,372,207.

7 Naville, C., Layotte, P.C., Pignard, G. and Guesnon, J. (1994) Well Seismic: Application of the TRAFOR MWD system to drill bit seismic profiling. EAEG Abstract G45, Vienna, Austria.

8 Rector, J.W. and Hardage, B.A. (1992) Radiation pattern and seismic waves generated by a working roller cone drill bit Geophysics, 57, 10.

9 Rector, J.W. (1993) Use of drillbit vibrations in the drilling of deep continental boreholes. Deep Continental Crust Symposium, Potsdam. 
10 Naville, C., Guesnon, J. and Mabile, C. (1998) Logging method and system for measuring mechanical parameters of formations crossed through by a borehole. US Patent No. 5,758,539.

11 Serbutoviez, S., Naville, C., Fay J.B., Verdier, F., Billet G. and Batini, F. (2001) Log of formation parameters while drilling. Poster Paper $3 E$, AAPG convention, Denver.

12 DRILCO (division of SMITH International, Inc.) (1986) Description of the Rubber spring SHOCK SUB ${ }^{\circledR}$ vibration dampener. In: The Composite Catalog 1986-87, 1751-1753.

13 Parfitt, S.H.L. and Abbassian, F. (1995) A model for Shock sub performance qualification. SPE/IADC 29354, Drilling Conference, Amsterdam.

14 Soulier, L. and Lemaître, M. (1993) EMWD data transmission status and perspectives. SPE/IADC 25686, Amsterdam.

15 Batini, F., Dini, I., Certo M., Cola T., Cecconi, F., Louis Soulier, L., Naville, C. and Serbutoviez, S. (2000) Seismic while drilling measurements in Italian deep geothermal wells. World Geothermal Congress, Japan.

16 Naville, C., Serbutoviez, S., Throo, A., Batini, F. and Dini, I. (2000) Drillbit SWD reverse walkaway using downhole reference signal. SPE 65115, EUROPEC Meeting, Paris, France.

17 Naville, C., Mabile, C., Guesnon, J. and Meynier, P. (2000) Method and device for the acquisition of signals while drilling. US Patent No. 6,023,444.

18 Cecconi, F. and Soulier, L. (2003) Device and method for seismic drill hole measuring. European Patent No. EP 1130 418 A1, US Patent No. 6,614,718 B2.

19 Naville, C., Serbutoviez, S., Bruneau, J., Japiot, H., Daures, R. and Gaborit, J.Y. (2001) "VSP-Dipmeter" from oriented 3 component and isotropic processing. Poster Paper 7A, AAPG Convention, Denver.
20 Borland, W., Codazzi, D., Einchcomb, C., Hashem, M., Hewett, V., Jackson, M., Meehan, R. and Tweedy, M. (1997) Real-time answers to well drilling and design questions. Schlumberger Oilfield Review, 9, 2, 2-15.

21 Armstrong, P., Nutt, L. and Minton, R. (2000) Drilling optimization using drill-bit seismic in the deepwater Gulf of Mexico. IADC/SPE 59222, New Orleans, Louisiana, USA.

22 Poletto, F., Bertelli, L., Miranda, F. and Rocca, F. (1998) Design of SWD 3D RVSP using SEISBIT® Technology, EAGE $60^{\text {th }}$ Conference, Paper 10-49, Leipzig, Germany.

23 Bertelli, L., Abramo, F., and Gatti, V. (1998) Seismic while Drilling and geophysical monitoring in the Southern Apennine range, EAGE $60^{\text {th }}$ Conference, Paper 10-50, Leipzig, Germany.

24 Malusa, M., Poletto, F., Mirande, F. and Bernasconi, G. (1998) SWD interpretation by modelling of pilot and seismic signals, EAGE $60^{\text {th }}$ Conference, Paper 10-51, Leipzig, Germany.

25 Underhill W., Esmersoy, C. and Hawthorn, A. (2001) Demonstration of real-time borehole seismic from an LWD tool. SPE 71365, New Orleans, Louisiana, USA, 30 Sept3 Oct.

26 King, P., Templeton, G., Reeder, M. and Bevali, S. (2002) Defining lateral velocity variations to improve reservoir mapping with new seismic measurements while drilling, Leadon field, UK. EAGE $64^{\text {th }}$ Conference, Paper B-25. Florence, Italy.

27 Haldorsen, J.B.U., Krasovec, M., Raikes, S., Harrold, T., Day, D.N. and Clippard, J.D. (2002) Comparison of full waveform seismic MWD and conventional VSP data from the South Caspian. EAGE $64^{\text {th }}$ Conference, Paper B-26, Florence, Italy.

Final manuscript received in July 2004 